\title{
Sediment Studies in the Assabet River, Central Massachusetts, 2003
}

By Marc J. Zimmerman and Jason R. Sorenson

Part 1

Sediment Distribution and Chemistry in Six Impoundments in the Assabet River, Central Massachusetts

Part 2

Phosphorus Dynamics in a Wastewater-Dominated Impoundment, Hudson, Massachusetts

Scientific Investigations Report 2005-5131 


\section{U.S. Department of the Interior \\ Gale A. Norton, Secretary \\ U.S. Geological Survey \\ Charles G. Groat, Director}

U.S. Geological Survey, Reston, Virginia: 2005

For sale by U.S. Geological Survey, Information Services
Box 25286, Denver Federal Center
Denver, CO 80225
For more information about the USGS and its products:
Telephone: 1-888-ASK-USGS
World Wide Web: http://www.usgs.gov/

\footnotetext{
Any use of trade, product, or firm names in this publication is for descriptive purposes only and does not imply endorsement by the U.S. Government.

Although this report is in the public domain, permission must be secured from the individual copyright owners to reproduce any copyrighted materials contained within this report.

Suggested citation:

Zimmerman, M.J., and Sorenson, J.R., 2005, Sediment studies in the Assabet River, central Massachusetts, 2003: U.S. Geological Survey Scientific Investigations Report 2005-5131, 87 p.
} 


\section{Contents}

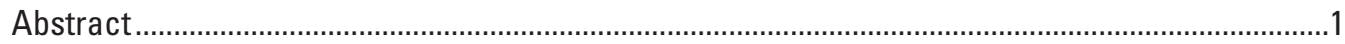

The Assabet River and its Sediments .......................................................................................2

Part 1. Sediment Distribution and Chemistry in Six Impoundments in the Assabet

River, Central Massachusetts .....................................................................................

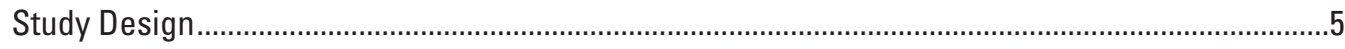

Mapping of Bathymetry and Sediment Thickness ..................................................................5

Selection of Sediment-Sampling Sites....................................................................................

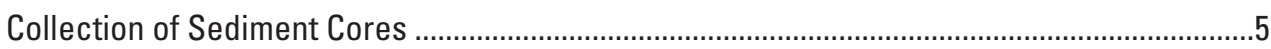

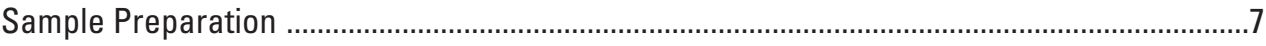

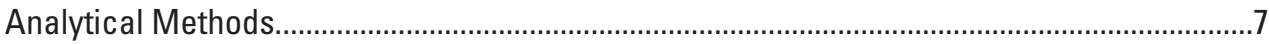

Quality Assurance and Quality Control ......................................................................................12

Sediment Thickness and Bathymetric Maps ...................................................................................13

Sediment Chemistry of the Assabet River Impoundments ............................................................21

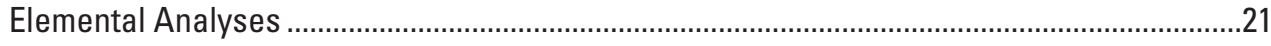

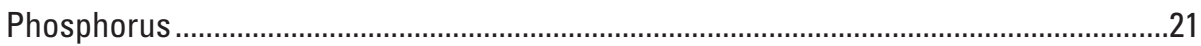

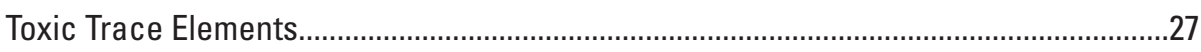

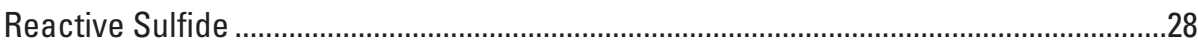

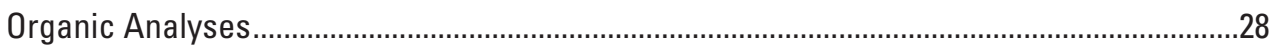

Volatile Organic Compounds and Organochlorine Pesticides ........................................29

Polycyclic Aromatic Hydrocarbons ...............................................................................29

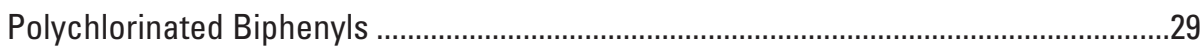

Extractable Petroleum Hydrocarbons ...................................................................................34

Potential for Adverse Biological Effects .....................................................................................34

Sediment Distribution and Chemistry_Possible Implications for Sediment

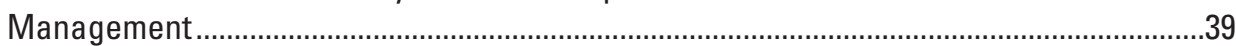

Part 2. Phosphorus Dynamics in a Wastewater-Dominated Impoundment, Hudson, Massachusetts ................................................................................................ 41

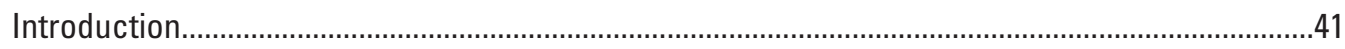

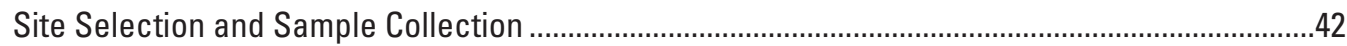

Reconnaissance and Site Selection........................................................................................42

Field Measurements and Collection of Phosphorus and Chloride Samples............................42

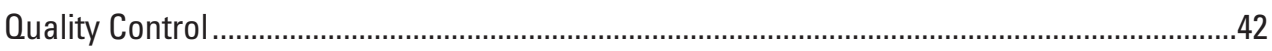

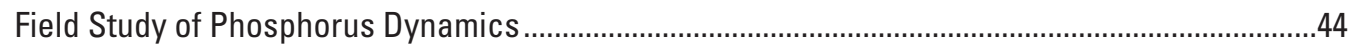

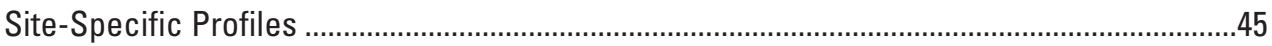

Changes in Phosphorus Storage ................................................................................................... 45

Mass Balance (Chloride:Total Phosphorus) ................................................................................49

Phosphorus Dynamics in the Hudson Impoundment......................................................................49

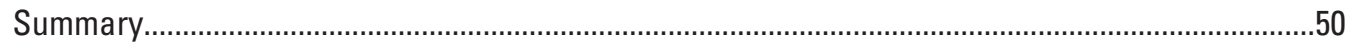

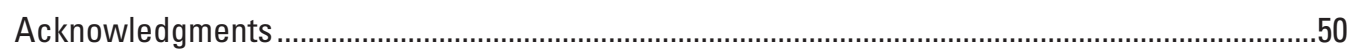

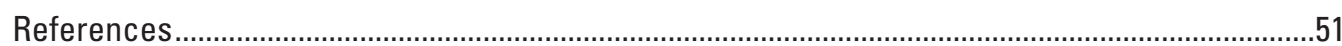




\section{Figures}

1. Map showing the Assabet River Basin in central Massachusetts

2-8. Photographs showing:

2. A probe being used to collect data for a map of sediment thickness and extent ....6

3. A piston corer being prepared for collection of a sediment core ..............................6

4. A Teflon piston being used to extrude core into a polycarbonate tube ....................7

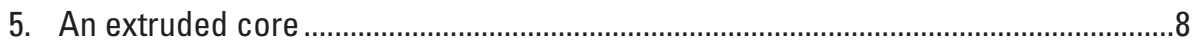

6. A sample being collected for volatile organic compound analysis ...........................8

7. A sample being collected for polychlorinated biphenyl and pesticide analyses .....9

8. A sample being prepared for metal analysis...

9-14. Maps showing:

9. Sediment thickness, phosphorus bulk-sediment profiles, exceedances of TEL (threshold effect level) and PEL (probable effect level) guidelines for toxic trace elements, and potential for sediment toxicity to aquatic life from cores collected in Aluminum City impoundment in Northborough, 2003 .......14

10. Sediment thickness, phosphorus bulk-sediment profiles, exceedances of TEL (threshold effect level) and PEL (probable effect level) guidelines for toxic trace elements, and potential for sediment toxicity to aquatic life from cores collected in Allen Street impoundment in Northborough, 2003

11. Sediment thickness, phosphorus bulk-sediment profiles, exceedances of TEL (threshold effect level) and PEL (probable effect level) guidelines for toxic trace elements, and potential for sediment toxicity to aquatic life from cores collected in Route 85 impoundment in Hudson, 2003.

12. Sediment thickness, phosphorus bulk-sediment profiles, exceedances of TEL (threshold effect level) and PEL (probable effect level) guidelines for toxic trace elements, and potential for sediment toxicity to aquatic life from cores collected in Gleasondale impoundment in Stow, 2003

13. Sediment thickness, phosphorus bulk-sediment profiles, exceedances of TEL (threshold effect level) and PEL (probable effect level) guidelines for toxic trace elements, and potential for sediment toxicity to aquatic life from cores collected in Ben Smith impoundment in Maynard, 2003

14. Sediment thickness, phosphorus bulk-sediment profiles, exceedances of TEL (threshold effect level) and PEL (probable effect level) guidelines for toxic trace elements, and potential for sediment toxicity to aquatic life from cores collected in Powdermill impoundment in Maynard and Acton, 2003.

15, 16. Graphs showing:

15. Total polycyclic aromatic hydrocarbon concentrations in core samples from six impoundments in the Assabet River, 2003

16. Concentrations of selected polychlorinated biphenyl Aroclors detected in core samples from six impoundments in the Assabet River, 2003.

17. Map showing Hudson impoundment with sampling sites for phosphorusrelease dynamics study, July to September 2003

18. Photograph showing platform attached to pushpoint sampler in preparation for pore-water sampling. 
19. Chart showing $A$, Total and orthophosphorus and dissolved oxygen watercolumn profiles at five stations in the Hudson impoundment, July to September 2003. Depth is given as vertical distance from sediment surface to water surface. $B$, Rainfall and changes in estimated total phosphorus storage in the Hudson impoundment, July to September 2003.

\section{Tables}

1. Identifiers and depths for samples collected in six impoundments in the Assabet River, Massachusetts.

2. Sediment-quality guidelines for freshwater organisms, human contact, and Massachusetts landfill reuse.

3. Concentrations of phosphorus, in percent, in bulk sediment samples from six impoundments in the Assabet River Basin, 2003.

4. Mean and median concentrations of trace metals in New England stream sediments.

5. Summary statistics of total bulk phosphorus concentrations in sediment samples from six impoundments in the Assabet River Basin, 2003

6. Median and mean values for total polycyclic aromatic hydrocarbon concentrations detected in sediment samples from six impoundments in the Assabet River Basin, 2003

7. Concentrations of polychlorinated biphenyl Aroclors in sediment samples from six impoundments in the Assabet River Basin, 2003

8. Concentrations of extractable petroleum hydrocarbons in sediment samples from six impoundments in the the Assabet River Basin, 2003.

9. Incidence of toxicity, in percent, and mean MPP values calculated from Probable Effect Concentration quotients for sediment samples from the six impoundments in the Assabet River Basin, 2003.

10. Selected characteristics of six impoundments in the Assabet River Basin. . .40

11. Mean and median total phosphorus and orthophosphorus concentrations, in milligrams per liter, of all samples in the water column or pore water at each sampling station in the Hudson impoundment, July to September 2003

12. Estimated phosphorus storage in the Hudson, Massachusetts, impoundment sections, July to September 2003

13. Ratios of chloride to total phosphorus at the inflow and outflow of the Hudson impoundment, July to September 2003

14. Concentrations of selected metals in sediment samples from six impoundments in the Assabet River Basin, 2003

15. Results of all elemental analyses performed by SGS Canada, Inc., Mineral Services, Toronto, Ontario, Canada, of sediment samples from six impoundments in the Assabet River Basin, 2003.

16. Concentrations of polycyclic aromatic hydrocarbons detected in sediment sampless from six impoundments in the Assabet River Basin, 2003

17. Water-quality data collected during study of phosphorus dynamics in the Hudson impoundment, 2003. 


\section{Conversion Factors, Datums, Water-Quality Information and Abbreviations}

\begin{tabular}{lcl}
\hline Multiply & \multicolumn{1}{c}{ By } & To obtain \\
\hline centimeter $(\mathrm{cm})$ & 0.3937 & inch (in.) \\
cubic meter $\left(\mathrm{m}^{3}\right)$ & 35.31 & cubic foot $\left(\mathrm{ft}^{3}\right)$ \\
cubic meter $\left(\mathrm{m}^{3}\right)$ & 1.308 & cubic yard $\left(\mathrm{yd}^{3}\right)$ \\
inch $(\mathrm{in})$. & 2.54 & centimeter $(\mathrm{cm})$ \\
inch $(\mathrm{in})$. & 25.4 & millimeter $(\mathrm{mm})$ \\
kilogram $(\mathrm{kg})$ & 2.2046 & pound, avoirdupois $(\mathrm{lb})$ \\
kilometer $(\mathrm{km})$ & 0.6214 & mile $(\mathrm{mi})$ \\
liter $(\mathrm{L})$ & 61.02 & cubic inch $\left(\mathrm{in}^{3}\right)$ \\
meter $(\mathrm{m})$ & 3.281 & foot $(\mathrm{ft})$ \\
meter $(\mathrm{m})$ & 1.094 & yard $(\mathrm{yd})$ \\
microgram $(\mu \mathrm{g})$ & $3.53 \times 10^{-8}$ & ounce, avoirdupois $(\mathrm{oz})$ \\
milligram $(\mathrm{mg})$ & $3.53 \times 10^{-5}$ & ounce, avoirdupois $(\mathrm{oz})$ \\
milliliter $(\mathrm{mL})$ & 0.06102 & cubic inch $\left(\mathrm{in}^{3}\right)$ \\
\hline
\end{tabular}

Temperature in degrees Celsius $\left({ }^{\circ} \mathrm{C}\right)$ may be converted to degrees Fahrenheit $\left({ }^{\circ} \mathrm{F}\right)$ as follows:

$$
{ }^{\circ} \mathrm{F}=\left(1.8 \times^{\circ} \mathrm{C}\right)+32
$$

Horizontal coordinate information is referenced to the North American Datum of 1983 (NAD 83).

Specific conductance is given in microsiemens per centimeter at 25 degrees Celsius $\left(\mu \mathrm{S} / \mathrm{cm}\right.$ at $\left.25^{\circ} \mathrm{C}\right)$.

Concentrations of chemical constituents in water are given either in milligrams per liter (mg/L) or micrograms per liter $(\mu \mathrm{g} / \mathrm{L})$.

$\begin{array}{llll}\mathrm{As} & \text { arsenic } & \text { PCB } & \text { polychlorinated biphenyl } \\ \mathrm{Cd} & \text { cadmium } & \text { PEC } & \text { probable effect concentration } \\ \mathrm{Cr} & \text { chromium } & \text { PEL } & \text { probable effect level } \\ \mathrm{Cu} & \text { copper } & \text { PVC } & \text { polyvinyl chloride } \\ \mathrm{DO} & \text { dissolved oxygen } & \text { RL } & \text { reporting level } \\ \mathrm{EPH} & \text { extractable petroleum hydrocarbon } & \text { TEL } & \text { threshold effect level } \\ \mathrm{GC} & \text { gas chromatography } & \text { TIN } & \text { triangular irregular network } \\ \mathrm{GIS} & \text { geographic information system } & \text { TMDL } & \text { total maximum daily load } \\ \mathrm{MS} & \text { mass spectrometry } & \text { TPH } & \text { total petroleum hydrocarbon } \\ \mathrm{Ni} & \text { nickel } & \text { USEPA } & \text { U.S. Environmental Protection Agency } \\ \mathrm{PAH} & \text { polycyclic aromatic hydrocarbon } & \text { VOC } & \text { volatile organic compound } \\ \mathrm{Pb} & \text { lead } & \mathrm{Zn} & \text { zinc }\end{array}$




\title{
Sediment Studies in the Assabet River, Central Massachusetts, 2003
}

\author{
By Marc J. Zimmerman and Jason R. Sorenson
}

\begin{abstract}
From its headwaters in Westborough, Massachusetts, to its confluence with the Sudbury River, the 53-kilometer-long Assabet River passes through a series of small towns and mixed land-use areas. Along the way, wastewater-treatment plants release nutrient-rich effluents that contribute to the eutrophic state of this waterway. This condition is most obvious where the river is impounded by a series of dams that have sequestered large amounts of sediment and support rooted and floating macrophytes and epiphytic algae. The water in parts of these impoundments may also have low concentrations of dissolved oxygen, another symptom of eutrophication.

All of the impoundments had relatively shallow maximum water depths, which ranged from approximately 2.4 to 3.4 meters, and all had extensive shallow areas. Sediment volumes estimated for the six impoundments ranged from approximately 380 cubic meters in the Aluminum City impoundment to 580,000 cubic meters in the Ben Smith impoundment. The other impoundments had sediment volumes of 120,000 cubic meters (Powdermill), 67,000 cubic meters (Gleasondale), 55,000 cubic meters (Hudson), and 42,000 cubic meters (Allen Street).

The principal objective of this study was the determination of sediment volume, extent, and chemistry, in particular, the characterization of toxic inorganic and organic chemicals in the sediments. To determine the bulk-sediment chemicalconstituent concentrations, more than one hundred sediment cores were collected in pairs from the six impoundments. One core from each pair was sampled for inorganic constituents and the other for organic constituents. Most of the cores analyzed for inorganics were sectioned to provide information on the vertical distribution of analytes; a subset of the cores analyzed for organics was also sectioned. Approximately 200
\end{abstract}

samples were analyzed for inorganic constituents and 100 for organics; more than 10 percent were quality-control replicate or blank samples.

Maximum bulk-sediment phosphorus concentrations in surface samples from the impoundments increased along a downstream gradient, with the exception of samples from the last impoundment, where the concentrations decreased. In addition, the highest phosphorus concentrations were generally in the surface samples; this finding may prove helpful if surface dredging is selected as a means to control phosphorus release from sediments. There is no known relation, however, between bulk-sediment concentration of phosphorus and the concentrations of phosphorus available to biota.

Potentially toxic metals, including arsenic, cadmium, chromium, copper, nickel, lead, and zinc were frequently measured at concentrations that exceeded U.S. Environmental Protection Agency sediment-quality guidelines for the protection of aquatic life and that occasionally exceeded Massachusetts Department of Environmental Protection guidelines governing landfill disposal (reuse). Due to the effects of matrix interference and sample dilution on laboratory analyses, neither pesticides nor volatile organic compounds were detected at any sites. However, samples collected in other studies from nearby streams indicated the possibility that pesticides might have been detected in the impoundments if not for these analytical problems. Although polychlorinated biphenyl concentrations, as individual Aroclors, generally exceeded published U.S. Environmental Protection Agency guideline concentrations for potential effects on aquatic life, the U.S. Environmental Protection Agency guideline concentrations for human contact or the Massachusetts guidelines for landfill reuse were rarely exceeded. Concentrations of polycyclic aromatic hydrocarbons, both individually and total, frequently were greater than guideline concentrations. Concentrations of total extractable petroleum hydrocarbons did not exceed Massachusetts guideline concentrations in any samples. 
When the sediment analytes from surface samples are considered together to compare their potential toxicity to aquatic organisms, it is clear that sediment exposure is likely to have harmful effects. By most measures, samples from the first and last impoundments in the sequence had the poorest sediment quality with respect to the degree and the frequency with which guideline concentrations were exceeded.

A consortium of towns along the river has investigated a range of options aimed at controlling concentrations of nutrients, phosphorus in particular, released from wastewatertreatment plants into the river and its impoundments. The second part of this study examined the changes in phosphorus concentrations in surface and pore waters in one impoundment during a 2-month period. The results were used to determine whether the sediments could release sufficient amounts of phosphorus to render ineffective decreased phosphorus releases from treatment plants. Knowledge of sediment characteristics and chemistry will allow local water managers to choose among the sediment-management options that may be considered for the Assabet River: decreasing concentrations of phosphorus released from treatment plants, partial or complete dredging, dam removal or modification, phosphorus sequestration by chemical treatment, and making no changes.

To investigate the dynamics of phosphorus concentrations in the impoundment in Hudson, Massachusetts, water samples were collected weekly at five locations. In addition to ortho- and total phosphorus, some samples were analyzed for chloride, which served as a conservative tracer for waters released from upstream wastewater-treatment plants. At each location, data were collected to provide water-column profiles of temperature, dissolved oxygen, and specific conductance.

In the study of phosphorus dynamics in the impoundment in Hudson, Massachusetts, phosphorus concentrations varied over time, primarily in bed-sediment samples, at the offchannel sampling locations where the water column was stratified. These variations, including some substantial increases in phosphorus concentrations in pore-water samples, however, did not appear to lead to increases in phosphorus exported from the impoundment. This observation suggests that most of the phosphorus released from the sediments was recycled internally in the impoundment.

Although net phosphorus storage did vary, it did not generally increase with time as total phosphorus entered the water column from sediments in stagnant areas in the Hudson impoundment. Physical and redox processes seem to control phosphorus release from sediments to the water column. These findings and the results of other studies indicate that the amount of phosphorus released from sediments over a yearly cycle was relatively small compared to the amount of phosphorus entering the system from upstream wastewatertreatment plants.

\section{The Assabet River and its Sediments}

The 53-km-long Assabet River is impounded by a series of dams as it flows northeastward from its source at the A1 impoundment in Westborough through the towns of Northborough, Marlborough, Hudson, Stow, Maynard, and Acton (fig. 1). Along the way, municipal wastewater-treatment plants in Westborough, Marlborough, Hudson, and Maynard discharge nutrient-rich effluent to the river.

Historically, the Assabet River Basin was characterized by small towns with centers along or near the river. Much of the surrounding land was forested or farmed. Dams impounding reaches of the Assabet River served to power the mills that constituted the economic bases for the towns along the river. Modern industries have also substantially contributed to the area's economic development. Water- and sedimentquality characteristics of the Assabet River reflect this history. The area has become more suburban over time with a rapid increase in the number of single-family homes, roads, and commercial developments. Rapid development in this area of Massachusetts has strained the basin's water resources by diminishing flow and affecting water quality. 


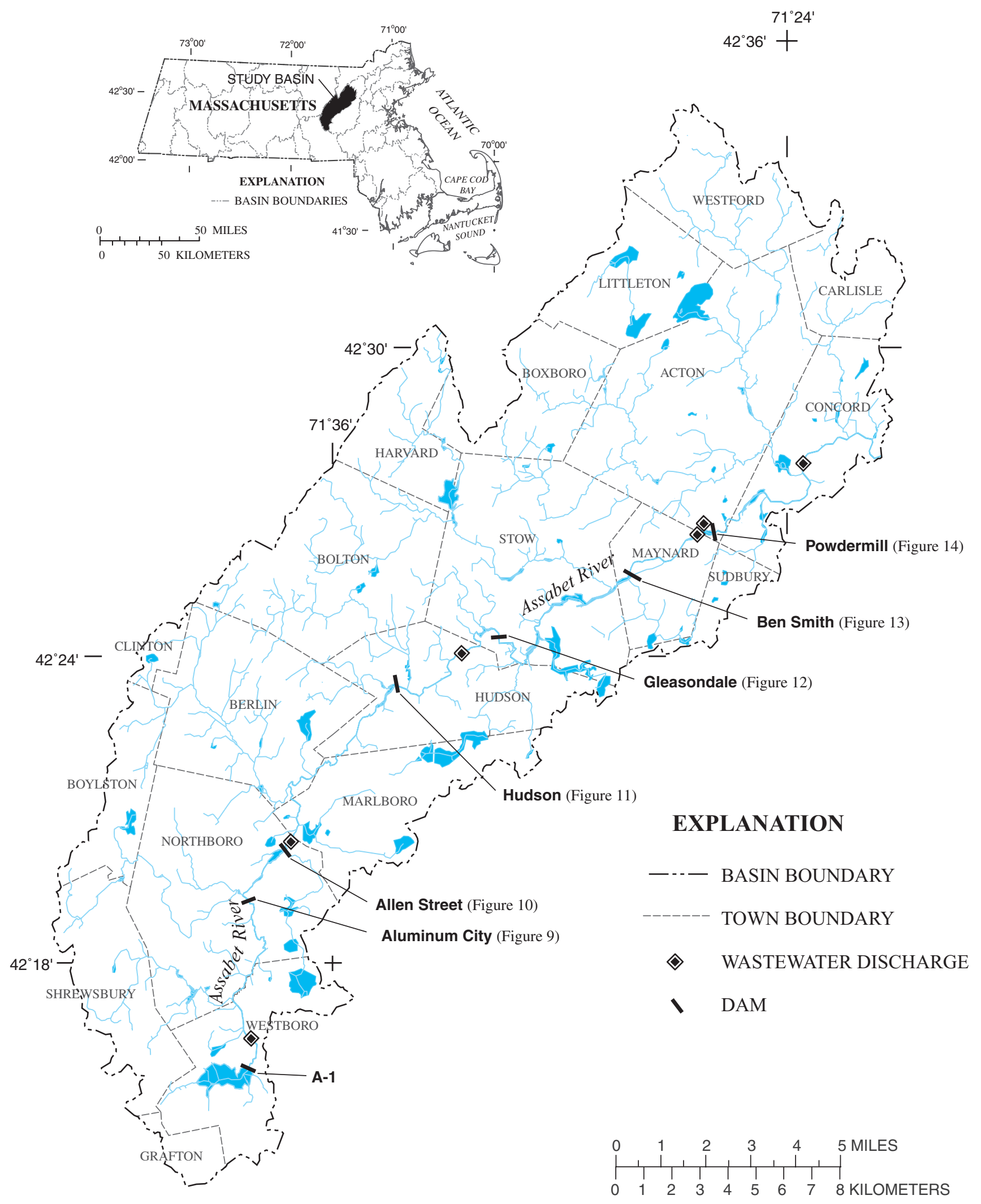

From USGS and MassGIS data sources, Massachusetts State Plane Coordinate System, Mainland Zone.

Figure 1. The Assabet River Basin in central Massachusetts. 
In spite of the Assabet River's diversity of wildlife, popularity for recreational activities, and recent designation as part of a Wild and Scenic River basin, it is a highly eutrophic system, primarily because of nutrient enrichment from the effluents of wastewater-treatment plants. The extent of eutrophication is evident in the impounded reaches, which support substantial growth of rooted and floating macrophytes.

During the summer and early fall of 2003, the U.S. Geological Survey (USGS), in cooperation with the Massachusetts Department of Environmental Protection (MDEP) and the U.S. Environmental Protection Agency (USEPA), mapped the extent and studied the chemical properties of sediments in six impoundments in the Assabet River Basin. The USGS also studied the dynamics of phosphorus release from sediments in a wastewater-dominated impoundment in Hudson, Massachusetts. This impoundment was one of the original six impoundments.

This two-part report provides the results of the assessment of the sediment extent and chemistry in the six impoundments in the Assabet River and describes the results of the study of the dynamics of phosphorus release. Obtaining data to determine whether there is a relation between the distribution of phosphorus in the sediments and the concentrations of phosphorus in the water column was a link between the two parts of this study.

Sediment was sampled from the following six impoundments along the Assabet River:

1. Route 20, also known as Aluminum City impoundment (Northborough, built in 1925);

2. Allen Street impoundment (Northborough, built in 1900);
3. Hudson (Washington Street) impoundment (Hudson, built in 1860), the site of the phosphorus dynamics study;

4. Gleasondale impoundment (Stow, built in 1924);

5. Ben Smith impoundment (Maynard, built in 1870); and

6. Powdermill impoundment (Maynard/Acton, built in 1921).

The interpretations of bulk-sediment chemistry data in this report include results of analyses for volatile organic compounds (VOCs), polycyclic (or polynuclear) aromatic hydrocarbons (PAHs), polychlorinated biphenyls (PCBs), organochlorine pesticides, extractable petroleum hydrocarbons $(\mathrm{EPH})$, reactive sulfide, and a selected group of metals and other elements, including phosphorus. The concentrations of these chemical constituents in the sediments are compared to standards for the disposal of dredged hazardous materials; for human contact; and for potential effects, including toxicity, on aquatic organisms.

The sediment-chemistry data are intended to provide managers and environmental regulators with information required to make informed choices of the best means for improving sediment and surface-water quality in the Assabet River Basin. Possible sediment-management options available to water-resource managers considering river restoration include: (1) reducing concentrations of phosphorus released from treatment plants; (2) dredging sediments (partial or total removal); (3) chemical treatment of sediments to prevent phosphorus release; (4) removal or structural modification of dams; and (5) making no changes. 


\section{Part 1. Sediment Distribution and Chemistry in Six Im- poundments in the Assabet River, Central Massachusetts}

\section{Study Design}

To determine the extent and volume of sediments and to create maps for sampling-site selection, the impoundment bathymetry and sediment thickness for the six impoundments affected by wastewater effluent on the Assabet River were delineated by manual probing. Representative physical and chemical properties of the sediment behind each dam were determined from sediment core samples collected at randomly selected sites. Samples were analyzed at laboratories in Massachusetts, Rhode Island, and Ontario, Canada.

\section{Mapping of Bathymetry and Sediment Thickness}

Data on water depth and soft-sediment thickness were collected by probing manually with an extendible stainlesssteel rod in the reaches behind the six dams (fig. 2). A total of 682 manual water-depth and sediment-thickness soundings were taken in the six impoundments: 34 at Aluminum City dam, 140 at Allen Street, 142 at Hudson, 91 at Gleasondale, 183 at Ben Smith, and 92 at Powdermill.

A Trimble TSC1 GPS unit was used to record depthsounding coordinates. The Trimble positional data were differentially corrected before being imported as point coverages into the geographic information system (GIS) ArcInfo (ESRI, 2002). Impoundment outlines were created from orthophotos with a resolution of 1:5000 (1/2 meter). An ARC Macro Language script positioned the point coverage of the depth soundings in the coverage of the river outlines, and a triangular irregular network (TIN) data set (a type of spatial coverage) was generated to create preliminary contours of the impoundment bathymetry.

\section{Selection of Sediment-Sampling Sites}

Fifty-seven primary sampling sites and 57 matching alternate sampling sites were chosen by using a random-selection subroutine within ARC/INFO GIS software (Scott, 1990). The number and distribution of sediment-sampling sites among the impoundments were determined by the relative size of each impoundment, by the locations of depositional environments, and by the locations of possible contamination source areas. On the basis of past experience with sediment sampling and input from stakeholders, the sampling network was designed to collect a sufficient number of samples to represent the potential sediment variability within the study area.

\section{Collection of Sediment Cores}

To achieve the project objectives of physically and chemically characterizing the bed sediments behind the 6 Assabet River impoundments, more than 100 sediment cores were collected from the 57 sampling sites. The two cores taken from each site were considered to be equally representative of the sediment at that site; one core was reserved for analysis of organic chemical constituents, and the other for analysis of inorganic constituents. At each site, field crews retrieved the longest possible soft-sediment core.

The randomly selected sites were identified in the field with a GPS unit. If cores could not be retrieved at the primary site, an alternate site was used. All coring was done from a flat-bottomed john boat equipped with a four-stroke outboard motor. All cores were retrieved with a piston corer (Aquatic Research Instruments, Hope, Idaho). 


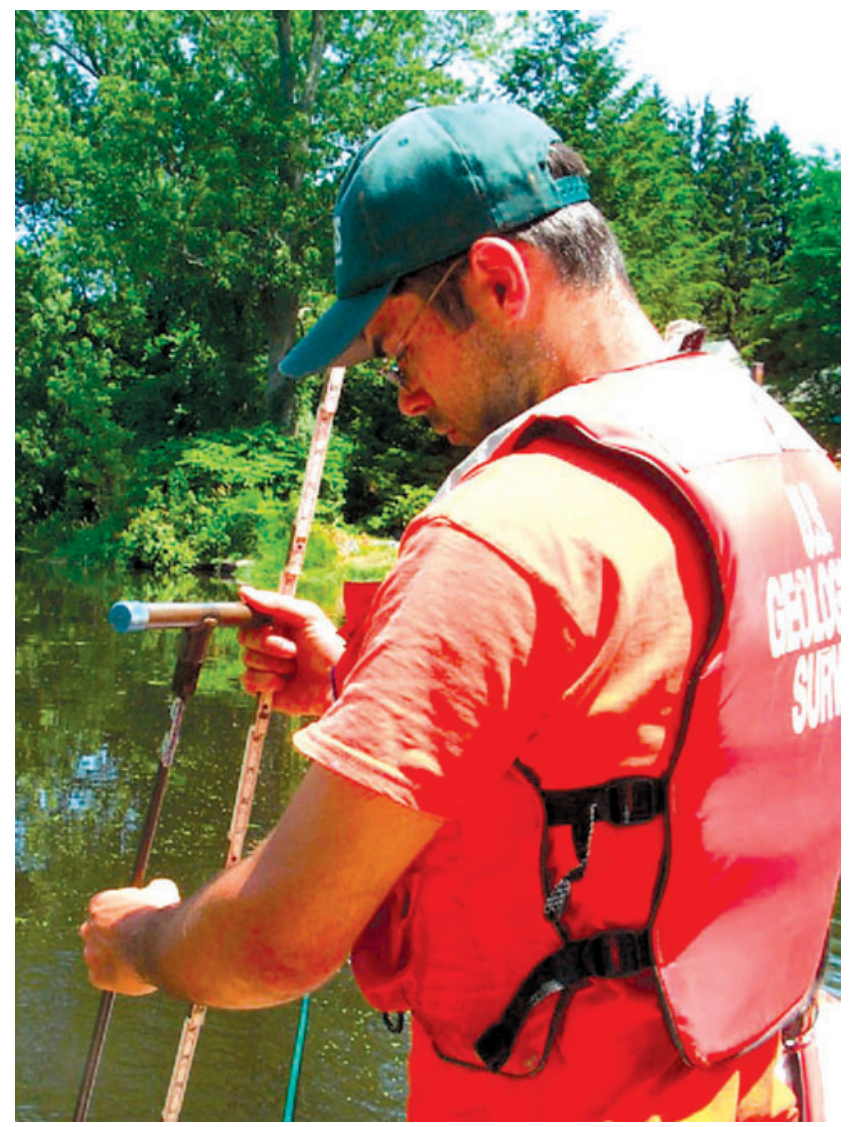

Figure 2. A probe is used to collect data for a map of sediment thickness and extent.

Upon arrival at a sampling location, the field crew anchored and braced the boat to provide a stable work platform against any existing wind or current. Driving steel rods into the sediment allowed the crew to approximate the maximum possible core length and to mark the sampling station. Polycarbonate plastic tubing was cut to the expected core length and secured to the core head with the piston in a ready position at the foot of the plastic core barrel (fig. 3). Polyvinyl chloride (PVC) pipe of 1-in. inner diameter was driven into the sediment to allow measurement of the total drive depth. The corer equipped with an extension rod was positioned at the sediment surface adjacent to the PVC pipe, and aligning marks were put on both the extension rod and the PVC pipe. One crew member held the piston cable in place, while the second manually drove the core barrel into the sediment until stopped by initial refusal. A 5-lb slide hammer was then used to drive the core barrel farther into the sediment until final

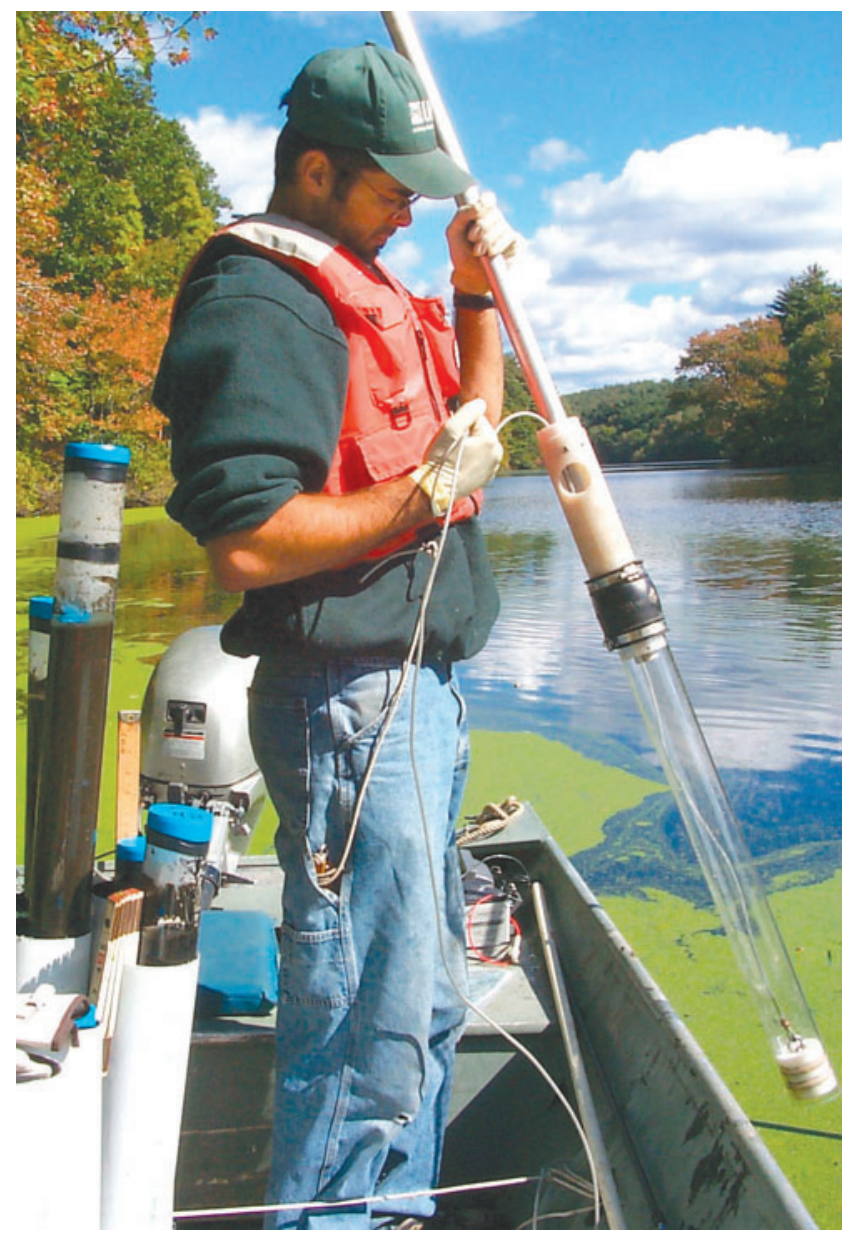

Figure 3. A piston corer is prepared for collection of a sediment core.

refusal; with the corer and the PVC pipe in this configuration, the distance between the previously aligned marks on the aluminum extension rod and the stationary PVC pipe represented the total drive depth. The difference between the total drive depth and the water depth provided the drive depth in the sediment and a way to determine the extent of compaction. The core was extracted with gloved hands and capped at both ends with native-water-rinsed polypropylene caps. To minimize any losses from the core sampler, the end cap was secured to the core tube before the end of the tube broke the surface of the water. On the boat, top and bottom polypropylene end caps were secured to the core with vinyl tape and the core was labeled. The second core was obtained in the same manner from a position less than $1 \mathrm{~m}$ from the first site. 
Cores were secured upright in a cooler and kept cool with ice for transportation to the USGS MA-RI Water Science Center office.

\section{Sample Preparation}

At the MA-RI Water Science Center laboratory, cores were placed in 55-gal plastic barrels filled with ice. Cores were extruded with a Teflon piston into a clean, half-section of a 4-in. diameter, 8-ft polycarbonate tube (figs. 4 and 5). The core lengths and lithological data were recorded and photographs were taken. Then, a 5-mL sample for VOC analysis was collected with a syringe (fig. 6). The remainder of the core was put into a precleaned 25-L Teflon bag which was massaged to thoroughly homogenize the core. A corner of the bag was then cut and samples were extruded into labeled glass jars for analysis (fig. 7); some of the cores designated for organiccompound analyses were sectioned into thirds before homogenizing to provide some information about variability with depth. Cores collected for elemental analysis were split into as many as five sections to determine depth variability (table 1). Each section was put into a pre-cleaned 1.5-L Teflon bag and thoroughly homogenized before extrusion into a labeled plastic Whirl-Pak bag for analysis (fig. 8). All samples were stored at $4^{\circ} \mathrm{C}$ until transport to their respective laboratories. Grainsize samples were extruded into Whirl-Pak bags and frozen for possible analysis at a later date.

\section{Analytical Methods}

Laboratory analyses included VOCs, PAHs, PCBs, organochlorine pesticides, EPH, reactive sulfide, and metals. The analyte list was chosen to correspond with analytes listed in regulations guiding the disposal of sediments.

SGS Canada, Inc., Minerals Services (formerly XRAL Laboratories), of Toronto, Ontario, analyzed sediment samples for 32 elements (mainly metals) by using inductively coupled plasma-emission spectrometry, after the samples were digested by aqua regia. Each element analyzed by this method has its own reporting level (RL).

The USEPA Region I laboratory in Chelmsford, MA, analyzed sediment samples for VOCs by using standard gas chromatography/mass spectrometry (GC/MS) techniques (U.S. Environmental Protection Agency, 1996a). The methodology can quantify the concentrations of 70 compounds in soils or sediments. The USEPA laboratory also analyzed sediment samples for PAHs (U.S. Environmental Protection Agency, 2000). The analytical method, which uses GC with mass selective detector, measures concentrations of $16 \mathrm{PAH}$ compounds. Nominally, project RLs for PAHs were $0.0017 \mathrm{mg} / \mathrm{kg}$. In practice, organic interferences required sample dilutions of up to 100 times with actual RLs as high as $0.620 \mathrm{mg} / \mathrm{kg}$.

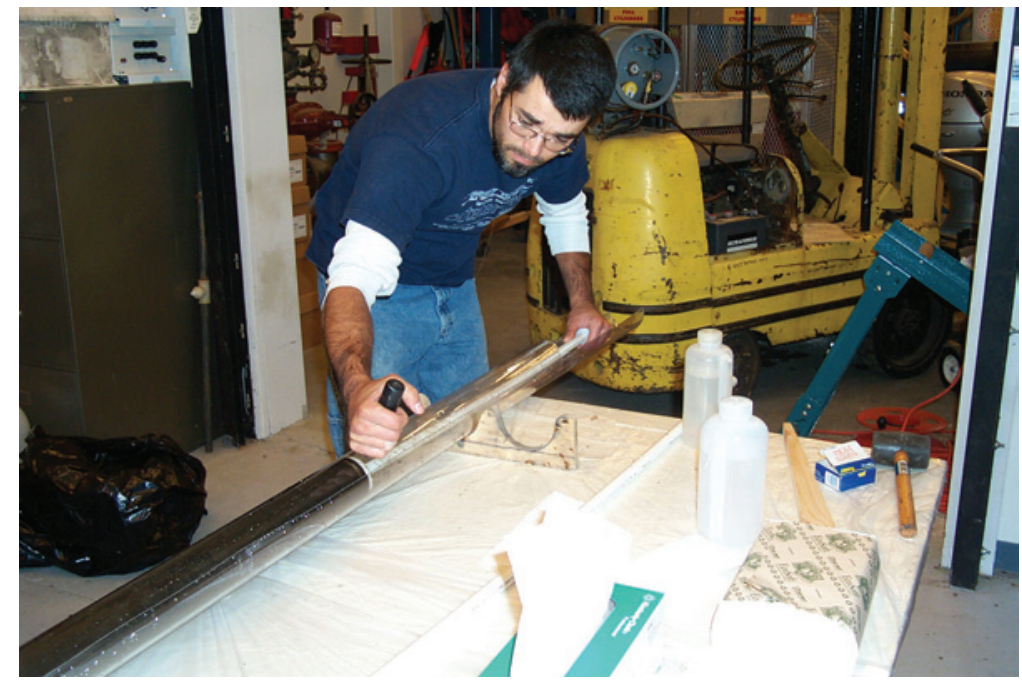

Figure 4. A Teflon piston is used to extrude core into a polycarbonate tube. 


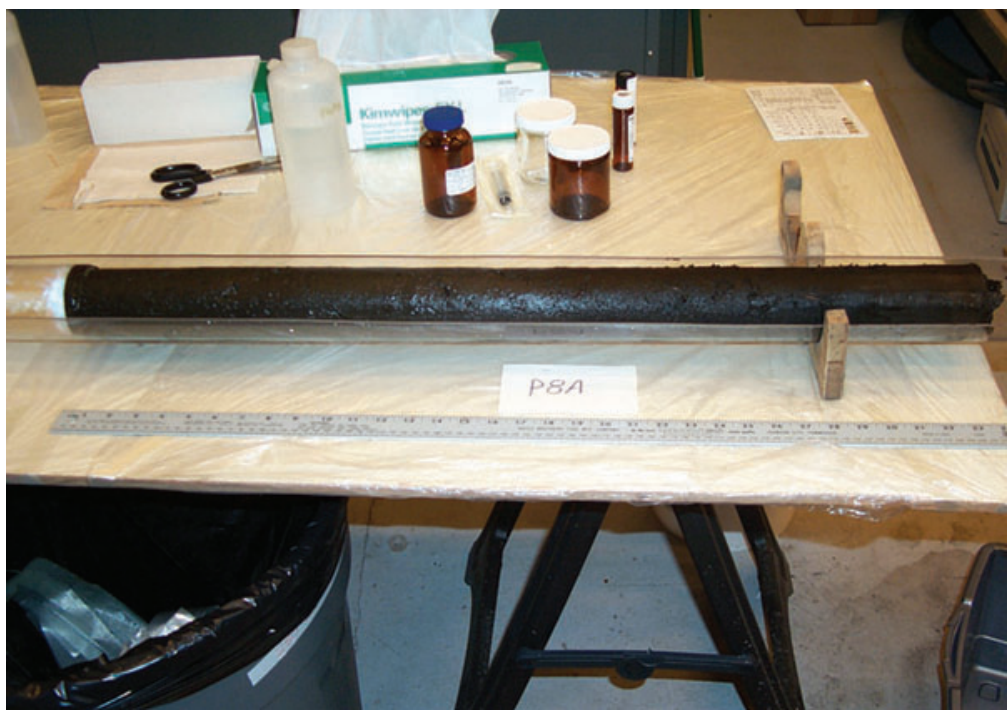

Figure 5. An extruded core.

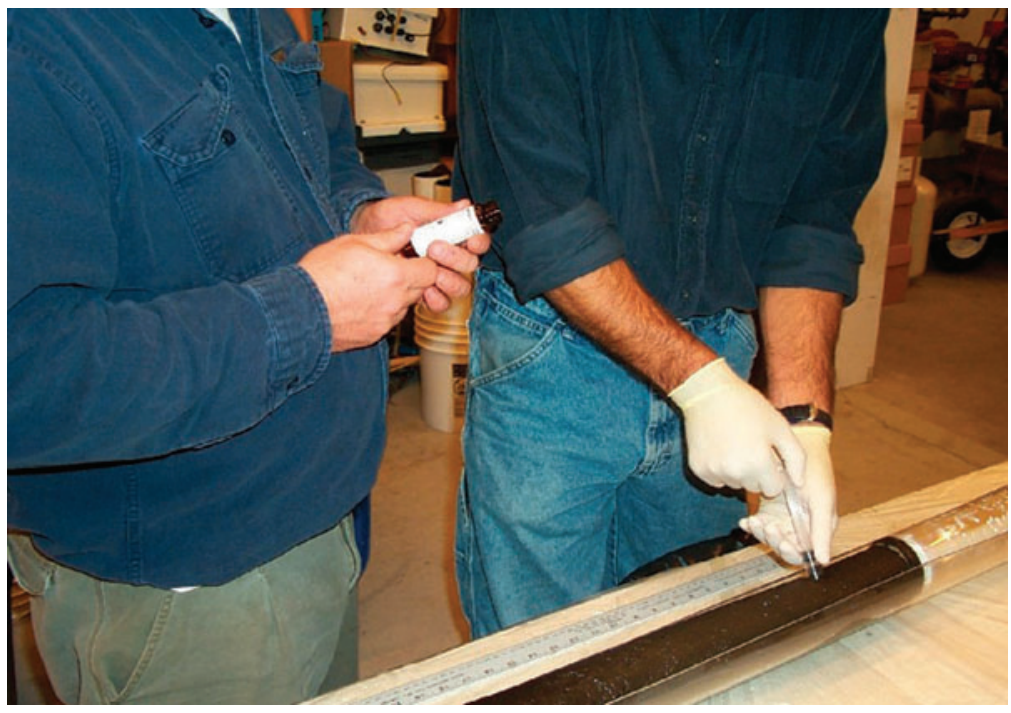

Figure 6. A sample is collected for volatile organic compound analysis. 


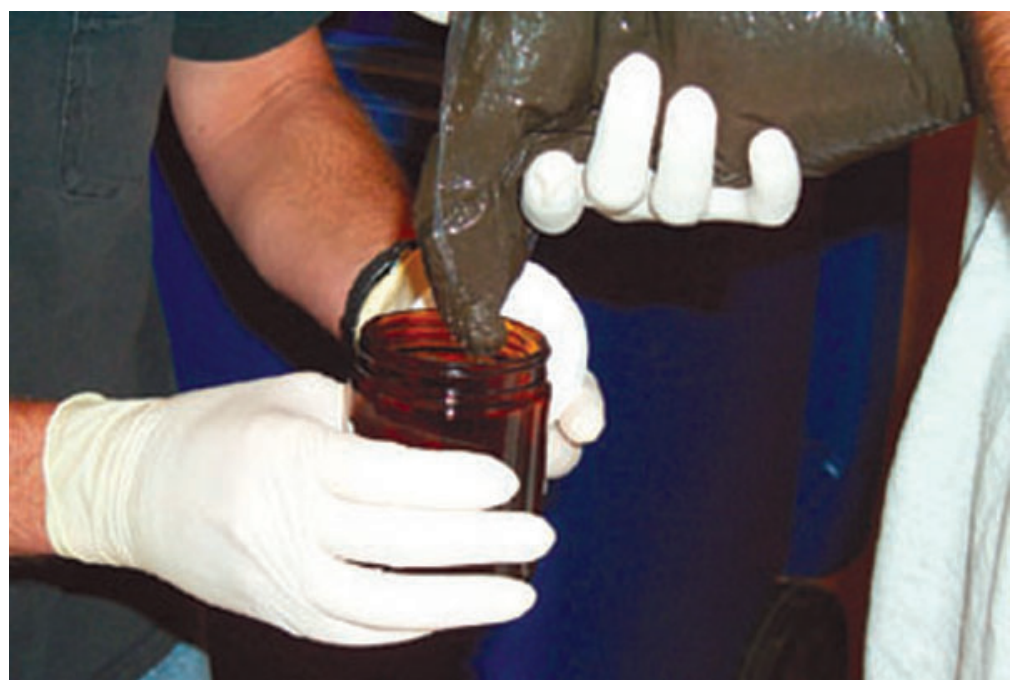

Figure 7. A sample is collected for polychlorinated biphenyl and pesticide analyses.

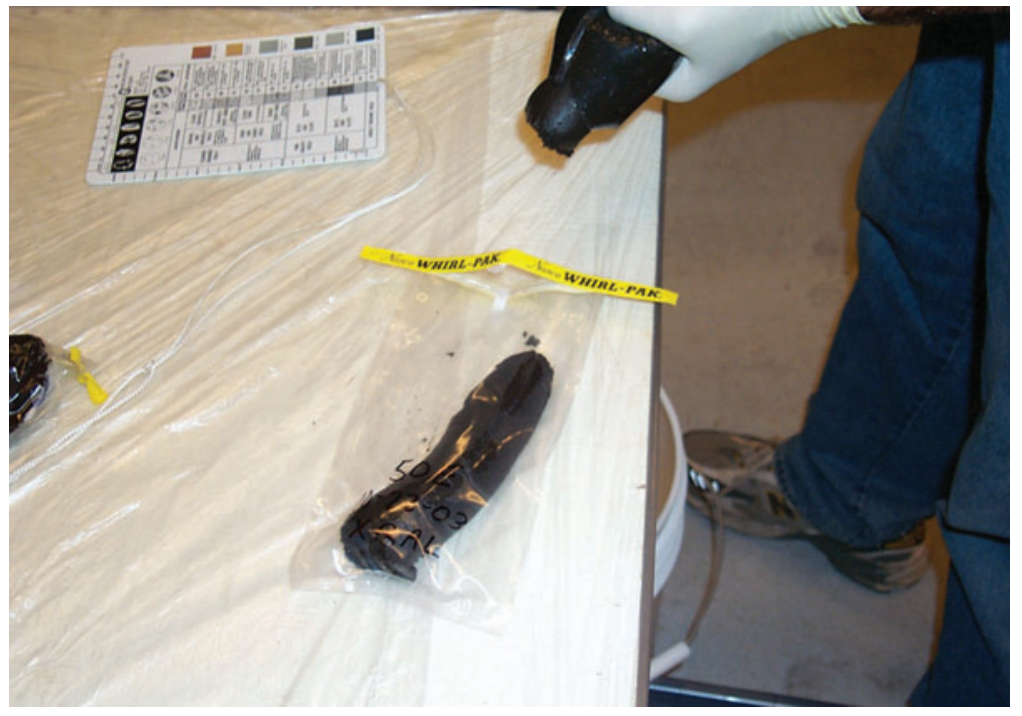

Figure 8. A sample is prepared for metal analysis. 
Table 1. Identifiers and depths for samples collected in six impoundments in the Assabet River, Massachusetts.

[Map ID: The identifier associated with a sampling site on a map (figs. 9-14). Field ID: core identifier. Sample ID: Identifier for a sample collected from a particular core, arranged alphabetically from the top of the core, with Q designating a replicate sample. in., inches]

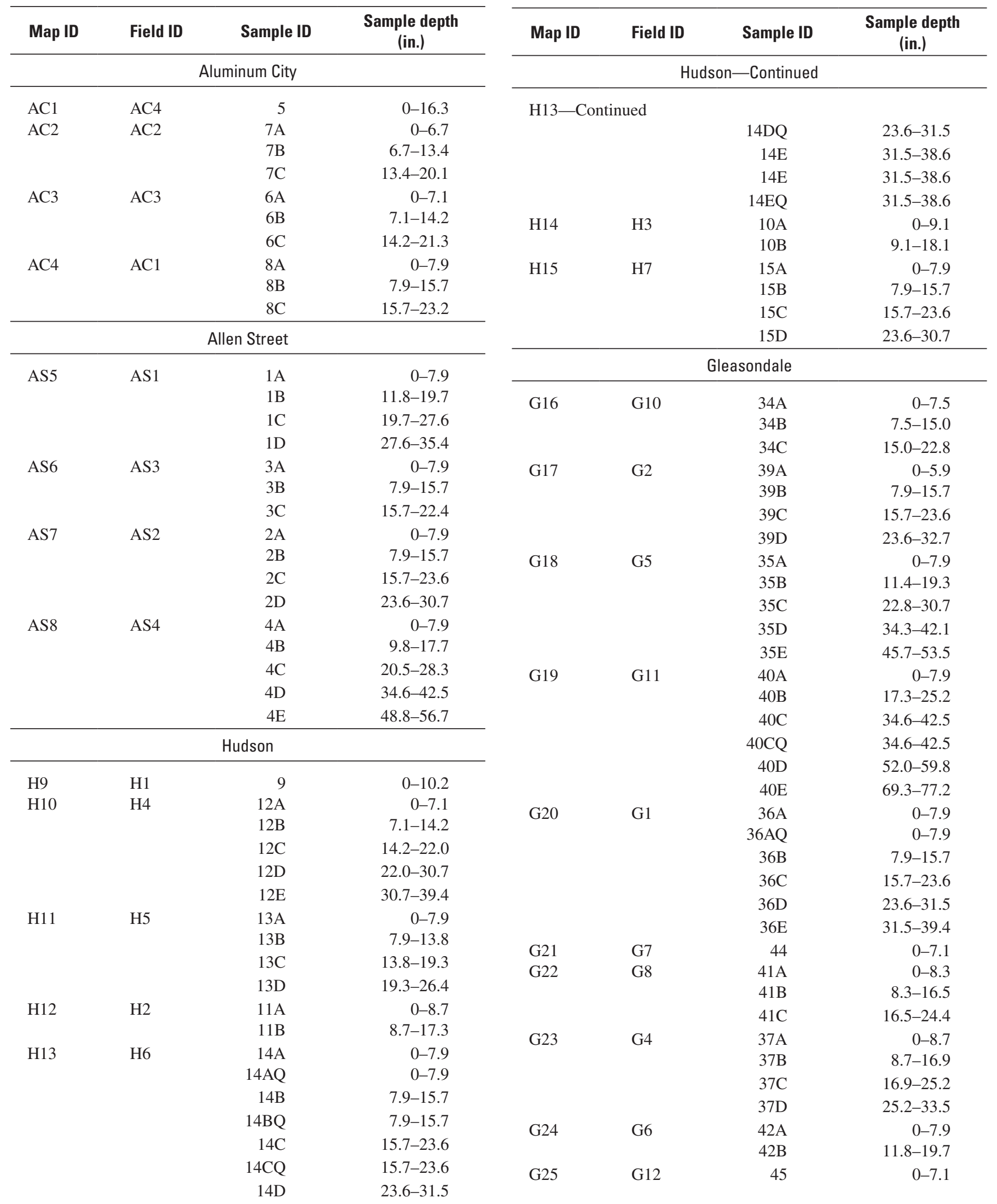


Table 1. Identifiers and depths for samples collected in six impoundments in the Assabet River, Massachusetts. - Continued

[Map ID: The identifier associated with a sampling site on a map (figs. 9-14). Field ID: core identifier. Sample ID: Identifier for a sample collected from a particular core, arranged alphabetically from the top of the core, with Q designating a replicate sample. in., inches]

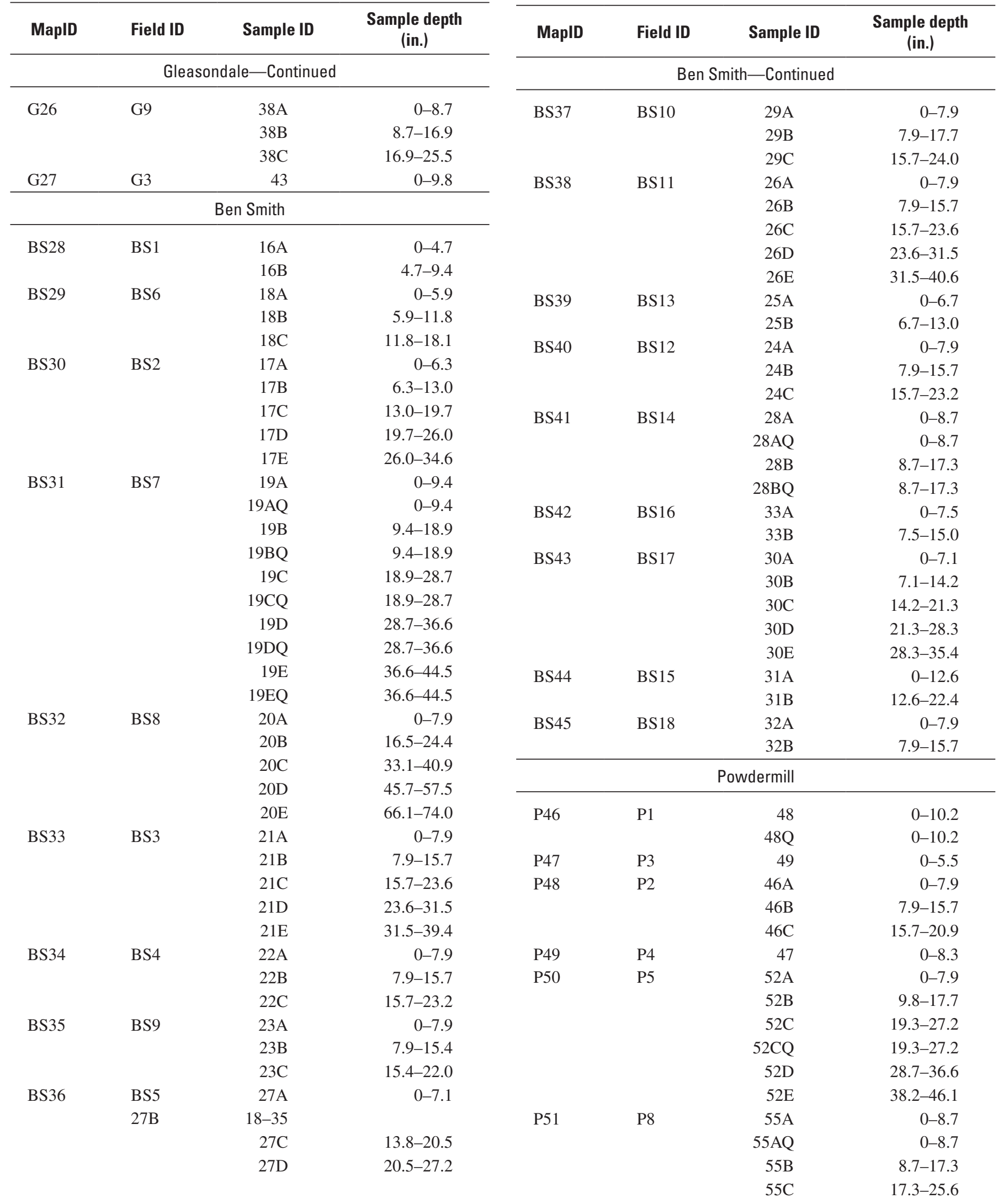


Table 1. Identifiers and depths for samples collected in six impoundments in the Assabet River, Massachusetts.-Continued

[Map ID: The identifier associated with a sampling site on a map (figs. 9-14). Field ID: core identifier. Sample ID: Identifier for a sample collected from a particular core, arranged alphabetically from the top of the core, with $\mathrm{Q}$ designating a replicate sample. in., inches]

\begin{tabular}{|c|c|c|c|}
\hline MapID & Field ID & Sample ID & $\begin{array}{c}\text { Sample depth } \\
\text { (in.) }\end{array}$ \\
\hline \multicolumn{4}{|c|}{ Powdermill-Continued } \\
\hline \multicolumn{4}{|c|}{ P51-Continued } \\
\hline & & $55 \mathrm{D}$ & $25.6-33.9$ \\
\hline \multirow[t]{6}{*}{ P52 } & P6 & $53 \mathrm{~A}$ & $0-7.9$ \\
\hline & & $53 \mathrm{~B}$ & $15.4-19.3$ \\
\hline & & $53 \mathrm{C}$ & $26.8-34.6$ \\
\hline & & $53 \mathrm{D}$ & $42.1-50.0$ \\
\hline & & 53DQ & $42.1-50.0$ \\
\hline & & $53 \mathrm{E}$ & $57.5-65.4$ \\
\hline \multirow[t]{4}{*}{ P53 } & P9 & $54 \mathrm{~A}$ & $0-8.7$ \\
\hline & & $54 \mathrm{~B}$ & $8.7-16.9$ \\
\hline & & $54 \mathrm{C}$ & $16.9-25.2$ \\
\hline & & $54 \mathrm{CQ}$ & $16.9-25.2$ \\
\hline \multirow[t]{4}{*}{ P54 } & $\mathrm{P} 10$ & $56 \mathrm{~A}$ & $0-7.9$ \\
\hline & & $56 \mathrm{~B}$ & $7.9-15.7$ \\
\hline & & $56 \mathrm{BQ}$ & 7.9-15.7 \\
\hline & & $56 \mathrm{C}$ & $15.7-23.6$ \\
\hline \multirow[t]{6}{*}{ P55 } & P11 & $51 \mathrm{~A}$ & $0-7.9$ \\
\hline & & $51 \mathrm{~B}$ & $9.8-17.7$ \\
\hline & & $51 \mathrm{BQ}$ & $9.8-17.7$ \\
\hline & & $51 \mathrm{C}$ & $19.7-27.6$ \\
\hline & & $51 \mathrm{D}$ & $29.5-37.4$ \\
\hline & & $51 \mathrm{E}$ & $29.8-47.2$ \\
\hline \multirow[t]{6}{*}{ P56 } & P7 & $50 \mathrm{~A}$ & $0-7.9$ \\
\hline & & 50AQ & $0-7.9$ \\
\hline & & 50B & $15.4-23.2$ \\
\hline & & $50 \mathrm{C}$ & $30.7-38.6$ \\
\hline & & $50 \mathrm{D}$ & $46.1-53.9$ \\
\hline & & $50 \mathrm{E}$ & $61.4-69.3$ \\
\hline \multirow[t]{2}{*}{ P57 } & $\mathrm{P} 12$ & 57 & 0-10.6 \\
\hline & & $57 \mathrm{Q}$ & $0-10.6$ \\
\hline
\end{tabular}

The EPH method, designed to assess exposure to petroleum hydrocarbons that may cause human health hazards (MDEP, 2002, 2004), measures the concentrations of aliphatic and aromatic hydrocarbons in soils or water by GC with a flame-ionization detector. Some of the petroleum products that this method may detect include kerosene, fuel oils \#2, \#4, and \#6, diesel oil, jet fuel, and some lubricating oils. These are essentially the same compounds targeted by the USEPA's PAH analyses, but the EPH-method RLs are $0.5 \mathrm{mg} / \mathrm{kg}$, which is higher than the $0.0017 \mathrm{mg} / \mathrm{kg}$ for the PAH analyses. New England Testing Laboratory, Providence, RI, performed the EPH analyses reported here.

The reactive sulfide method determines the amount of the highly corrosive and toxic vapor hydrogen sulfide which is released when sediment is placed in contact with acid. At present, Massachusetts has no regulatory standard, but the State's policy calls for lime stabilization of dredged sediments with reactive sulfide concentrations greater than 500 parts per million $(500 \mathrm{mg} / \mathrm{kg}$ ). New England Testing Laboratory used a standard procedure (U.S. Environmental Protection Agency, $1996 \mathrm{~b}$ ) with a reporting level of $5 \mathrm{mg} / \mathrm{kg}$ to analyze the sediments in this study for reactive sulfide.

Alpha Analytical, Inc., Westborough, MA, used capillarycolumn gas chromatography (U.S. Environmental Protection Agency, 1996c, d) to analyze sediment samples for PCBs and organochlorine pesticides. The RLs for PCBs $(0.017 \mathrm{mg} / \mathrm{kg})$ and organochlorine pesticides $(0.0008 \mathrm{mg} / \mathrm{kg})$ were also affected by sample dilutions that may have raised the RLs by a factor of as much as 100 .

\section{Quality Assurance and Quality Control}

Several precautionary steps were taken to ensure that sediment-sample collection and processing did not introduce contamination to the samples. In the field, sediment cores were collected with freshly manufactured plastic sleeves that were rinsed with ambient water at the site before core collection. Cores were capped and sealed at both ends in the field and returned to the Water Science Center office in plastic containers for processing. The cores were extruded (fig. 4) onto a large-diameter plastic tube that had been cut in half 
lengthwise, thoroughly cleaned with methanol and hydrochloric acid, and rinsed with distilled water. All parts of the extrusion apparatus were washed and rinsed with distilled water before samples were collected from a fresh core. All samples were handled with fresh latex gloves that were always discarded between consecutive collections of samples and frequently during the processing of samples from a single core.

Reproducibility of the sample homogenization process was tested with replicate analyses of approximately 10 percent of the samples of each type. Relative Percent Difference (RPD) calculations based on the results for replicate sample pairs rarely exceeded the 50-percent limit. The single pair of PAH-analysis results that exceeded the 50-percent RPD limit was from environmental and quality-control samples that exhibited systematic differences. These two samples, however, were handled differently in the analytical laboratory (one sample was diluted, whereas the other was not), and the individual sample with low PAH concentrations also had low percent recoveries of surrogates that would account for the differences. Other RPDs exceeding the 50-percent limit were distributed randomly among impoundments and within samples. Of the exceedances for the six sample pairs that had RPD limit exceedances, four were represented by a single element (three pairs of measurements of molybdenum at concentrations close to its reporting level and one pair of measurements of chromium). The RPD values that exceeded the RPD limit in two sets of organic-compound samples are attributable to differences in sample dilution at the analytical laboratory. The replicate-sample results showed that the sampling process produced consistently representative data for this study.

\section{Sediment Thickness and Bathymetric Maps}

Although sediment-thickness data associated with the core sites were not used to create the sediment maps, data obtained by manual probing indicate the core sites where sediment thicknesses and water depths were greatest. Sedimentcore lengths were generally less than the lengths measured by manual probing because a thin, pointed metal rod can penetrate sediments farther than a 2 to 3 -in.-diameter flat-edged, plastic tube.

Data collected by manual probing were used to determine the water-depth contour lines on the bathymetric maps of the impoundments (figs. 9 to 14). The maximum water depth was least in the Aluminum City impoundment $(3.9 \mathrm{ft})$ and greatest in the Gleasondale impoundment (11 ft). Water depths were not related to a fixed datum and could change with streamflow.

The Aluminum City impoundment (fig. 9) was found to be rock-bottomed (rip-rapped) near the dam and to have primarily rock and sand refusal in the upstream reach. Its thickest sediments were measured near the dam (core site AC4, $3.3 \mathrm{ft}$ ) and close to the farthest upstream core site (AC1, $2.4 \mathrm{ft})$. The greatest water depth measured at the time of sediment mapping was $3.9 \mathrm{ft}$.

The thickest sediment deposits in the Allen Street impoundment (fig. 10) were measured near core sites AS6 and AS8 (11 ft). Probe refusal at the Allen Street impoundment was caused by sand and gravel within the channels upstream of AS5 and the area immediately downstream from the Allen Street bridge. The wide depositional area of the impoundment generally had a refusal caused by fine sand, silt, and clay. A maximum water depth of $8.2 \mathrm{ft}$ was measured above thin sediment deposits between sites AS6 and AS8.

In Hudson, the impoundment's thickest sediment (7.5 ft) was measured in the area north of H12 (fig. 11); sediment thicknesses exceeding $6 \mathrm{ft}$ were also measured in the vicinity of H15. The bottom of the Hudson impoundment was characterized by sand and gravel in the river channel and fine materials in lateral depositional areas. Water depths reached more than $10 \mathrm{ft}$ near in the channel leading to the dam.

The deepest manual probes in Gleasondale sediments were made in the upstream areas (fig. 12) in the general vicinity of G18, G19, and G20, where they penetrated farther than $18 \mathrm{ft}$ without reaching refusal; however, the probes may have penetrated preimpoundment sediment deposits. The downstream reach had a relatively steep gradient that may have caused sediment scouring and shallow sediment thicknesses. Water depths approached $11 \mathrm{ft}$ near G22. 


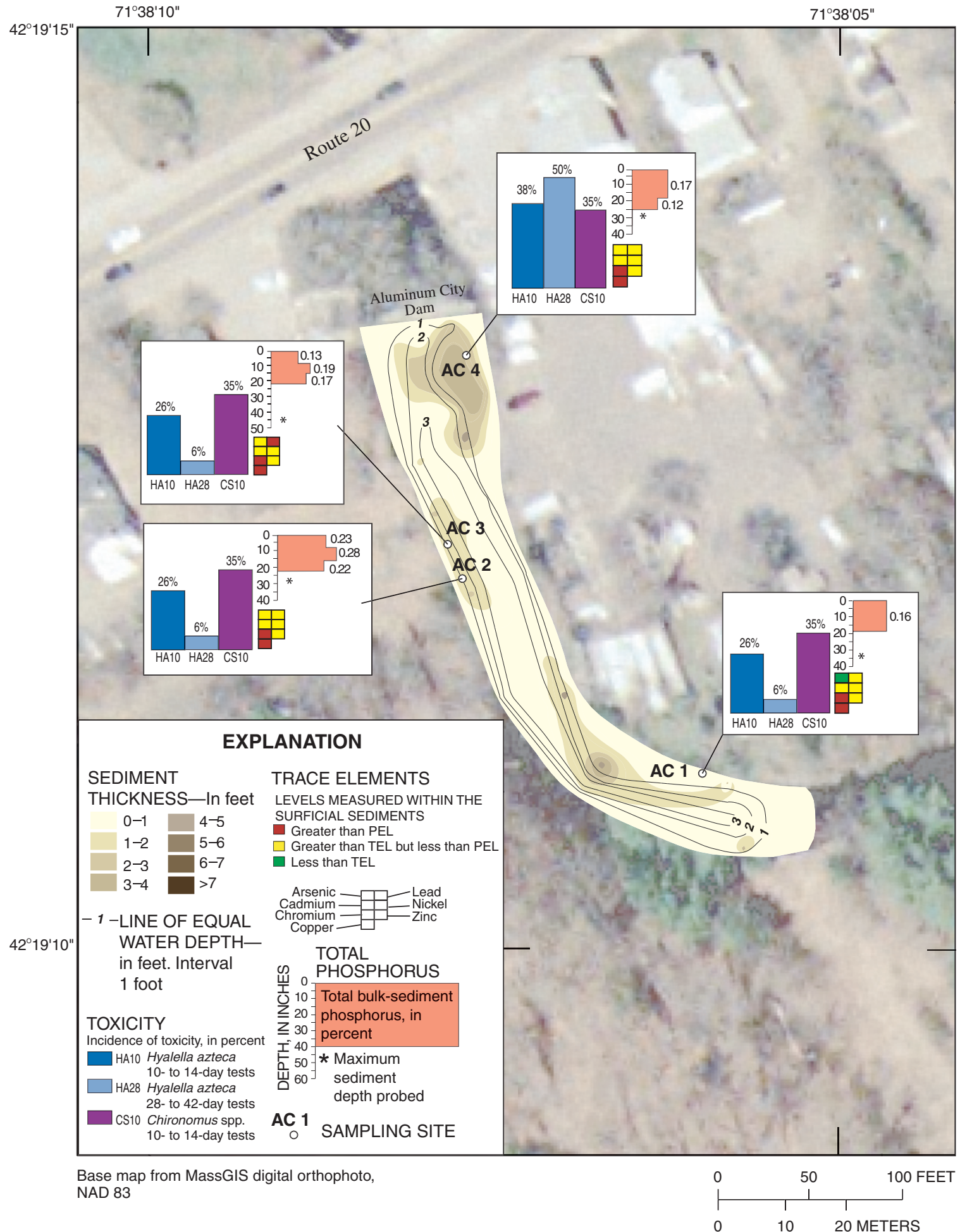

Figure 9. Sediment thickness, phosphorus bulk-sediment profiles, exceedances of TEL (threshold effect level) and PEL (probable effect level) guidelines for toxic trace elements, and potential for sediment toxicity to aquatic life from cores collected in Aluminum City impoundment in Northborough, Massachusetts, 2003. 


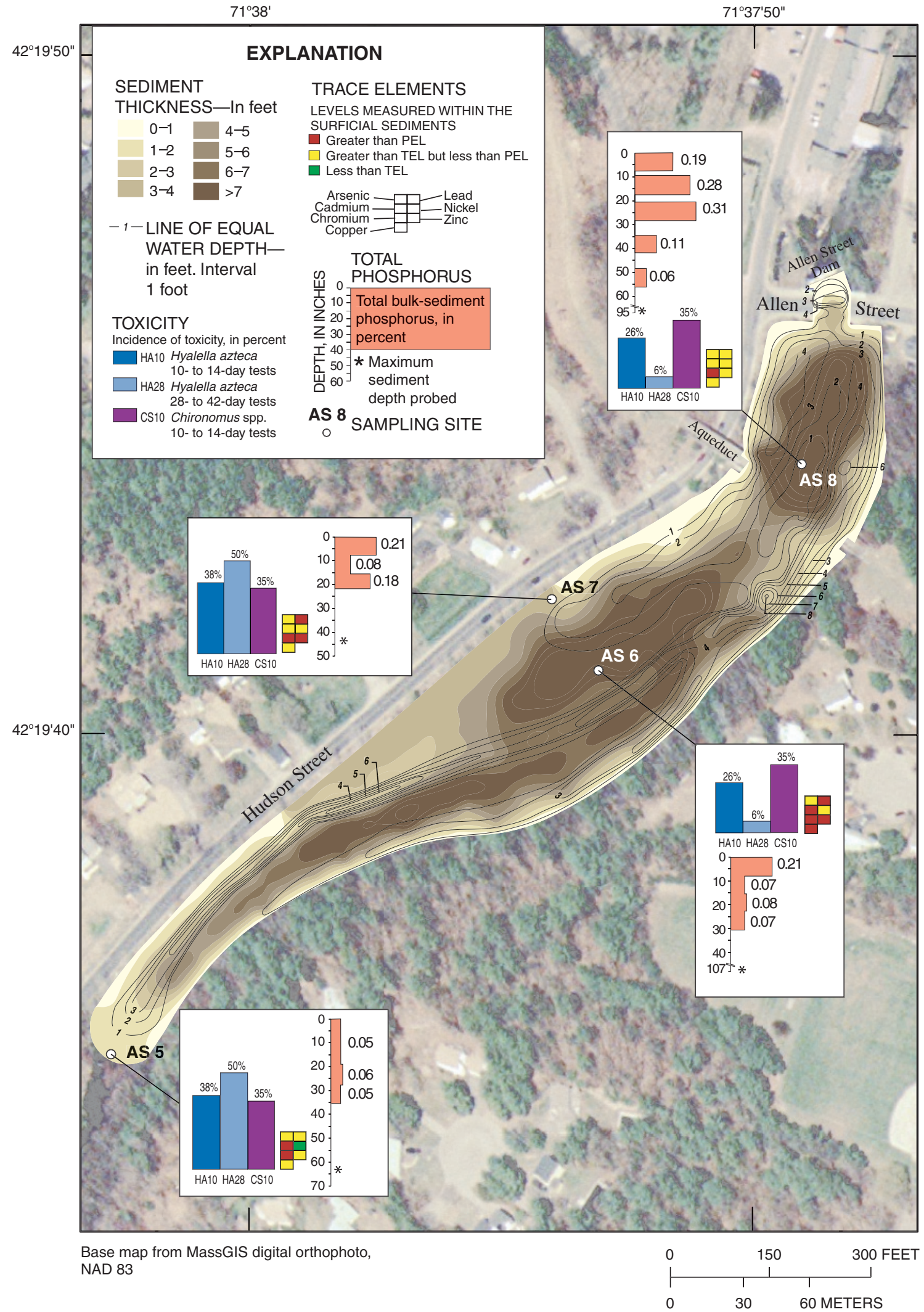

Figure 10. Sediment thickness, phosphorus bulk-sediment profiles, exceedances of TEL (threshold effect level) and PEL (probable effect level) guidelines for toxic trace elements, and potential for sediment toxicity to aquatic life from cores collected in Allen Street impoundment in Northborough, Massachusetts, 2003. 


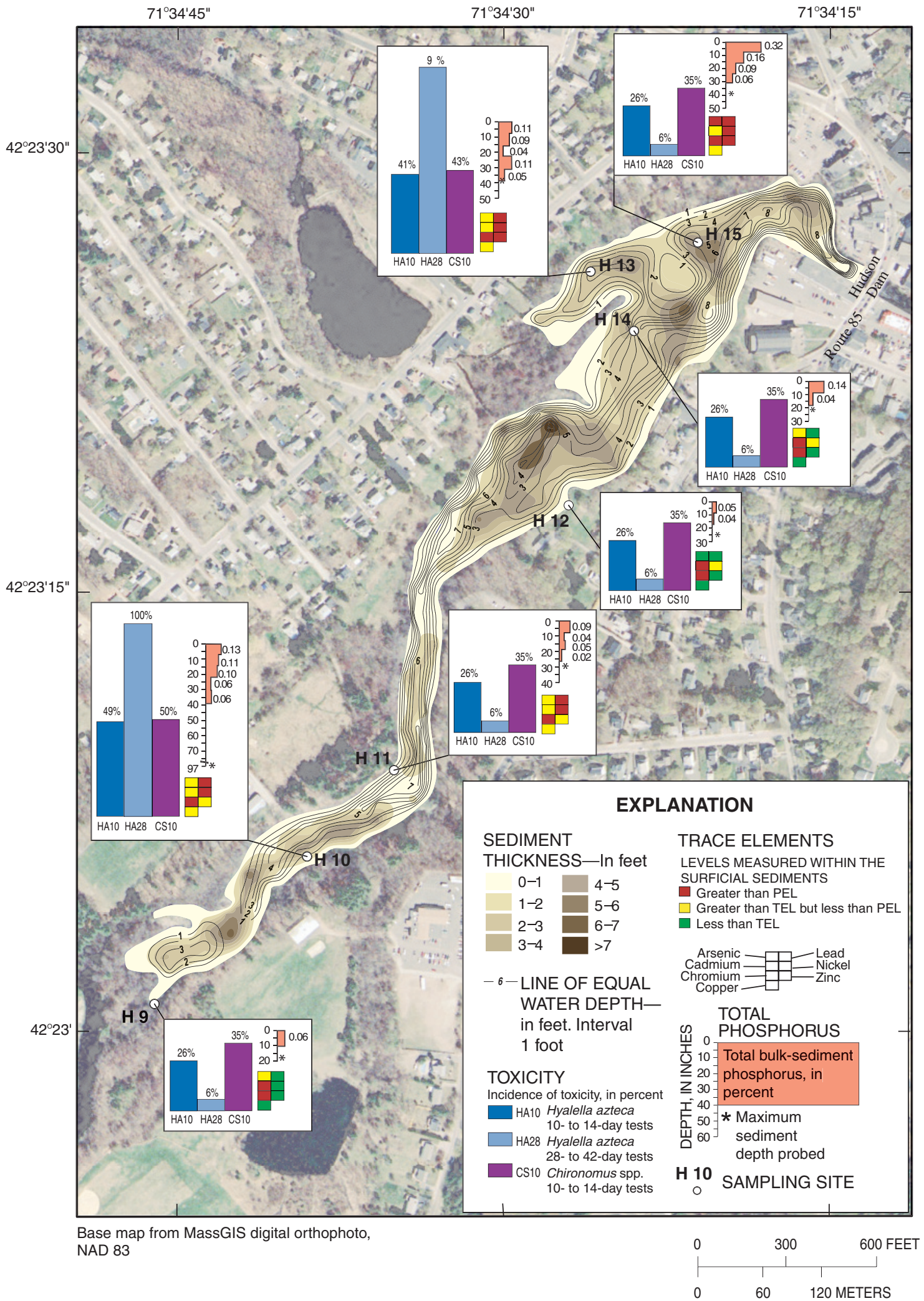

Figure 11. Sediment thickness, phosphorus bulk-sediment profiles, exceedances of TEL (threshold effect level) and PEL (probable effect level) guidelines for toxic trace elements, and potential for sediment toxicity to aquatic life from cores collected in Route 85 impoundment in Hudson, Massachusetts, 2003. 


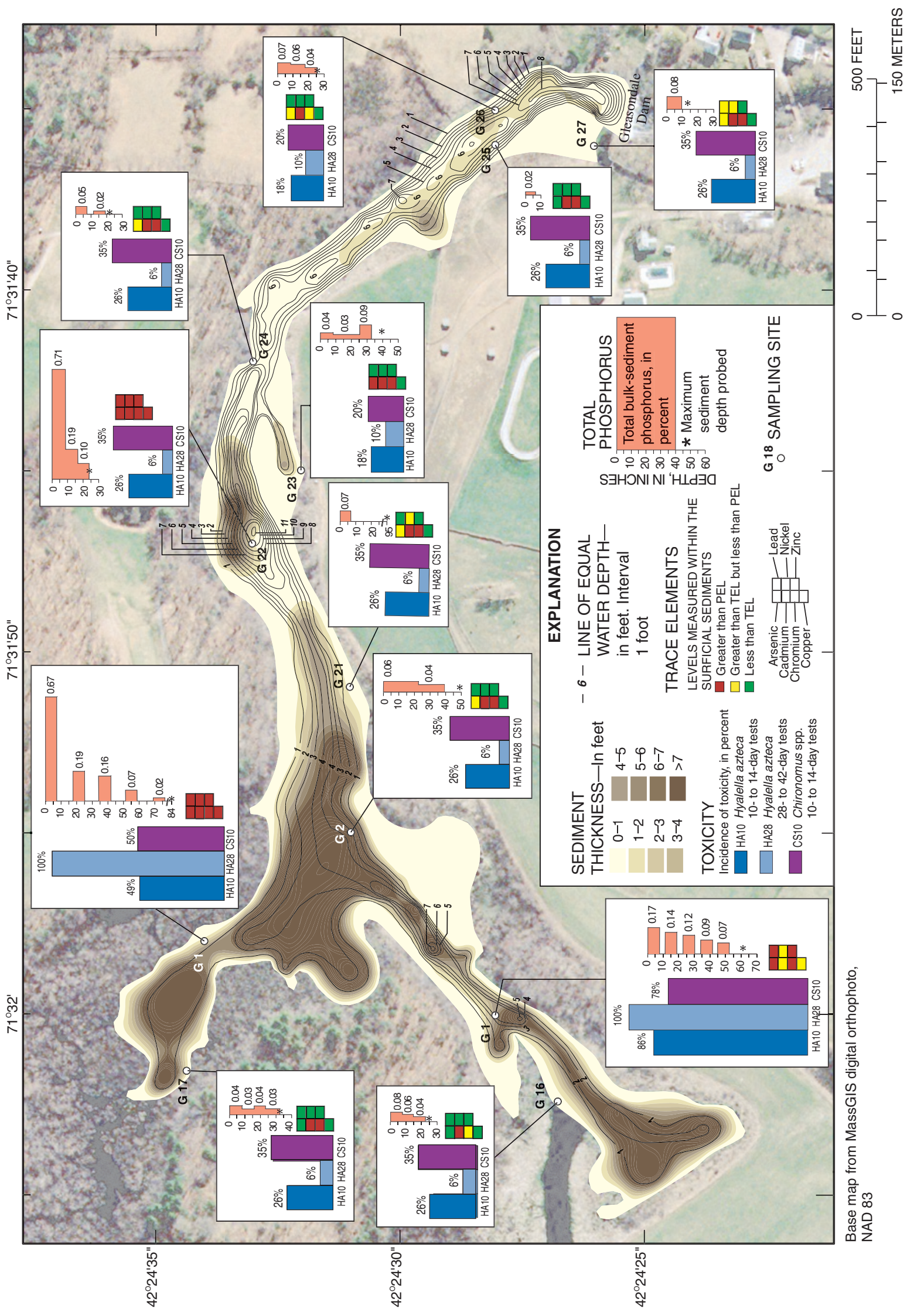

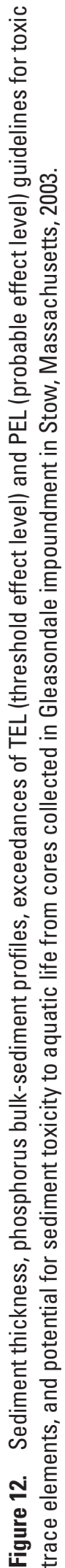




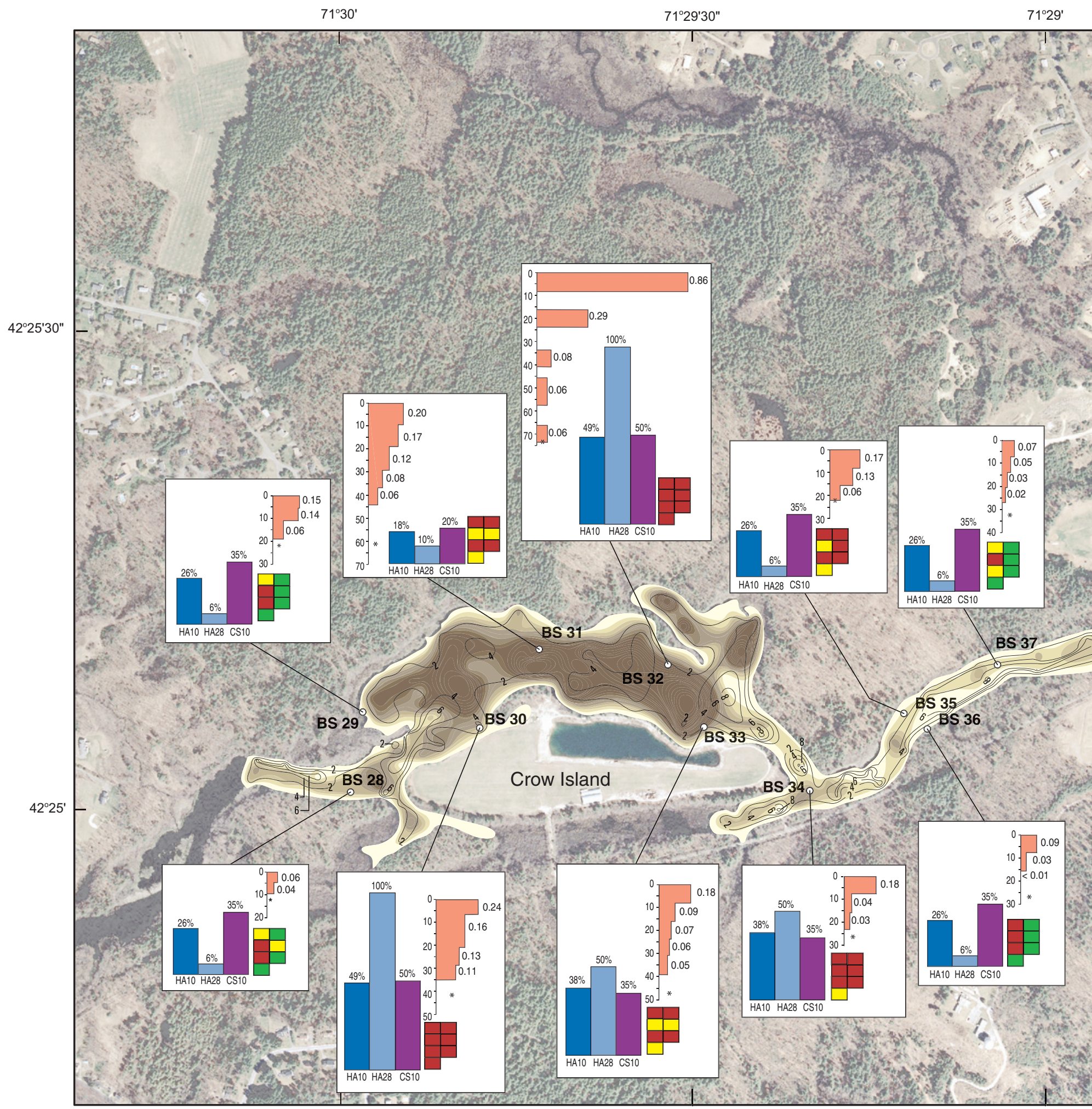

Base map from MassGIS digital orthophoto, NAD 83 
$71^{\circ} 28^{\prime} 30^{\prime \prime}$

$71^{\circ} 28$

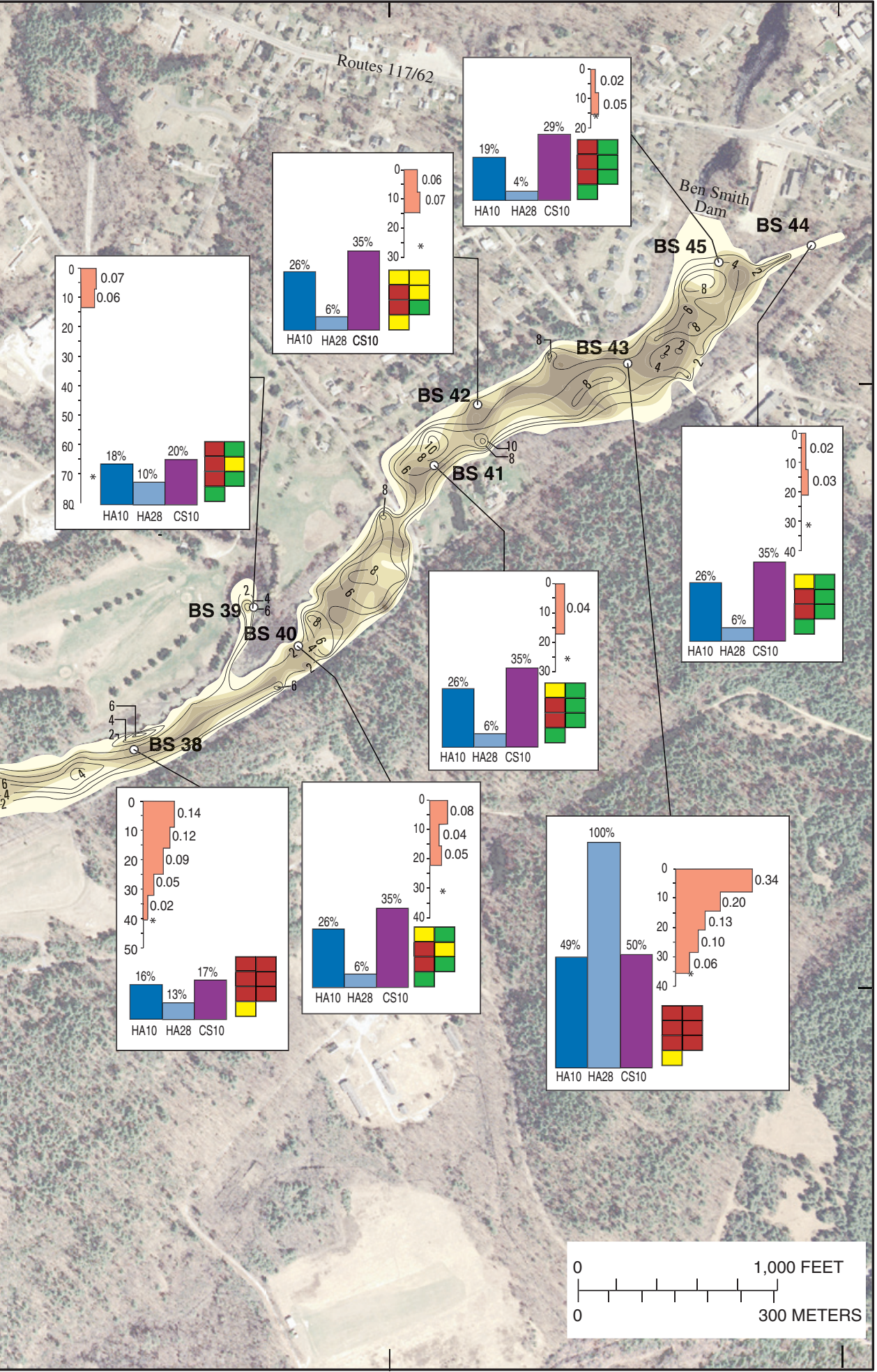

\section{EXPLANATION}

\section{SEDIMENT \\ THICKNESS-In feet

$\begin{array}{lll}0-1 & 4-5 \\ 1-2 & 5-6 \\ 2-3 & 6-7 \\ 3-4 & >7\end{array}$ \\ 3-4 $>7$}

\section{TOXICITY}

Incidence of toxicity, in percent

HA10 Hyalella azteca 10- to 14-day tests

HA28 Hyalella azteca 28- to 42-day tests

CS10 Chironomus spp. 10- to 14-day tests

-6-LINE OF EQUAL WATER DEPTHin feet. Interval 2 feet

\section{TRACE ELEMENTS}

LEVELS MEASURED WITHIN THE SURFICIAL SEDIMENTS

Greater than PEL

$\square$ Greater than TEL but less than PEL

$\square$ Less than TEL

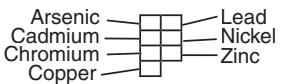

TOTAL

Щ 0 PHOSPHORUS

I 10 - Total bulk-sediment

20 20 phosphorus, in

$\geqq 30$ percent

I 40 * Maximum

岀 $60^{-}$sediment

depth probed

\section{BS 44 SAMPLING SITE}

Figure 13. Sediment thickness, phosphorus bulksediment profiles, exceedances of TEL (threshold effect level) and PEL (probable effect level) guidelines for toxic trace elements, and potential for sediment toxicity to aquatic life from cores collected in Ben Smith impoundment in Maynard, Massachusetts, 2003. 

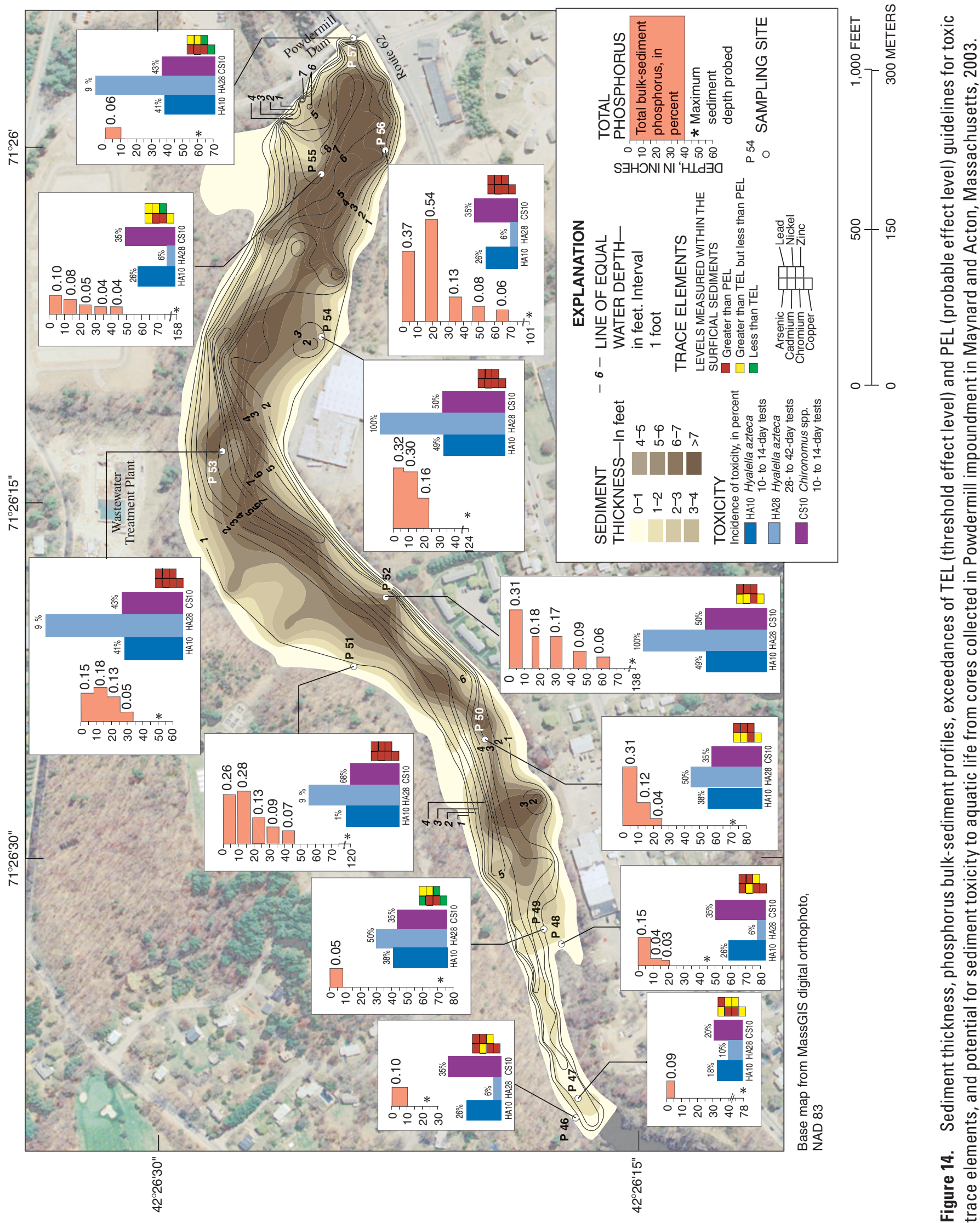
The elongated Ben Smith impoundment was characterized by extensive, thick sediment deposits in the vicinity of Crow Island (fig. 13). The probe reached through more than $15 \mathrm{ft}$ of sediment at several places and more than $24 \mathrm{ft}$ near BS32. The bottom of the narrow channel section between BS34 and BS41 was sandy with finer materials distributed along the lateral edges. In the vicinity of the dam, the bottom materials were predominantly coarse sand and gravel. Water depths exceeded $8 \mathrm{ft}$ near the dam.

The Powdermill impoundment was characterized by having a narrow, rocky channel upstream from P49. Sediments were distributed uniformly throughout the main body of the impoundment, with the thickest sediments approximately along the impoundment's midline (fig. 14). Sandy conditions dominated the impoundment's bottom. Water depths were more than $8 \mathrm{ft}$ just upstream of the dam.

Ben Smith impoundment had the greatest volume of sediment and Aluminum City the least, as calculated by the TIN computer program. In decreasing order, the impoundments' sediment volumes were: Ben Smith $\left(580,000 \mathrm{~m}^{3}\right)$, Powdermill $\left(120,000 \mathrm{~m}^{3}\right)$, Gleasondale $\left(67,000 \mathrm{~m}^{3}\right)$, Hudson $\left(55,000 \mathrm{~m}^{3}\right)$, Allen Street $\left(42,000 \mathrm{~m}^{3}\right)$, and Aluminum City $\left(380 \mathrm{~m}^{3}\right)$. These sediment-volume estimates may include some preimpoundment material, and thus may overestimate the amount of impounded sediment.

\section{Sediment Chemistry of the Assabet River Impoundments}

The concentrations of metals detected were compared among the impoundments and with results from analyses of the chemistry of sediments in other New England rivers (Chalmers, 2002; Robinson and others, 2004). The results were also compared with sediment-quality guidelines (table 2) related to 1) potential effects on freshwater organisms, 2) dangerous levels for human contact, and 3) permitted levels for reuse (disposal) in landfills. The potential effects on freshwater organisms are further organized into three groups: a) threshold effect level (TEL), the concentration below which adverse effects are rarely observed; b) probable effect level (PEL), the concentration above which adverse effects are commonly observed; and c) probable effect concentration (PEC), the concentration above which adverse effects are expected. In general, the PEC is greater than the PEL; the exception is $\mathrm{Cu}$. The TEL and PEL are used in discussions of the effects of metals on biota and the PEC is used in discussions of the combined effects of metals, PAHs, and PCBs on biota.

\section{Elemental Analyses}

Dividing the results of the elemental analyses performed by SGS Canada Inc., Minerals Services, into three categories — phosphorus (as a bulk-sediment analyte), toxic metals, and other elements - groups the data in a meaningful way for efficient interpretation. The vertical distribution of phosphorus in sediments throughout the study area (table 3 ) was investigated because the sediments may serve as a potential phosphorus source. The toxic trace elements constitute a seven-element subset of metals (table 14, at back of report) often referred to as critical contaminants. The remaining elements are not generally considered commonly occurring toxics requiring special attention to minimize potential harm to aquatic life or humans; their concentrations are reported (table 15, at back of report), but not discussed in comparisons among the Assabet impoundments.

\section{Phosphorus}

A recent survey of stream sediments in New England (Chalmers, 2002) reported bulk concentrations of phosphorus in samples collected primarily in urban and rural settings. The median concentration from that study is slightly higher than those for the individual impoundments reported here (table 4). The maximum phosphorus concentrations in the Assabet River sediments, however, exceeded the maxima reported in the other study.

Bulk-sediment phosphorus concentrations ranged from less than the RL of 0.01 percent at site BS37 (subsample from approximately $2 \mathrm{ft}$ below the sediment surface) to 0.86 percent at site BS32 (surface sample). Throughout the six-impoundment system, the highest phosphorus concentrations generally were measured in samples collected closest to the sediment surface (table 5; figs. 9 to 14). Three possible explanations for this distribution of phosphorus concentrations are: (1) high concentrations of phosphorus transported in the water column may serve as a continuous supply of phosphorus; (2) rooted macrophytes will take up available phosphorus from surficial sediments, and as these plants die and decay, all or part of their phosphorus will be deposited on the sediment surface, where it may once again become available; (3) phosphorus may dissolve in deep, anaerobic sediment, diffuse upward, and precipitate at the sediment-water interface.

Comparing the means, medians, minima, and maxima of concentrations of all samples and of only surface samples from the impoundments reveals phosphorus-concentration trends with reservoir position (table 5). In the environmental samples, the median phosphorus concentration was 0.08 percent and the mean concentration was 0.12 percent. Sediment samples from Aluminum City, from all impoundments, had the highest median ( 0.17 percent) and mean ( 0.18 percent) phosphorus concentrations. Sediment samples from Aluminum City had the lowest maximum ( 0.28 percent) but the highest minimum ( 0.12 percent) phosphorus concentrations of samples collected at all depths from all impoundments. Phosphorus-concentration maxima increased downstream from Aluminum City until the Powdermill impoundment, where the maximum concentration decreased. The minima of all samples generally decrease in the downstream direction. 
Table 2. Sediment-quality guidelines for freshwater organisms, human contact, and Massachusetts landfill reuse.

[Sources: Massachusetts Department of Environmental Protection, 1995; Breault and others, 2000; Ingersoll and others, 2001. EPH, extractable petroleum hydrocarbon; PAH, polycyclic aromatic hydrocarbon; PCB, polychlorinated biphenyl; PEC, Probable Effect Concentration, concentration above which adverse effects are expected; PEL, Probable Effect Level, concentration above which adverse effects are commonly observed; TEL, Threshold Effect Level, concentration below which adverse effects are rarely observed; $\mathrm{TPH}$, total petroleum hydrocarbon; $\mu \mathrm{g} / \mathrm{kg}$, micrograms per kilogram; $\mathrm{mg} / \mathrm{kg}$, milligrams per kilogram; $<$, actual value is less than value shown; --, no value available]

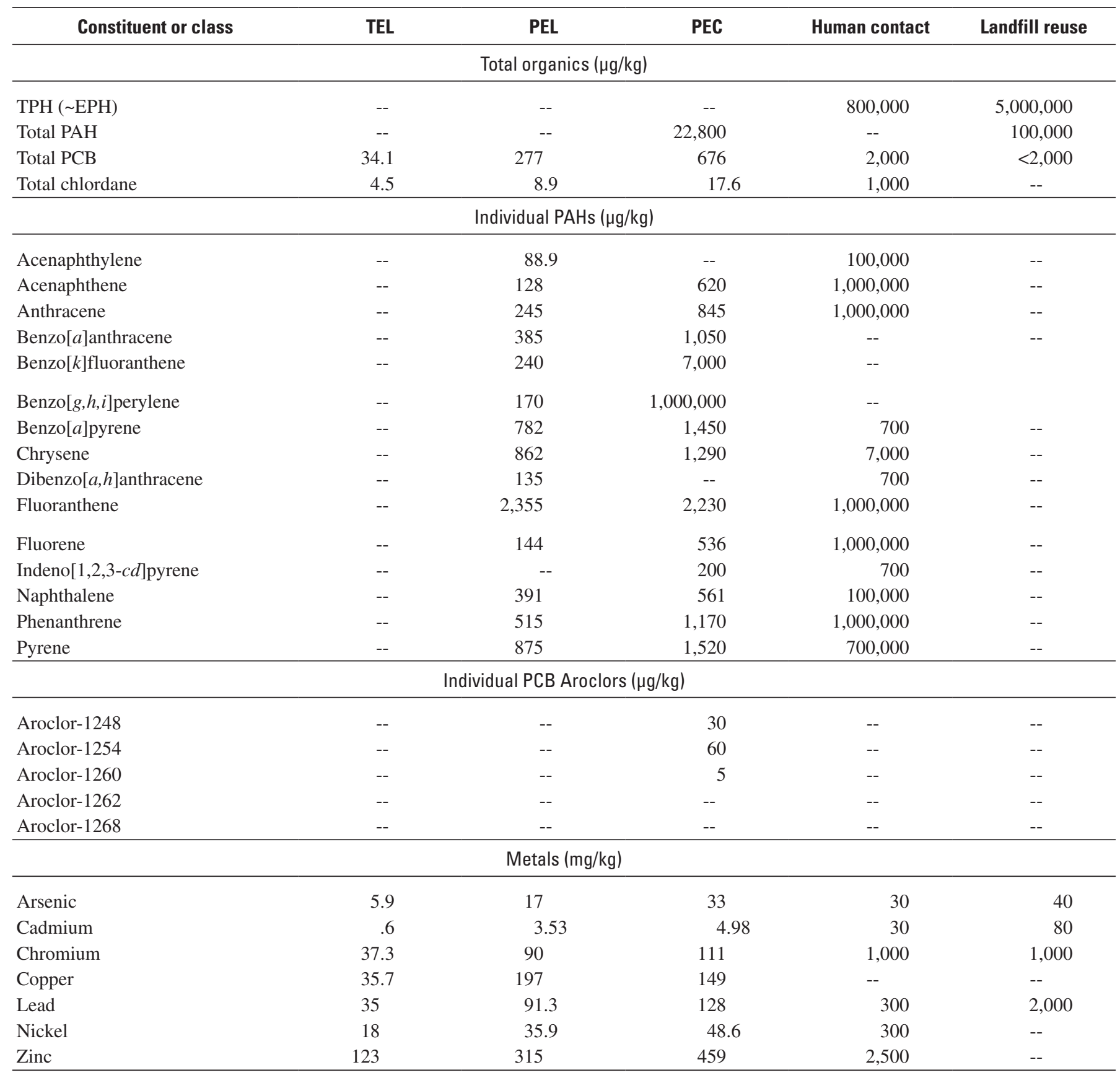


Table 3. Concentrations of phosphorus, in percent, in bulk sediment samples from six impoundments in the Assabet River Basin, Massachusetts, 2003.

[Map ID: The identifier associated with a sampling site on a map (figs. 9-14). Sample ID: Identifier for a sample collected from a particular core, arranged alphabetically from the top of the core. $<$, actual value is less than value shown]

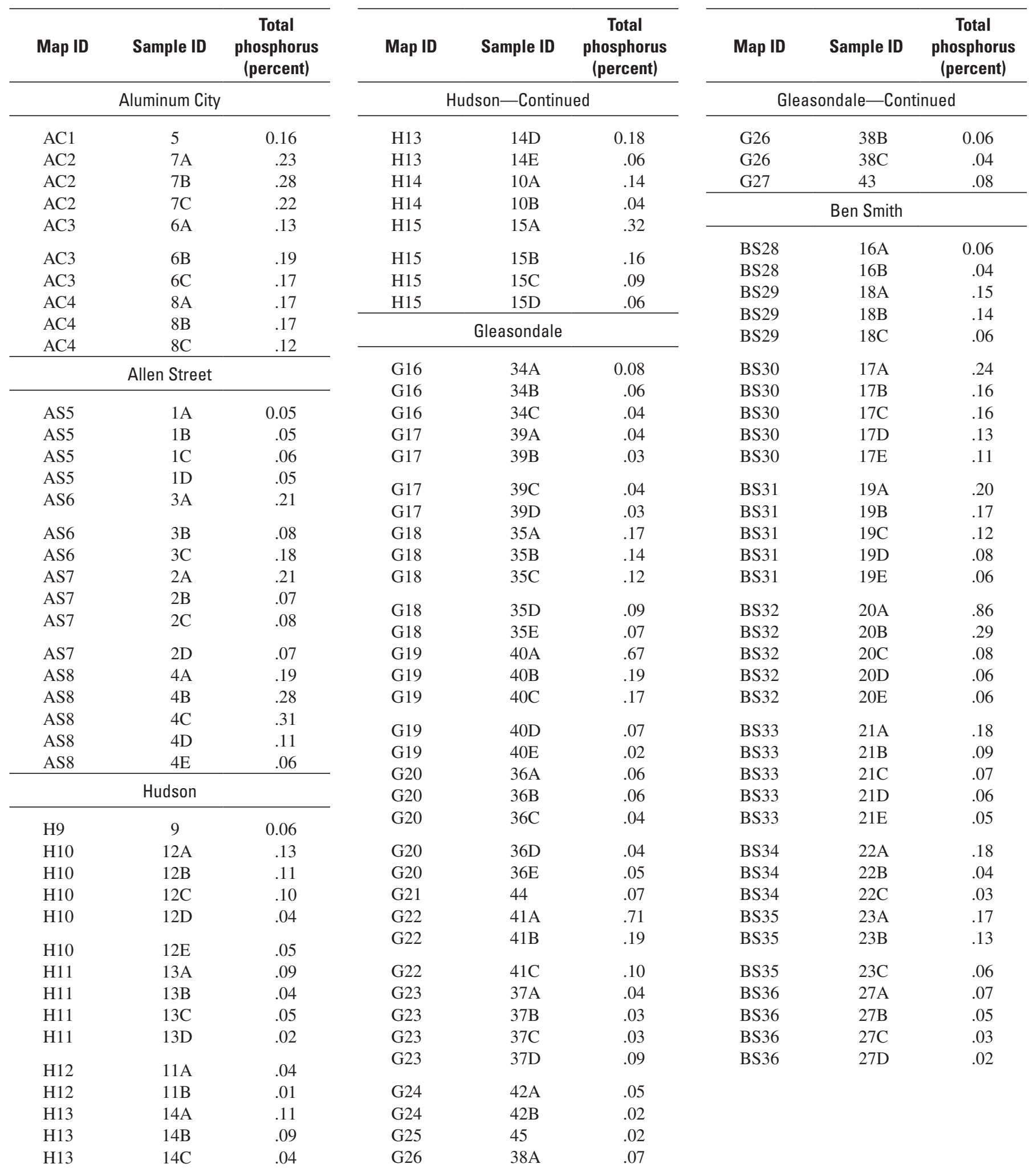


Table 3. Concentrations of phosphorus, in percent, in bulk sediment samples from six impoundments in the Assabet River Basin, Massachusetts, 2003.-Continued

[Map ID: The identifier associated with a sampling site on a map (figs. 9-14). Sample ID: Identifier for a sample collected from a particular core, arranged alphabetically from the top of the core. $<$, actual value is less than value shown]

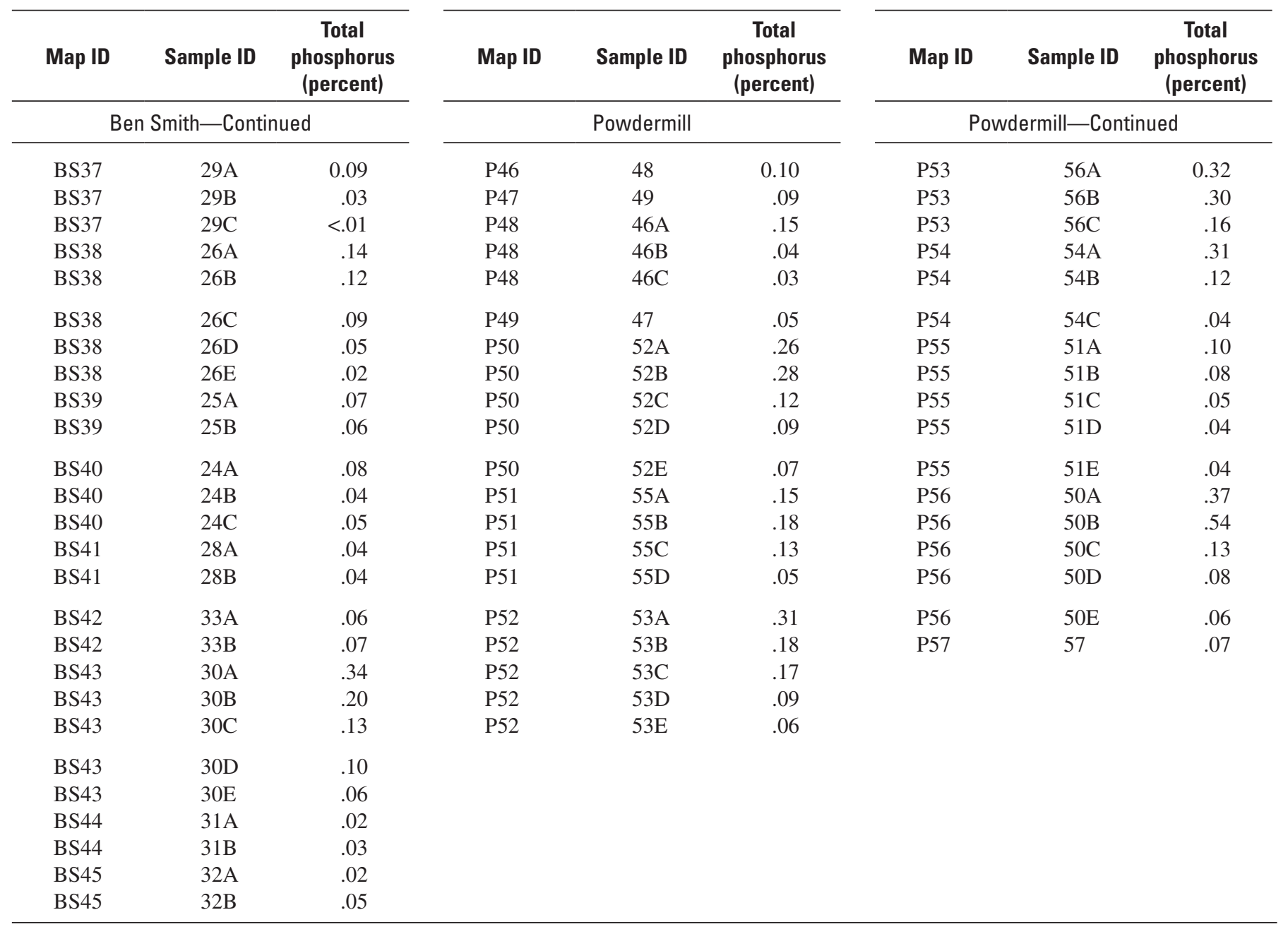


Table 4. Mean and median concentrations of trace metals in New England stream sediments.

[mg/kg, milligrams per kilogram; NA, not available; <, actual value is less than value shown; --, no data]

\begin{tabular}{|c|c|c|c|c|c|c|c|c|}
\hline \multirow{2}{*}{ Trace metal } & \multicolumn{4}{|c|}{ Previous investigations } & \multicolumn{4}{|c|}{ Current (2003) investigations } \\
\hline & Mean & Median & Mean & Median & Mean & Median & Mean & Median \\
\hline Aluminum, percent & -- & -- & 5.60 & 5.65 & 1.22 & 1.20 & 0.13 & 0.08 \\
\hline Antimony, mg/kg & -- & -- & 2.70 & 2.40 & $<5$ & $<5$ & $<5$ & $<5$ \\
\hline Arsenic, mg/kg & 5.08 & 2.80 & 39.2 & 19.0 & 10.0 & 9.00 & 11.0 & 11.0 \\
\hline Beryllium, mg/kg & -- & -- & 3.00 & 2.80 & NA & .50 & $<.5$ & $<.5$ \\
\hline Bismuth, mg/kg & -- & -- & NA & $<1$ & NA & $<5$ & $<5$ & $<5$ \\
\hline Cadmium, mg/kg & -- & -- & 3.75 & 2.10 & 2.00 & 2.00 & NA & 1.00 \\
\hline Calcium, percent & -- & -- & 1.34 & 1.40 & .45 & .45 & .32 & .29 \\
\hline Chromium, mg/kg & -- & -- & 134 & 99.0 & 336 & 149 & 168 & 154 \\
\hline Lanthanum, mg/kg & 53.7 & 41.0 & 50.5 & 46.0 & 14.7 & 15.5 & 13.3 & 13.4 \\
\hline Lead, mg/kg & 44.1 & 30.0 & 229 & 190 & 113 & 82.0 & 153 & 150 \\
\hline Magnesium, percent & -- & -- & .70 & .71 & .38 & .36 & 1.09 & 1.02 \\
\hline Manganese, mg/kg & -- & -- & 3,500 & 1,850 & 465 & 481 & 358 & 280 \\
\hline Molybdenum, mg/kg & -- & -- & 4.85 & 2.60 & 5.50 & 5.50 & NA & 2.50 \\
\hline Nickel, mg/kg & -- & -- & 43.4 & 45.0 & 25.0 & 24.0 & 21.0 & 19.0 \\
\hline Phosphorus, percent & -- & -- & .23 & .22 & .18 & .17 & .13 & .08 \\
\hline Potassium, percent & -- & -- & 1.46 & 1.40 & .17 & .16 & .17 & .17 \\
\hline Scandium, mg/kg & 9.78 & 9.00 & 8.71 & 8.50 & 1.66 & 1.60 & 1.79 & 1.80 \\
\hline Zinc, mg/kg & 49.8 & 43.0 & 439 & 295 & 379 & 285 & 295 & 216 \\
\hline Zirconium, mg/kg & 723 & 535 & -- & -- & 2.79 & 2.80 & 2.25 & 2.00 \\
\hline
\end{tabular}


Table 4. Mean and median concentrations of trace metals in New England stream sediments.-Continued [mg/kg, milligrams per kilogram; NA, not available; <, actual value is less than value shown; --, no data]

\begin{tabular}{|c|c|c|c|c|c|c|c|c|}
\hline \multirow{3}{*}{ Trace metal } & \multicolumn{8}{|c|}{ Current (2003) investigations } \\
\hline & \multirow{2}{*}{$\begin{array}{c}\text { Hudson } \\
\text { Mean } \\
\end{array}$} & \multicolumn{3}{|c|}{ Gleasondale } & \multirow{2}{*}{$\begin{array}{c}\text { Ben Smith } \\
\text { Mean }\end{array}$} & \multicolumn{3}{|c|}{ Powdermill } \\
\hline & & Median & Mean & Median & & Median & Mean & Median \\
\hline Aluminum, percent & 1.28 & 1.27 & 1.03 & 1.00 & 1.25 & 1.32 & 1.28 & 1.21 \\
\hline Antimony, mg/kg & $<5$ & $<5$ & $<5$ & $<5$ & $<5$ & $<5$ & NA & $<5$ \\
\hline Arsenic, mg/kg & 17.0 & 9.00 & 17.0 & 11.0 & 22.0 & 13.0 & 22.5 & 14.0 \\
\hline Barium, mg/kg & 73.5 & 43.0 & 79.6 & 53.0 & 79.2 & 54.0 & 133 & 95.5 \\
\hline Beryllium, mg/kg & NA & .70 & NA & $<.5$ & NA & .70 & NA & .55 \\
\hline Bismuth, mg/kg & $<5$ & $<5$ & $<5$ & $<5$ & $<5$ & $<5$ & $<5$ & $<5$ \\
\hline Cadmium, mg/kg & NA & $<1$ & NA & $<1$ & NA & $<1$ & NA & $<1$ \\
\hline Calcium, percent & 1.99 & 2.15 & .31 & .29 & .27 & .27 & .43 & .29 \\
\hline Chromium, mg/kg & 155 & 155 & 205 & 194 & 177 & 170 & 588 & 322 \\
\hline Cobalt, mg/kg & 26.1 & 22.0 & 11.0 & 8.00 & 1.89 & 1.62 & 19.0 & 13.0 \\
\hline Copper, mg/kg & 44.0 & 14.0 & 61.0 & 11.0 & 49.0 & 13.0 & 291 & 89.2 \\
\hline Iron, percent & 1.97 & 1.66 & 1.54 & 1.40 & 49.3 & 13.4 & 1.96 & 1.94 \\
\hline Lanthanum, mg/kg & 22.0 & 15.3 & 13.1 & 12.2 & 19.6 & 15.0 & 15.6 & 12.9 \\
\hline Lead, mg/kg & 95.0 & 20.0 & 68.0 & 16.0 & 121 & 16.0 & 248 & 171 \\
\hline Magnesium, percent & .30 & .27 & .30 & .32 & .25 & .27 & .31 & .32 \\
\hline Manganese, mg/kg & 412.2 & 243 & 320 & 245 & 519 & 439 & 348 & 292 \\
\hline Molybdenum, mg/kg & NA & $<.2$ & 4.00 & 3.00 & 4.00 & 4.00 & 5.81 & 5.00 \\
\hline Nickel, mg/kg & 26.0 & 22.0 & 24.0 & 17.0 & 25.0 & 16.0 & 47.8 & 30.0 \\
\hline Phosphorus, percent & .12 & .08 & .11 & .06 & .11 & .07 & .15 & .11 \\
\hline Potassium, percent & .30 & .25 & .15 & .16 & .09 & .08 & .14 & .14 \\
\hline Scandium, mg/kg & 1.99 & 2.15 & 1.71 & 1.70 & 1.82 & 1.80 & 1.76 & 1.70 \\
\hline Silver, mg/kg & NA & $<.2$ & NA & $<.2$ & NA & .20 & NA & 1.20 \\
\hline Sodium, percent & .30 & .27 & .04 & .04 & .04 & .04 & .04 & .04 \\
\hline Strontium, mg/kg & 24.0 & 23.0 & 22.0 & 21.0 & 21.0 & 20.0 & 8.13 & 7.00 \\
\hline Tin, mg/kg & NA & $<1$ & NA & $<1$ & .03 & .02 & 67.6 & 50.5 \\
\hline Titanium, mg/kg & .04 & .04 & .03 & .03 & .03 & .02 & .04 & .04 \\
\hline Vanadium, mg/kg & 155 & 155 & .03 & .03 & 23.0 & 24.0 & 28.0 & 28.0 \\
\hline Zinc, $\mathrm{mg} / \mathrm{kg}$ & 132 & 63.0 & 134 & 37.0 & 144 & 37.0 & 319 & 163 \\
\hline Zirconium, mg/kg & NA & 1.60 & 2.13 & 2.30 & 1.41 & 1.30 & 2.59 & 2.15 \\
\hline
\end{tabular}

Table 5. Summary statistics of total bulk phosphorus concentrations in sediment samples from six impoundments in the Assabet River Basin, Massachusetts, 2003.

[All concentrations in percent. $<$, actual value is less than value shown]

\begin{tabular}{lcccccccc}
\hline \multicolumn{1}{c}{ Impoundment } & $\begin{array}{c}\text { Median, } \\
\text { all } \\
\text { samples }\end{array}$ & $\begin{array}{c}\text { Mean, } \\
\text { all } \\
\text { samples }\end{array}$ & $\begin{array}{c}\text { Maximum, } \\
\text { all } \\
\text { samples }\end{array}$ & $\begin{array}{c}\text { Minimum, } \\
\text { all } \\
\text { samples }\end{array}$ & $\begin{array}{c}\text { Median, } \\
\text { surface } \\
\text { samples }\end{array}$ & $\begin{array}{c}\text { Mean, } \\
\text { surface } \\
\text { samples }\end{array}$ & $\begin{array}{c}\text { Maximum, } \\
\text { surface } \\
\text { samples }\end{array}$ & $\begin{array}{c}\text { Minimum, } \\
\text { surface } \\
\text { samples }\end{array}$ \\
\hline Aluminum City & 0.17 & 0.18 & 0.28 & 0.12 & 0.17 & 0.17 & 0.23 \\
Allen Street & .08 & .13 & .31 & .05 & .21 & .17 & .21 & .05 \\
Hudson & .06 & .08 & .32 & .01 & .11 & .13 & .32 \\
Gleasondale & .06 & .10 & .71 & .02 & .07 & .17 & .71 \\
Ben Smith & .07 & .11 & .86 & $<.01$ & .12 & .17 & .04 & .02 \\
Powdermill & .07 & .15 & .54 & .03 & .15 & .19 & .02 \\
\hline
\end{tabular}


Whereas the medians and means of the surface samples exhibited no trends with reservoir position, the surface-sample phosphorus maxima and minima exhibited trends similar to those for all samples. Three of the maximum surface values were the same as the maximum values for all samples.

Within some of the individual impoundments, the distribution of sediment phosphorus concentrations varied considerably. At Aluminum City (fig. 9), the smallest impoundment, where only four sets of cores were collected, sample concentrations ranged from 0.12 (in the sample from the greatest depth at site $\mathrm{AC} 4$ ) to 0.28 percent (at site $\mathrm{AC} 2$ in the sample from the intermediate depth). At Allen Street (fig. 10), the phosphorus concentrations were lowest in the core collected farthest upstream (AS5). The farthest downstream core (AS8) yielded samples with the highest phosphorus concentrations ( 0.28 and 0.31 percent) measured in this impoundment. In the Hudson impoundment (fig. 11), the highest phosphorus concentrations, 0.16 to 0.32 percent, were found in upper sediment layers at the most downstream sites (H14 and H15). In the Gleasondale impoundment (fig. 12), phosphorus concentrations were generally low, but the surface samples from sites G19 and G22 had high concentrations, 0.67 and 0.71 percent, respectively. Of all the impoundments, the Gleasondale impoundment had the steepest bed-slope gradient, and the downstream sediment thicknesses were not great; it is possible that phosphorus-bearing sediments did not settle out in that section. At Ben Smith (fig. 13), most of the high phosphorus concentrations were found in cores from the upper reaches of the impoundment (BS29 to BS35), although a few comparable concentrations were found in cores BS38 and BS43 from the downstream half of the impoundment. Finally, in the Powdermill impoundment (fig. 14), the highest concentrations of phosphorus were detected in cores P50 through P54 and P56, which were collected between the middle and the downstream end of the impoundment. This area coincides with the outfall from the Maynard wastewater-treatment plant.

The maps provide data useful for deciding the extent of sediment to dredge, both by surface area and by depth, if that option is considered; however, no target bulk-sediment phosphorus concentration that would eliminate or minimize nuisance plant growth has been established. The data indicate that if surficial sediments were removed, the sediments at greater depths would still contain phosphorus.

\section{Toxic Trace Elements}

The occurrence, distribution, and potential toxic effects of seven metals-arsenic (As), cadmium (Cd), chromium (Cr), copper $(\mathrm{Cu})$, nickel $(\mathrm{Ni})$, lead $(\mathrm{Pb})$, and zinc $(\mathrm{Zn})$, metals that may come from natural weathering, from industrial areas, agricultural applications, or automobile traffic (Robinson and others, 2004) — were assessed in the surficial sediment samples of the six Assabet impoundments (table 14; figs. 9 to 14). Even at low ambient concentrations, these metals can prove harmful to aquatic organisms, because they concentrate through bioaccumulation. Mercury, another commonly cited toxic metal, is not considered here because the required sample storage and analysis methods for mercury were beyond the scope of this investigation.

Results of recent studies generally bracket the concentrations reported in this study (table 4). Robinson and others (2004) studied sediment samples from New England rivers whose watersheds represented a broad range of land uses, including relatively undisturbed areas. Their results generally described streams in which the concentrations of all four (As, $\mathrm{Cu}, \mathrm{Pb}$, and $\mathrm{Zn}$ ) of the seven toxic metals reported had lower concentrations than were detected in the Assabet sediments; exceptions were the high concentrations of strontium and zirconium that they reported. In contrast, the mean and median concentrations of the seven toxic metals calculated from Chalmers's (2002) data, with the exception of chromium, were higher than those determined in the Assabet sediment samples; her study focused on streams whose chemistry was strongly affected by urban land use, a likely source of metal contamination. In both of these studies, surficial-sediment samples were sieved and were not necessarily digested with aqua regia, procedures that could have affected the concentrations measured.

Among the Assabet impoundments, highest average concentrations for the seven metals were found in either the Aluminum City impoundment $(\mathrm{Cd}, \mathrm{Cu}$, and $\mathrm{Zn})$ or the Powdermill impoundment (As, $\mathrm{Cr}, \mathrm{Ni}$, and $\mathrm{Pb}$ ); however, sediment samples from many sites in all of the six impoundments had high metal concentrations (table 14). At Aluminum City, extremely high concentrations of $\mathrm{Cr}(2,070 \mathrm{mg} / \mathrm{kg})$ and $\mathrm{Zn}$ $(1,220 \mathrm{mg} / \mathrm{kg})$ were found in samples from AC4; samples from $\mathrm{AC} 3$ and AC2 also had high metal concentrations. The highest metal concentrations in samples from Allen Street were detected at AS6, AS7, and AS8; in particular, samples from AS8 had high concentrations of $\mathrm{Cu}(807 \mathrm{mg} / \mathrm{kg})$ and $\mathrm{Zn}(551$ $\mathrm{mg} / \mathrm{kg}$ ) and samples from AS7 and AS6 had high concentrations of $\mathrm{Zn}$ (827 and $487 \mathrm{mg} / \mathrm{kg}$, respectively). In the Hudson impoundment, high concentrations of $\mathrm{Zn}, \mathrm{Pb}, \mathrm{Cr}$, and $\mathrm{Cu}$ were detected in samples from H10, H11, H13 and H15; Zn, of these four metals, was generally found in highest concentrations in samples collected from these sites. In Gleasondale, samples from sites G18, G19, and G22 all were characterized by high metal concentrations. Sites with high concentrations of metals were scattered throughout the elongated Ben Smith impoundment (in particular, BS30 to BS35, BS38, and BS43), but these sites were most densely distributed in the wide upstream section of the impoundment (fig. 13). About half the sites within the Powdermill impoundment yielded samples of sediment with high metal concentrations: P46, P48, P51 to P54, and P56. Powdermill yielded 15 detections of metal concentrations higher than $1,000 \mathrm{mg} / \mathrm{kg}$.

Concentrations of metals in many of the sediment samples from the six impoundments exceeded sediment-quality guidelines (table 2; figures 9 to 14 describe which sediment concentrations exceeded the TEL and PEL for surface samples only. See tables 3 and 15 to determine exceedances for all sediment samples.) 
Arsenic concentrations in samples from all of the impoundments were generally higher than the TEL of $5.9 \mathrm{mg} / \mathrm{kg}$. At Aluminum City and Allen Street, the PEL was not exceeded; in the Hudson impoundment, the PEL of $17 \mathrm{mg} / \mathrm{kg}$ was exceeded at four of seven sites; the humancontact guideline of $30 \mathrm{mg} / \mathrm{kg}$ was exceeded at $\mathrm{H} 11$ and $\mathrm{H} 15$ and the landfill-reuse guideline of $40 \mathrm{mg} / \mathrm{kg}$ was exceeded at H15. At Gleasondale, the PEC guideline for As was exceeded at G18-G20 and G22, and the human-contact guideline at G18-G20. At Ben Smith, the PEL or PEC was equaled or exceeded at all but two sites in at least one sample. In the Powdermill impoundment, sites noted previously as having sediment samples with multiple, high-concentration detections (P48, P50 to P54, and P56) also had As concentrations exceeding either or both of the human-contact and the landfill-reuse guidelines.

Most of the Cd analyses returned values below the reporting level of $1 \mathrm{mg} / \mathrm{kg}$, leaving uncertainty about the frequency with which the TEL of $0.6 \mathrm{mg} / \mathrm{kg}$ was exceeded. The PEL of $3.53 \mathrm{mg} / \mathrm{kg}$ or the PEC of $4.98 \mathrm{mg} / \mathrm{kg}$ was exceeded in 1 sediment sample at Aluminum City, 2 at Allen Street, none at Hudson, 2 at Gleasondale, 7 at Ben Smith, and 11 at Powdermill. Human-contact and landfill-disposal guidelines for $\mathrm{Cd}$ were not exceeded at any of the impoundments.

Only a single sediment sample had a $\mathrm{Cr}$ concentration lower than the TEL of $37.3 \mathrm{mg} / \mathrm{kg}$. Most $\mathrm{Cr}$ concentrations were higher than the PEC of $111 \mathrm{mg} / \mathrm{kg}$. Eight samples from sites in the Powdermill impoundment (P48, P51-P54, and P56) had $\mathrm{Cr}$ concentrations higher than the $1,000 \mathrm{mg} / \mathrm{kg}$ maximum concentration allowable for human contact and landfill disposal.

All but two samples from the Aluminum City impoundment had $\mathrm{Cu}$ concentrations higher than the PEL of $197 \mathrm{mg} / \mathrm{kg}$. Half of the samples from Allen Street had concentrations of $\mathrm{Cu}$ less than the PEC of $149 \mathrm{mg} / \mathrm{kg}$ and higher than the TEL of $35.7 \mathrm{mg} / \mathrm{kg}$. At Hudson, 13 of 23 samples had $\mathrm{Cu}$ concentrations lower than the TEL and none exceeded the PEC. At Gleasondale also, 23 of 37 samples had concentrations less than the TEL; in samples from sites G19 and G22, the PEL was exceeded. In the Ben Smith impoundment, the PEC was exceeded in samples from five sites (BS30, BS31, BS32, BS34, and BS43) and the PEL was exceeded in two samples (BS30 and BS32). At Powdermill, the PEL was exceeded at the same seven sites (P46, P48, P51, P52, P53, P54, and P56).

In sediment samples from all the impoundments, sediment concentrations of Ni frequently exceeded the 18 $\mathrm{mg} / \mathrm{kg}$ TEL. At Aluminum City and Allen Street, the PEL (35.9 mg/kg) was not exceeded. At Hudson, samples from sites $\mathrm{H} 10, \mathrm{H} 13$, and $\mathrm{H} 15$ had concentrations higher than the PEC $(48.6 \mathrm{mg} / \mathrm{kg})$. In the Gleasondale impoundment, the PEC was exceeded at G19 and G22; at Ben Smith and Powdermill, samples from sites BS30, B32, B34, B35, B38, B43, P46, P48, and P50 to P56 had samples with concentrations higher than either the PEL or PEC.
All the sediment samples collected at Aluminum City and Allen Street had $\mathrm{Pb}$ concentrations that exceeded the TEL $(35 \mathrm{mg} / \mathrm{kg})$, and more than half had concentrations that also exceeded the PEC (128 mg/kg). More than half of the samples from Hudson, Gleasondale, and Ben Smith had $\mathrm{Pb}$ concentrations lower than the TEL. Most of the other sample Pb concentrations, however, were higher than the PEC; one sample from $\mathrm{H} 10$ had a $\mathrm{Pb}$ concentration of $324 \mathrm{mg} / \mathrm{kg}$, which exceeded the human-contact guideline of $300 \mathrm{mg} / \mathrm{kg}$, and a sample from $\mathrm{BS} 38$ had a $\mathrm{Pb}$ concentration of $3,800 \mathrm{mg} / \mathrm{kg}$ - higher than the maximum for landfill reuse $(2,000 \mathrm{mg} / \mathrm{kg})$. At Powdermill, 12 of the sites had samples with $\mathrm{Pb}$ concentrations that exceeded the PEC, and 12 samples had concentrations (at P50 to P54 and P56) higher than the human-contact guideline; none exceeded the landfill-disposal guideline.

The sediment-quality guidelines for $\mathrm{Zn}$ are higher than the other metals. Nevertheless, all the samples from Aluminum City had Zn concentrations in excess of the $123 \mathrm{mg} / \mathrm{kg}$ TEL; four samples had concentrations that exceeded the PEL (315 mg/kg) or PEC (459 mg/kg). Concentrations in 12 of the 16 samples collected at Allen Street also exceeded the TEL and 5 also exceeded the PEC. At Hudson, most of the samples had $\mathrm{Zn}$ concentrations lower than the TEL; none exceeded the PEC, but samples from H13 and H15 had Zn concentrations higher than the PEL. At Gleasondale, concentrations in samples from only sites G18, G19, and G22 exceeded the sediment-quality guidelines. In the Ben Smith impoundment, most of the samples whose concentrations exceeded the $\mathrm{Zn}$ guidelines were taken from the upstream area, the $\mathrm{Zn}$ PEC was exceeded by concentrations in at least one sample from BS30 to BS32, BS34, and BS38. At Powdermill, Zn concentrations in more than half (21) of the samples exceeded the TEL; 8 of those samples also had $\mathrm{Zn}$ concentrations greater than the PEC; 4 were in excess of $1,000 \mathrm{mg} / \mathrm{kg}$.

\section{Reactive Sulfide}

Only one sample had a reactive sulfide concentration $(1,570 \mathrm{mg} / \mathrm{kg})$ that exceeded the minimum reporting level of $5 \mathrm{mg} / \mathrm{kg}$. The sample came from a completely homogenized, 62-cm core from the Gleasondale impoundment, site G22 (fig. 12). Sediment from this site also exhibited higher concentrations of toxic metals than sediment from the other sites at Gleasondale (table 3).

\section{Organic Analyses}

Because only a subset of the cores selected for organicchemistry analyses were sectioned, it is not possible to make broad generalizations about concentration trends with depth. Changes with depth are discussed for individual cores and more general interpretations are based on means or medians of all samples collected within an impoundment. 


\section{Volatile Organic Compounds and Organochlorine Pesticides}

Matrix interference in all VOC and organochlorinepesticide samples required sample dilution by factors as great as 100. Such dilutions caused reporting levels to increase by the same factors. As a probable result of these effects, the analytical laboratories reported no detections for either category of compound. The lack of detections, however, should not be interpreted to mean that the compounds were absent in the tested samples because the compounds were detected in New England by Harris (1997) and Chalmers (2002). A regional study of organochlorine pesticides in New England conducted from 1992 to 1994 by Harris (1997) reported the detection of dichlorodiphenyltrichloroethane, chlordane, and some of their metabolites, as well as nonachlor and dieldrin. A more recent study (Chalmers, 2002) reported detections of the same compounds in sediments in a different set of New England streams.

\section{Polycyclic Aromatic Hydrocarbons}

PAHs are one of the most frequently detected types of compounds in sediments. As particles from incomplete hydrocarbon combustion and in runoff from roads and parking lots, PAHs eventually enter water bodies, adsorb to other particles, and sink to the bottom. These compounds exhibit carcinogenic and mutagenic properties (Somers and others, 2004), and hence may affect human health and aquatic life.

Among the six impoundments, the highest mean and median total PAH concentrations, $89,500 \mu \mathrm{g} / \mathrm{kg}$ and $16,500 \mu \mathrm{g} / \mathrm{kg}$, respectively, were found in sediment samples from the Powdermill impoundment. Samples from Ben Smith had the lowest median total PAH concentration $(615 \mu \mathrm{g} / \mathrm{kg})$, and Aluminum City had the lowest mean total PAH concentration $(2,850 \mu \mathrm{g} / \mathrm{kg})$; Ben Smith also had a relatively low mean total PAH concentration $(4,520 \mu \mathrm{g} / \mathrm{kg})$. In samples from Allen Street, Hudson, and Gleasondale, the mean PAH concentrations were similar, whereas the medians differed considerably in samples from these three impoundments (table 6).

No general total PAH vertical-distribution patterns appear obvious among the sectioned samples (table 16, at back of report). Many seem to decrease with increasing depth (for example, AC4, H13, G18, BS30, BS32, BS38, BS43, P54), while others increase (BS31, P48), and some exhibit no clear trend with depth (AS7, G19, P56). These data demonstrate, at minimum, the variability in the distribution of $\mathrm{PAH}$ compounds deposited over time.

Concentrations of total PAHs in many (9 of 20) of the samples from the Powdermill impoundment exceed the PEC sediment-quality guideline of 22,800 $\mu \mathrm{g} / \mathrm{kg}$ (Ingersoll and others, 2000; table 16). Few samples from the other impoundments exceed this value: Aluminum City (0), Allen Street (1), Hudson (3), Gleasondale (4), and Ben Smith (2) (fig. 15).
Table 6. Median and mean values for total polycyclic aromatic hydrocarbon concentrations detected in sediment samples from six impoundments in the Assabet River Basin, Massachusetts, 2003.

[All values are in micrograms per kilogram]

\begin{tabular}{lrr}
\hline \multicolumn{1}{c}{ Impoundment } & Median & Mean \\
\hline Aluminum City & 2,950 & 2,850 \\
Allen Street & 12,100 & 19,000 \\
Hudson & 1,140 & 18,900 \\
Gleasondale & 3,000 & 16,700 \\
Ben Smith & 615 & 4,520 \\
Powdermill & 16,500 & 89,500 \\
\hline
\end{tabular}

A sample from the Powdermill impoundment had the highest total PAH concentration (site P50, 1,100,000 $\mu \mathrm{g} / \mathrm{kg}$ ); this impoundment had a sample from one additional site (P52) with a total PAH concentration that exceeded the Massachusetts standard of $100,000 \mu \mathrm{g} / \mathrm{kg}$ for sediment reuse at lined landfills. Other impoundment sites exhibiting high total PAH concentrations include AS5 and AS7 (Allen Street), H10 and H13 (Hudson), G18 and G19 (Gleasondale), BS30 and BS31 (Ben Smith), and P46, P47, P48, P53, and P56 (Powdermill).

Many samples had concentrations of individual PAH compounds that exceeded PEL and PEC sediment-quality guidelines (tables 3 and 16). The Powdermill impoundment yielded the largest percentage of samples that exceeded the guidelines; Aluminum City and Ben Smith yielded the smallest percentage of samples.

\section{Polychlorinated Biphenyls}

Total PCB concentrations and individual Aroclor concentrations differed substantially within and among the impoundments (table 7; fig. 16). No PCBs were detected in any of the Hudson-impoundment samples. Only Aroclors 1248, 1254, and 1260 were detected in samples from Aluminum City, Allen Street, and Ben Smith impoundments; only Aroclors 1254, 1260, and 1262 were detected in Ben Smith; and only Aroclors 1254, 1260, and 1268 were found in samples from Powdermill.

Only one sample, from Gleasondale impoundment site $\mathrm{G} 18$, had a total PCB concentration $(3,100 \mu \mathrm{g} / \mathrm{kg})$ that exceeded the maximum allowable for sediment reuse in lined landfills and for human contact $(2,000 \mu \mathrm{g} / \mathrm{kg})$; however, all samples except for two (AC4 and BS28) with detectable PCB concentrations exceeded the TEL sediment-quality guideline of $34.1 \mu \mathrm{g} / \mathrm{kg}$; about half of the sites (14 of 30) also had total PCB concentrations greater than the PEL of $277 \mu \mathrm{g} / \mathrm{kg}$; eight of the sites (G18, G19, BS30, BS33, BS34, BS43, P48, and $\mathrm{P} 56)$ also had total $\mathrm{PCB}$ concentrations that were higher than the PEC of $676 \mu \mathrm{g} / \mathrm{kg}$. In addition, most of the samples in which Aroclors 1248, 1254, and 1262 were detected exceeded the PEC values for these individual PCB Aroclors (table 2). 


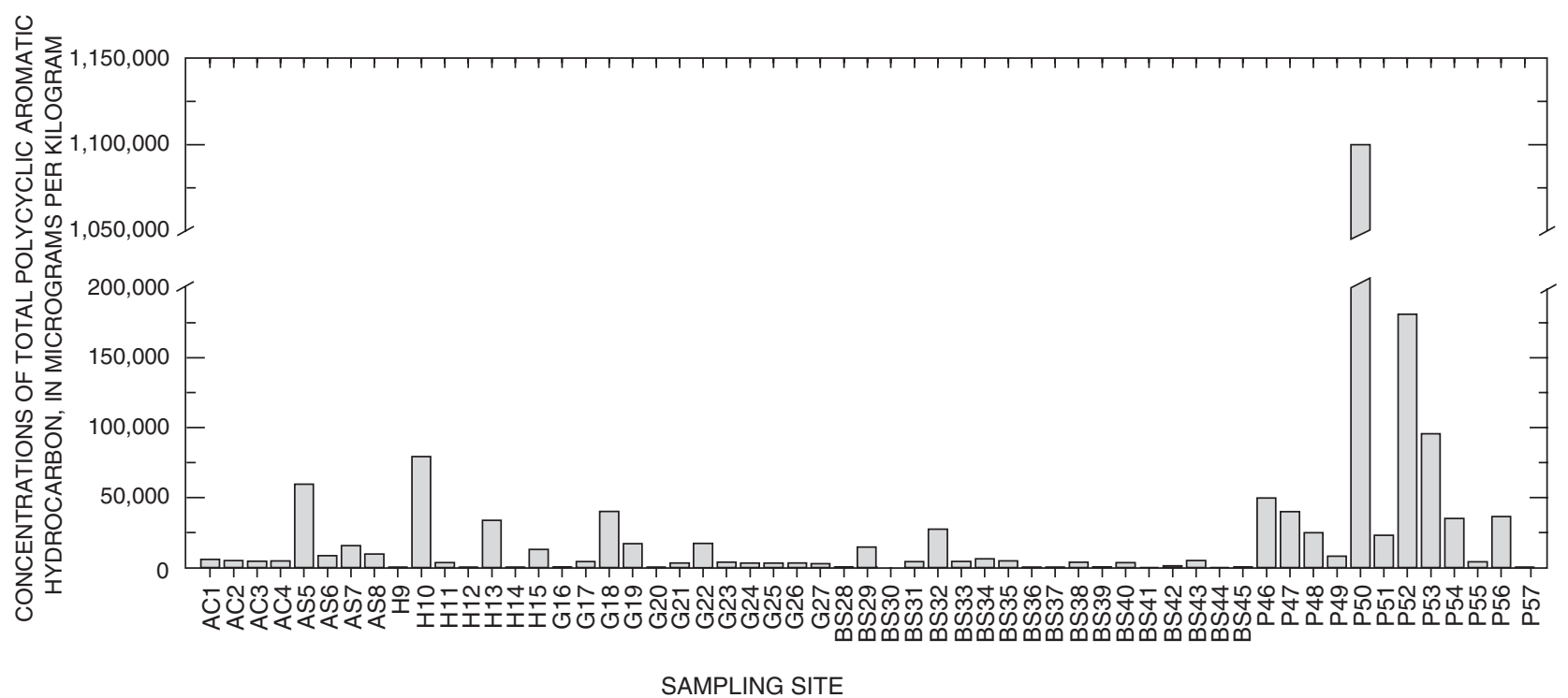

Figure 15. Total polycyclic aromatic hydrocarbon concentrations in core samples from six impoundments in the Assabet River, central Massachusetts, 2003.

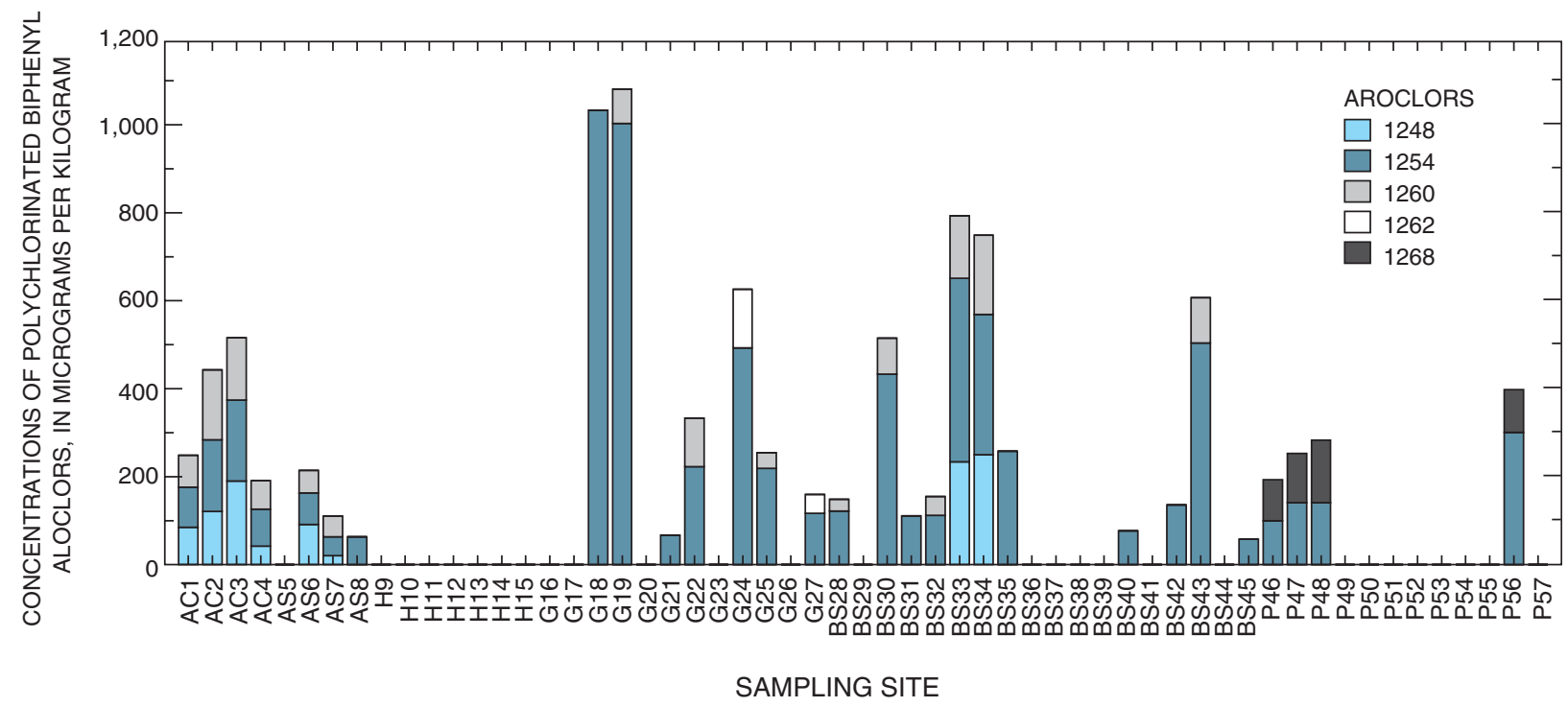

Figure 16. Concentrations of selected polychlorinated biphenyl Aroclors detected in core samples from six impoundments in the Assabet River, central Massachusetts, 2003. 
Table 7. Concentrations of polychlorinated biphenyl Aroclors in sediment samples from six impoundments in the Assabet River Basin, Massachusetts, 2003.

[All values are in micrograms per kilogram. Minimum reporting level is 0.17 micrograms per kilogram. Map ID: The identifier associated with a sampling site on a map (figs. 9-14). Sample ID: Identifier for a sample collected from a particular core, arranged alphabetically from the top of the core, with Q designating a replicate sample. Total PCB: Sum of detectable concentrations of Aroclors rounded to three significant figures. Shaded numbers exceed sediment-quality guidelines. PCB, polychlorinated biphenyl, --, not detected]

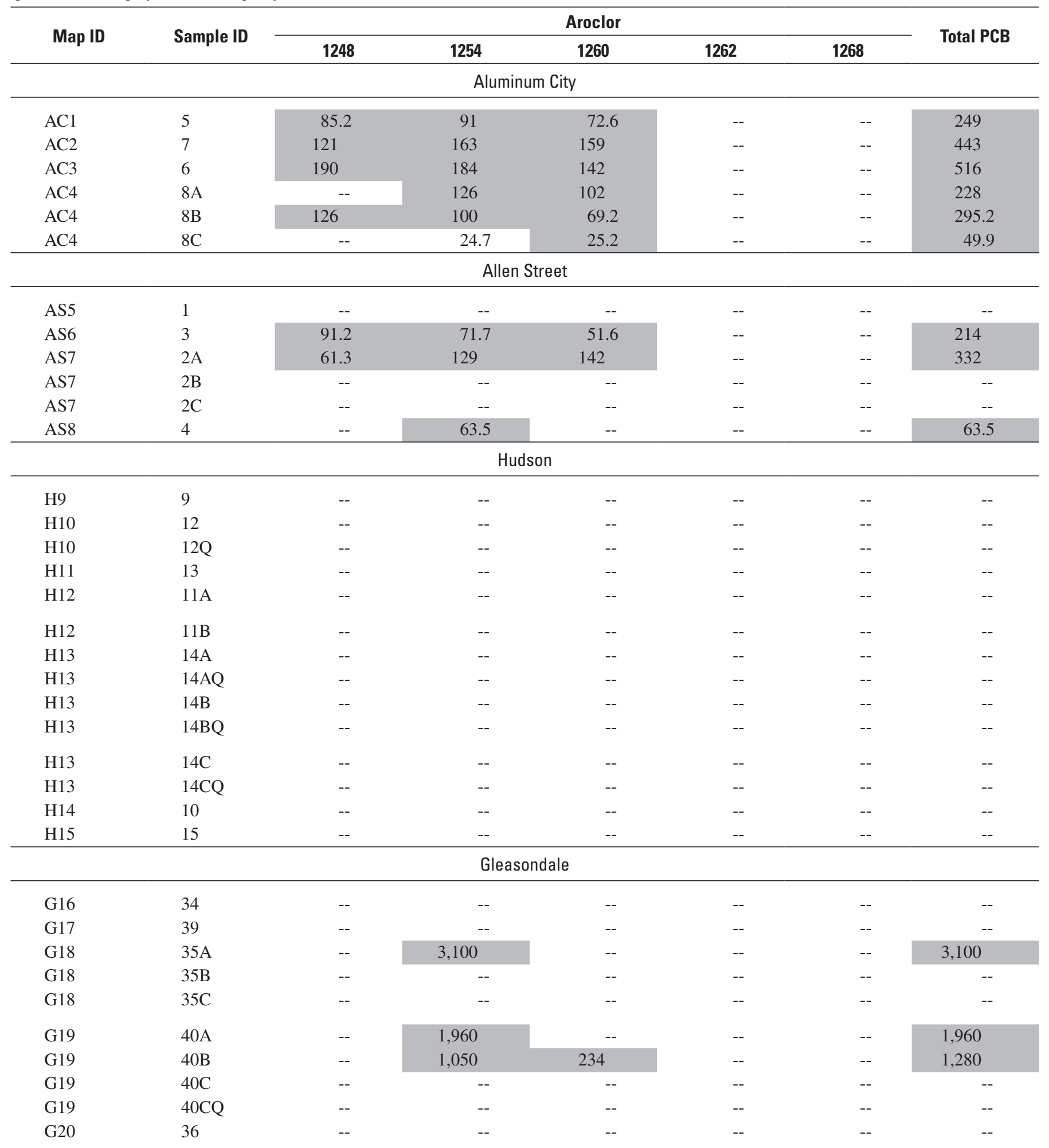


Table 7. Concentrations of polychlorinated biphenyl Aroclors in sediment samples from six impoundments in the Assabet River Basin, Massachusetts, 2003.-Continued

[All values are in micrograms per kilogram. Minimum reporting level is 0.17 micrograms per kilogram. Map ID: The identifier associated with a sampling site on a map (figs. 9-14). Sample ID: Identifier for a sample collected from a particular core, arranged alphabetically from the top of the core, with Q designating a replicate sample. Total PCB: Sum of detectable concentrations of Aroclors rounded to three significant figures. Shaded numbers exceed sediment-quality guidelines. PCB, polychlorinated biphenyl, --, not detected]

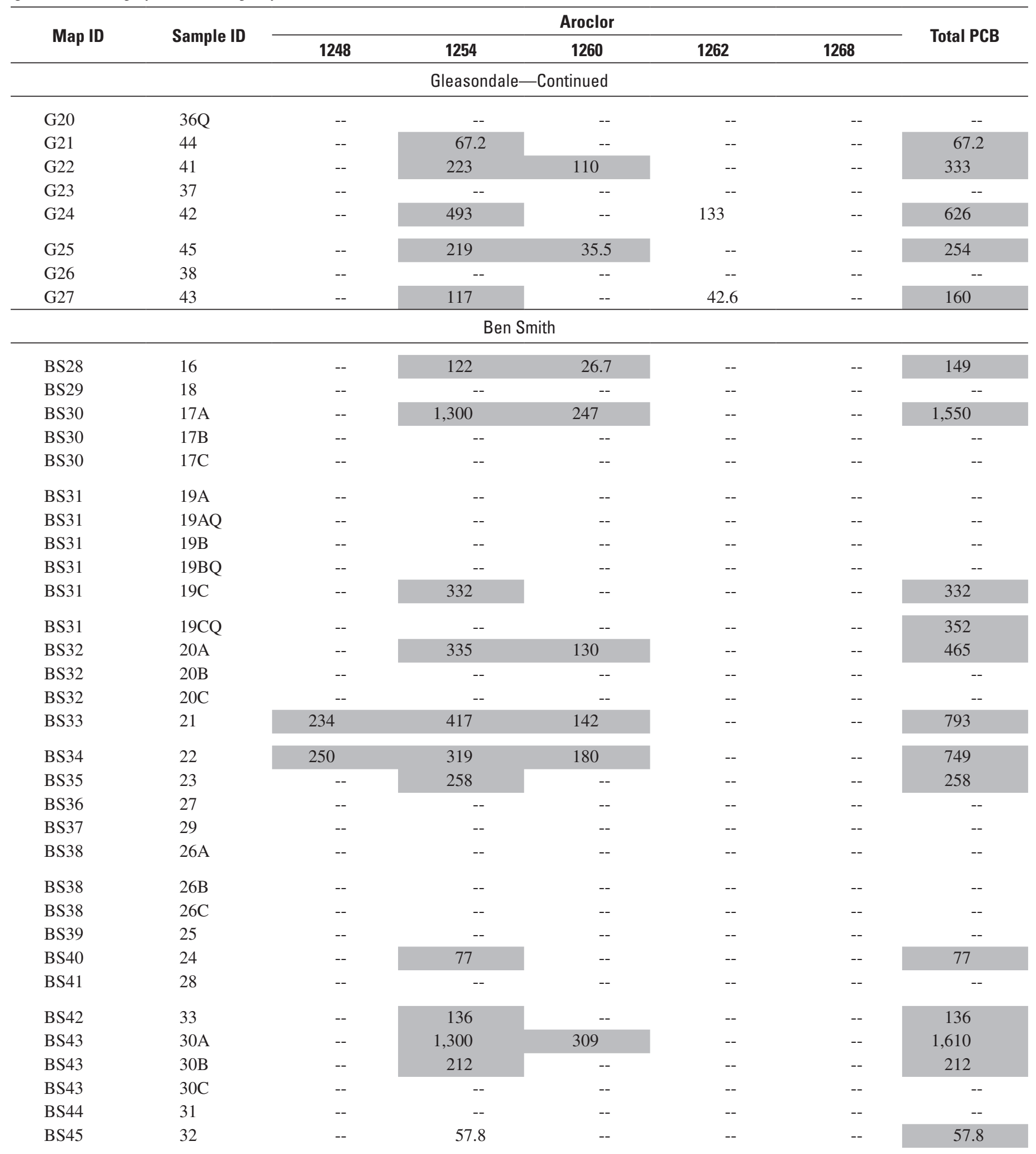


Table 7. Concentrations of polychlorinated biphenyl Aroclors in sediment samples from six impoundments in the Assabet River Basin, Massachusetts, 2003.-Continued

[All values are in micrograms per kilogram. Minimum reporting level is 0.17 micrograms per kilogram. Map ID: The identifier associated with a sampling site on a map (figs. 9-14). Sample ID: Identifier for a sample collected from a particular core, arranged alphabetically from the top of the core, with Q designating a replicate sample. Total PCB: Sum of detectable concentrations of Aroclors rounded to three significant figures. Shaded numbers exceed sediment-quality guidelines. PCB, polychlorinated biphenyl, --, not detected]

\begin{tabular}{|c|c|c|c|c|c|c|c|}
\hline \multirow{2}{*}{ Map ID } & \multirow{2}{*}{ Sample ID } & \multicolumn{5}{|c|}{ Aroclor } & \multirow{2}{*}{ Total PCB } \\
\hline & & 1248 & 1254 & 1260 & 1262 & 1268 & \\
\hline \multicolumn{8}{|c|}{ Powdermill } \\
\hline P46 & 48 & -- & 91.7 & -- & -- & 116 & 208 \\
\hline P46 & $48 \mathrm{Q}$ & -- & 108 & -- & -- & 69.3 & 177 \\
\hline P47 & 49 & -- & 141 & -- & -- & 112 & 253 \\
\hline P48 & $46 \mathrm{~A}$ & -- & -- & -- & -- & -- & -- \\
\hline P48 & $46 \mathrm{~B}$ & -- & -- & -- & -- & -- & -- \\
\hline P48 & $46 \mathrm{C}$ & -- & 422 & -- & -- & 424 & 846 \\
\hline P49 & 47 & -- & -- & -- & -- & -- & -- \\
\hline P50 & 52 & -- & -- & -- & -- & -- & -- \\
\hline P51 & 55 & -- & -- & -- & -- & -- & -- \\
\hline P52 & 53 & -- & -- & -- & -- & -- & -- \\
\hline P53 & 56 & -- & -- & -- & -- & -- & -- \\
\hline P54 & $54 \mathrm{~A}$ & -- & -- & -- & -- & -- & -- \\
\hline P54 & $54 \mathrm{~B}$ & -- & -- & -- & -- & -- & -- \\
\hline P54 & $54 \mathrm{C}$ & -- & -- & -- & -- & -- & -- \\
\hline P55 & $51 \mathrm{~A}$ & -- & -- & -- & -- & -- & -- \\
\hline P55 & $51 \mathrm{~B}$ & -- & -- & -- & -- & -- & -- \\
\hline P55 & $51 \mathrm{C}$ & -- & -- & -- & -- & -- & -- \\
\hline P56 & $50 \mathrm{~A}$ & -- & 631 & -- & -- & 177 & 808 \\
\hline P56 & $50 \mathrm{AQ}$ & -- & 726 & 381 & -- & 178 & 1,280 \\
\hline P56 & $50 \mathrm{~B}$ & -- & 273 & -- & -- & 113 & 386 \\
\hline P56 & $50 \mathrm{C}$ & -- & -- & -- & -- & -- & -- \\
\hline P57 & 57 & -- & -- & -- & -- & -- & -- \\
\hline
\end{tabular}




\section{Extractable Petroleum Hydrocarbons}

$\mathrm{EPH}$ analysis, the measure of the sum of the concentrations of extractable aliphatic $\left(\mathrm{C}_{9}\right.$ to $\mathrm{C}_{18}$ and $\mathrm{C}_{19}$ to $\left.\mathrm{C}_{36}\right)$ and aromatic $\left(\mathrm{C}_{11}\right.$ to $\left.\mathrm{C}_{22}\right)$ petroleum hydrocarbons, provides data used to evaluate the effect of exposure of these compounds on human health. The sum of the concentrations of these compounds for a particular sample, plus the sum of the 17 PAHs also determined by this method, yields the traditional total petroleum hydrocarbon (TPH) value (Massachusetts Department of Environmental Protection, 2004).

The sources of petroleum hydrocarbons are atmospheric, and include incomplete combustion as well as direct releases of petroleum hydrocarbons. The EPH-method analyses are reported at levels greater than those required for cleanup in drinking-water-resources areas. Because this report previously considered the results of more sensitive analyses for individual PAHs, and because the Massachusetts EPH toxicological approach focuses on human health concerns, this section does not refer to specific PAHs determined by the EPH method.

The Powdermill impoundment had the highest median and mean total EPH concentrations along with the highest concentrations measured in individual samples in this study (table 8). The highest measured total EPH concentration ( $438 \mathrm{mg} / \mathrm{kg}$ from the surface sample at site P54) was at least an order of magnitude less than the maximum allowable concentration for landfill reuse of approximately $5,000 \mathrm{mg} / \mathrm{kg}$ (the TPH maximum of $5,000 \mathrm{mg} / \mathrm{kg}$ implicitly includes the PAH maximum of $100 \mathrm{mg} / \mathrm{kg}$ ).

Few samples had individual PAH concentrations that were high enough to be detected by the EPH method (concentration data not included in this report). In the Powdermill impoundment, samples with concentrations high enough to allow detection of individual PAHs by means of the EPH method were taken from sites P46 to P54; the three remaining downstream sites (P55 to P57) were close to the dam and a diversion outlet through which hydraulic conditions may have carried particles with high PAH concentrations out of the impoundment. Two sites at Hudson (H10 and H13) and one at Ben Smith (BS30) also had a few PAHs that were detectable by the EPH method.

\section{Potential for Adverse Biological Effects}

Sediment-quality guidelines (Ingersoll and others, 2001; McDonald and others, 2000) were used to evaluate the potential for bottom sediments from the six impoundments to have toxic effects on aquatic biota. The chemical compositions of the Assabet River impoundment sediment samples were compared with the chemistry of sediments known to have toxic effects from a database of 1,657 previous North American sediment-toxicity studies; the guidelines were derived from this database (Ingersoll and others, 2001). Because none of the samples in this database were from New England, regional variability was not considered in interpreting results. The likelihood that any one sample will have a toxic effect, the "incidence of toxicity," refers to the percentage of sediment samples having any negative effect on the growth or survivability of test organisms.

The sediment-quality database incorporates measures by test assays of the growth and survivability of two benthic organisms: the amphipod, Hyalella azteca (HA10 and HA28, 10 and 28-day tests, respectively) and an aquatic insect larva, Chironomous spp. (CS10 day test). The longer HA28 test is generally more sensitive and provides a higher incidence of toxicity values than the short-term test (Ingersoll and others, 2001).

The USEPA determined PECs for 28 freshwater-sediment contaminants of concern in the major chemical groups of trace metals, PAHs, PCBs, and pesticides (MacDonald and others, 2000; Ingersoll and others, 2001); these contaminants are considered to be reliable predictors of sediment toxicity. PEC values are used to estimate sediment toxicity where adverse conditions for biota are expected. In the development of the sediment-quality guidelines, toxicity predictions were considered reliable if the toxicity was correctly predicted for more than $75 \%$ of the sediment samples.

Data from sediment samples were processed as described by MacDonald and others (2000) and Ingersoll and others (2001). Censored data from a particular site were given values equal to one half of the RL. If all data from a site were censored, then concentrations equal to the RL were assigned. After these data filters were applied, individual concentrations of trace elements, PAHs, and PCBs at a particular site were added within their respective groups to yield total values. If the total of nondetected values (that is, the sum of the assigned RLs) at a site was greater than that chemical group's PEC value, then that total was excluded from the calculations. Total values not excluded were divided by their respective PEC values to obtain a PEC quotient.

The PEC quotients of the chemical groups for each site were then summed and averaged and referred to as mean MPP values for that site (MPP refers to Metals, PAHs, and PCBs). In this study, mean MPPs were determined by two methods: (1) an equal-weight mean of the three chemical groups, referred to as $M P P($ and $)$, and (2) $M P P($ or $)$, a mean calculated only for metals and PAHs (shown in boldface type in table 9). Because of analytical interferences reported by the laboratory, pesticide values were all less than RLs and were omitted entirely from the toxicity estimations. The mean MPP values were compared to five PEC-quotient ranges developed by Ingersoll and others (2001) to establish a relation between the ranges and the incidences of sediment toxicity determined by the organism tests; the PEC-quotient ranges are: $<0.1,0.1$ to $<0.5,0.5$ to $<1.0,1.0$ to $<5.0$, and $>5.0$. For example, a mean MPP range of 0.5 to 1.0 is associated with a 50-percent incidence of toxicity in the HA28 test (Zimmerman and Breault, 2003). 
Table 8. Concentrations of extractable petroleum hydrocarbons in sediment samples from six impoundments in the the Assabet River Basin, Massachusetts, 2003.

[All concentrations are shown in milligrams per kilogram. Minimum reporting level is 10 milligrams per kilogram. Total EPH and means and medians for each impoundment were calculated using 10 as an estimate for all $<10$ values where other values were 10 or greater. Map ID: The identifier associated with a sampling site on a map (figs. 9-14). Sample ID: Identifier of a sample collected from a particular core, arranged alphabetically from the top of the core. EPH, extractable petroleum hydrocarbon; <, actual value is less than value shown]

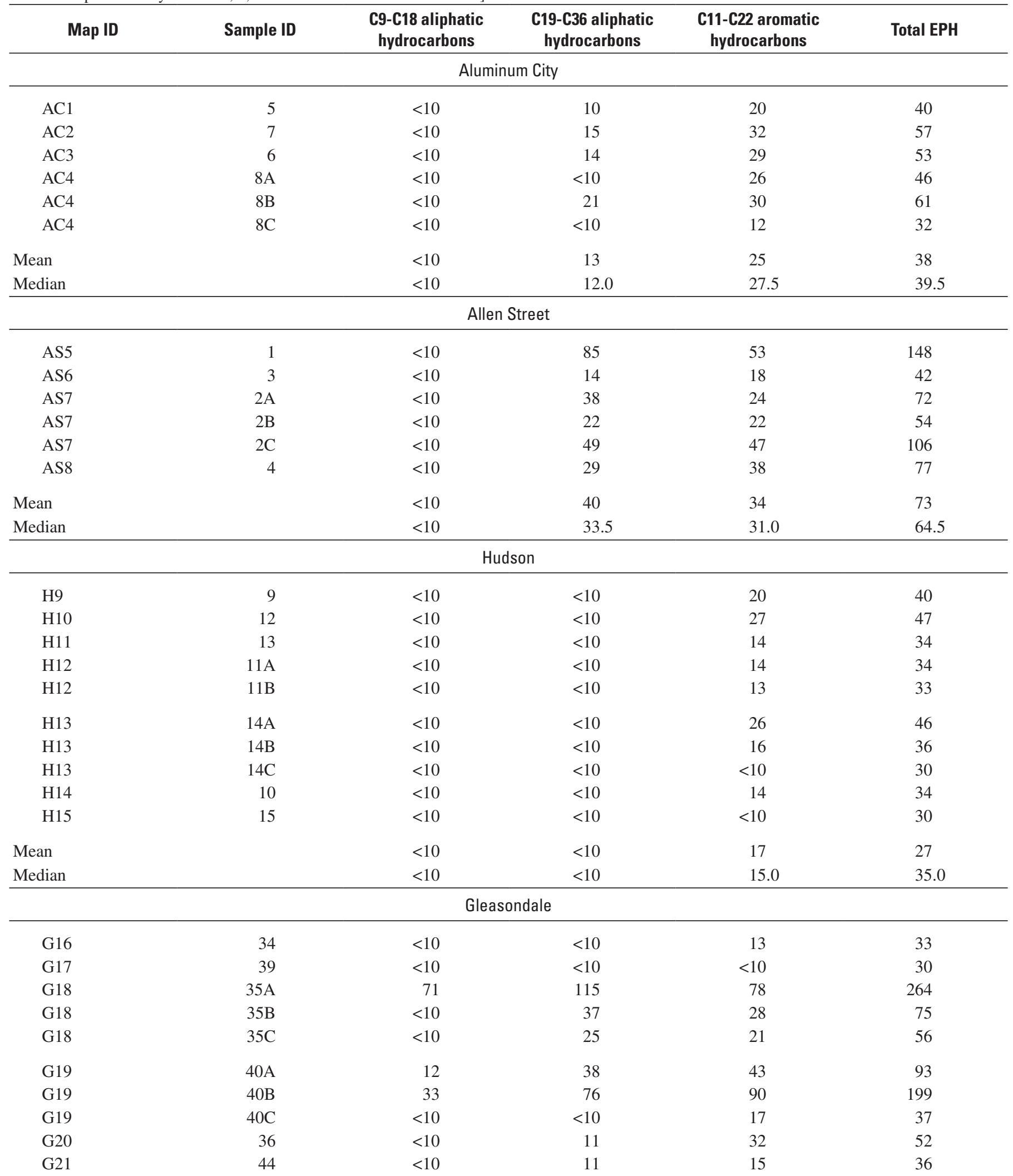


Table 8. Concentrations of extractable petroleum hydrocarbons in sediment samples from six impoundments in the the Assabet River Basin, Massachusetts, 2003.-Continued

[All concentrations are shown in milligrams per kilogram. Minimum reporting level is 10 milligrams per kilogram. Total EPH and means and medians for each impoundment were calculated using 10 as an estimate for all $<10$ values where other values were 10 or greater. Map ID: The identifier associated with a sampling site on a map (figs. 9-14). Sample ID: Identifier of a sample collected from a particular core, arranged alphabetically from the top of the core. EPH, extractable petroleum hydrocarbon; <, actual value is less than value shown]

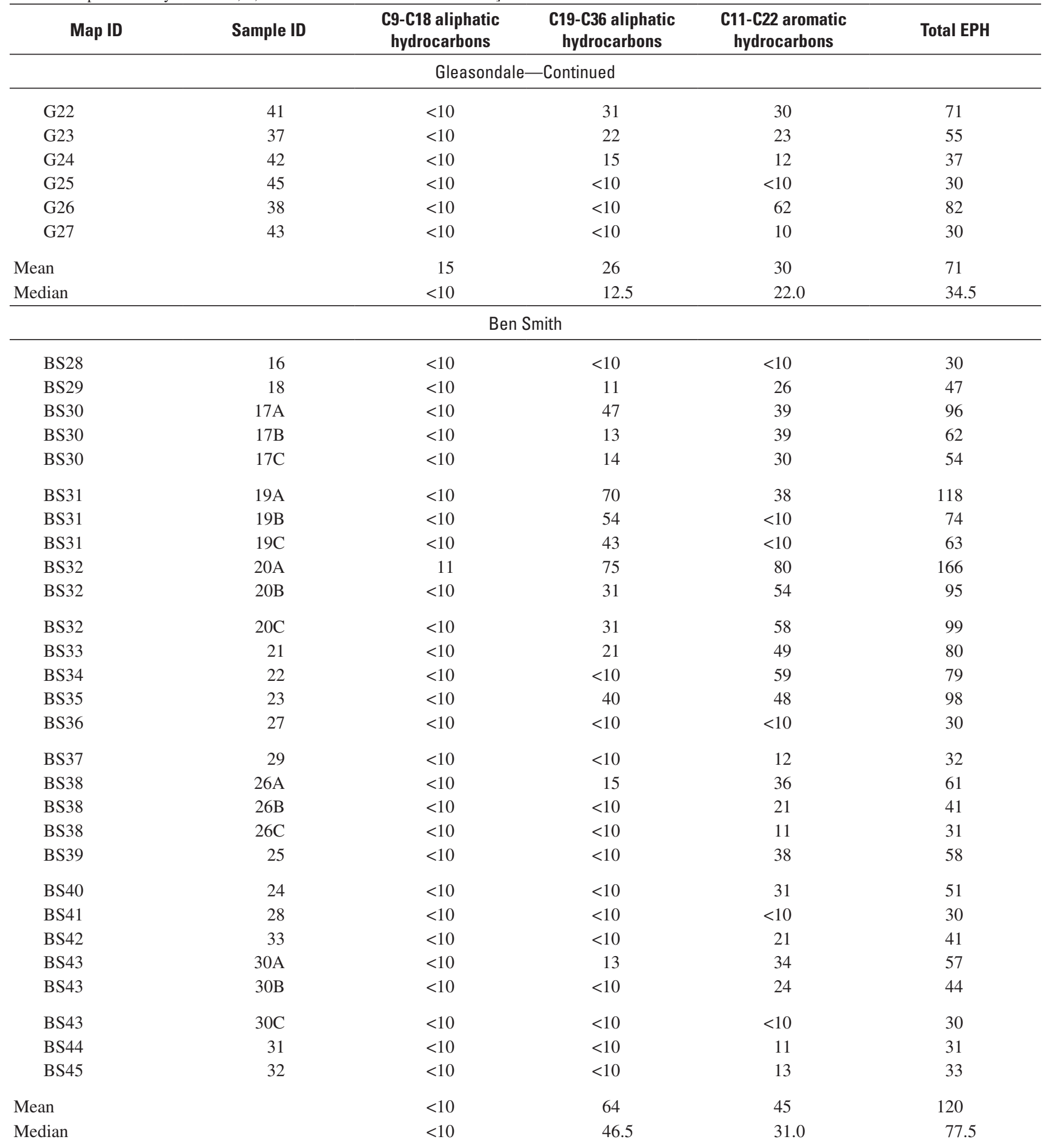


Table 8. Concentrations of extractable petroleum hydrocarbons in sediment samples from six impoundments in the the Assabet River Basin, Massachusetts, 2003.-Continued

[All concentrations are shown in milligrams per kilogram. Minimum reporting level is 10 milligrams per kilogram. Total EPH and means and medians for each impoundment were calculated using 10 as an estimate for all < 10 values where other values were 10 or greater. Map ID: The identifier associated with a sampling site on a map (figs. 9-14). Sample ID: Identifier of a sample collected from a particular core, arranged alphabetically from the top of the core. EPH, extractable petroleum hydrocarbon; <, actual value is less than value shown]

\begin{tabular}{|c|c|c|c|c|c|}
\hline Map ID & Sample ID & $\begin{array}{l}\text { C9-C18 aliphatic } \\
\text { hydrocarbons }\end{array}$ & $\begin{array}{l}\text { C19-C36 aliphatic } \\
\text { hydrocarbons }\end{array}$ & $\begin{array}{l}\text { C11-C22 aromatic } \\
\text { hydrocarbons }\end{array}$ & Total EPH \\
\hline \multicolumn{6}{|c|}{ Powdermill } \\
\hline P47 & 49 & $<10$ & 12 & 41 & 63 \\
\hline P48 & $46 \mathrm{~A}$ & $<10$ & $<10$ & $<10$ & 30 \\
\hline P49 & 47 & $<10$ & 14 & 31 & 55 \\
\hline P50 & 52 & 14 & 54 & 92 & 160 \\
\hline P51 & 55 & 14 & 178 & 31 & 223 \\
\hline P52 & 53 & $<10$ & 24 & 55 & 89 \\
\hline P53 & 56 & 22 & 41 & 118 & 181 \\
\hline P55 & $51 \mathrm{~A}$ & $<10$ & $<10$ & $<10$ & 30 \\
\hline P55 & $51 \mathrm{~B}$ & $<10$ & $<10$ & $<10$ & 30 \\
\hline P55 & $51 \mathrm{C}$ & $<10$ & $<10$ & $<10$ & 30 \\
\hline P56 & $50 \mathrm{~A}$ & 12 & 75 & 45 & 132 \\
\hline P56 & $50 \mathrm{~B}$ & 13 & 142 & 77 & 232 \\
\hline P56 & $50 \mathrm{C}$ & 10 & 10 & $<10$ & 30 \\
\hline P57 & 57 & $<10$ & $<10$ & $<10$ & 30 \\
\hline Mean & & 11.9 & 64.3 & 44.9 & 121 \\
\hline Median & & $<10$ & 46.5 & 31.0 & 77.5 \\
\hline
\end{tabular}


Table 9. Incidence of toxicity, in percent, and mean MPP values calculated from Probable Effect Concentration quotients for sediment samples from the six impoundments in the Assabet River Basin, Massachusetts, 2003.

[Map ID: The identifier associated with a sampling site on a map (figs. 9-14). Data for HA10, HA28, and CS10 toxicity tests from the U.S. Environmental Protection Agency (2000) and Ingersoll and others (2001). Boldface type indicates Mean MPP (or) method was used because of censored data. All other Mean MPP data were calculated by the Mean MPP (and) method. Sites H13, P46, and P54 were sampled at three depths in the cores indicated by the letter A, B, C appended to the Map ID]

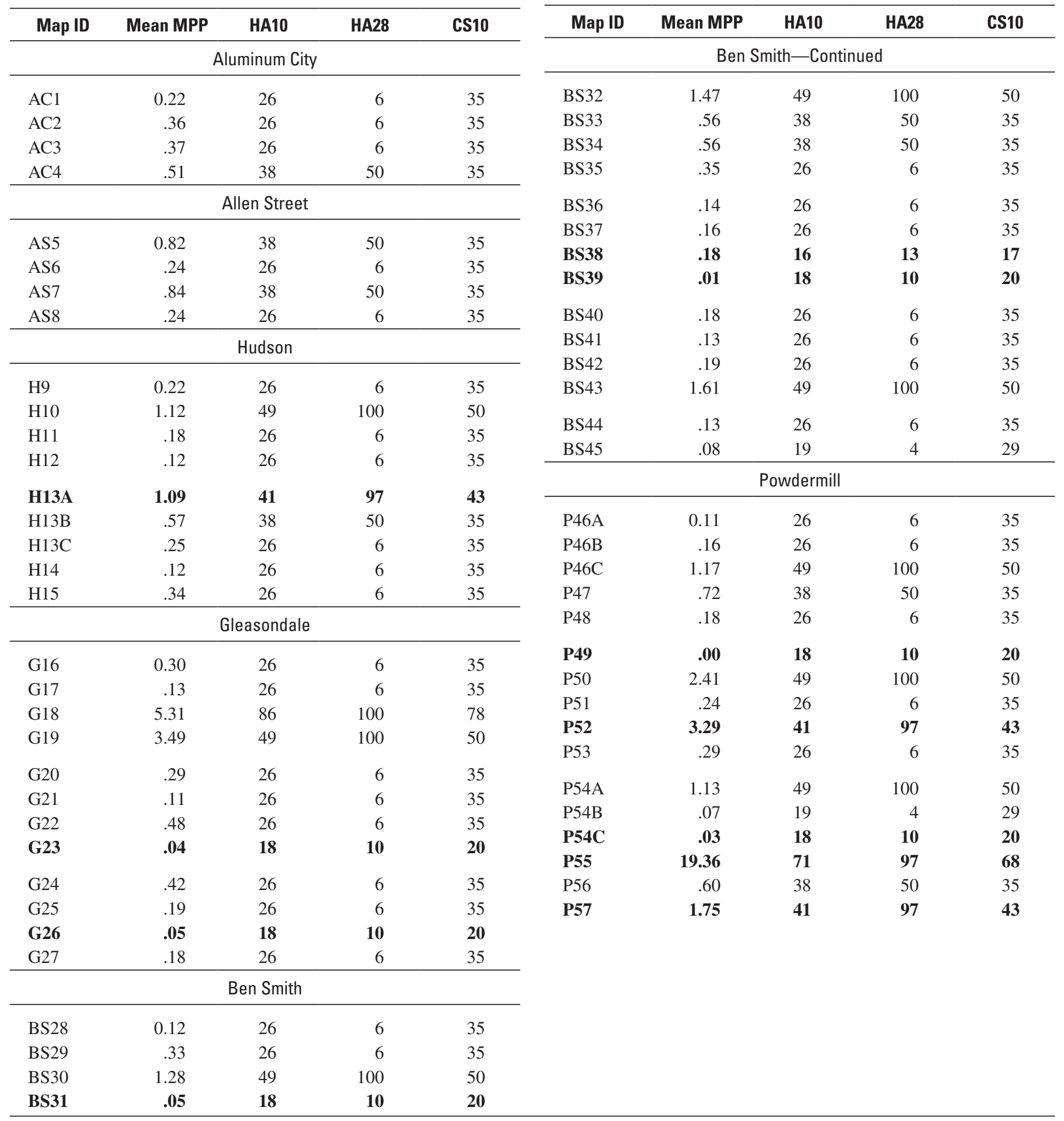


Sediment-sample mean MPP values indicated an increasing trend downstream. For simplicity's sake, the incidences of toxicity that were used for comparison were from the HA28 test, a more sensitive test than the HA10 and CS10 tests. From the Aluminum City impoundment, the highest mean MPP from site AC4 (0.51) was associated with an incidence of toxicity of 50 percent. Allen Street sediment samples from sites AS5 and AS7 both had mean MPP values greater than 0.80 and incidences of toxicity of 50 percent. Two Hudson impoundment sites, $\mathrm{H} 10$ and $\mathrm{H} 13$, gave samples with high mean MPPs and incidences of toxicity of 100 and 97 percent, respectively. Samples from sites G18 and G19 in the Gleasondale impoundment gave some of the largest mean MPPs of the study: 5.31 and 3.49, respectively, with 100 percent incidences of toxicity. The Ben Smith impoundment had five sites that gave samples with mean MPPs greater than 0.5 and incidences of toxicity of 50 or 100 percent: BS30 (1.28), BS32 (1.47), BS33 (0.56), BS34 (0.56), and BS43 (1.61). A sample from a site in the Powdermill impoundment had the highest mean MPP of the study: P55 (19.36). The Powdermill impoundment also had seven other sites that gave samples with high mean MPPs and incidences of toxicity greater than 50 percent: sites $\mathrm{P} 46$ (1.17, in the deepest sediment sample), P47 (0.72), P56 (0.60), P50 (2.41), P52 (3.29), P54 (1.13, in the surface sample), and P57 (1.75).

As a result of the sediment-processing procedures, all incidence-of-toxicity results (figs. 9 to 14 ) represent the entire core sample except for the results for stations H13, P46, and P54, which include the toxicity at three individual depths within the cores. The incidences of toxicity for the surface sediments at these three sites appear to be higher than for some of the completely homogenized samples (with the exception of site P46, which was effectively a surface-sediment core sample because its total length was less than $30 \mathrm{~cm}$ ). Likewise, the deepest sediments appear to have lower toxicities than some of the completely homogenized samples. An entire core with retrieval depths more than $60 \mathrm{~cm}$ may include preimpoundment sediments that have not been affected by human activities; thus, analytical results of tests on such a core may show a bias toward a lower toxicity. If this hypothesis is valid, the incidences of toxicity presented in this report (with the exception of sites H13, P46, and P54) may be underestimated.

\section{Sediment Distribution and Chemistry- Possible Implications for Sediment Management}

The six Assabet River impoundments differed greatly in size and sediment volume, with Aluminum City having a sediment volume of only $380 \mathrm{~m}^{3}$ and Ben Smith 580,000 $\mathrm{m}^{3}$ (table 10). Results of chemical analyses of sediment differed considerably within and among the impoundments. In general, guideline exceedances increased in the downstream direction. The chemical analyses revealed that toxic metal and PAH concentrations exceeded quantitative sediment-quality guidelines in almost all samples. PCBs were not detected in as many samples as metals and PAHs were, but all PCB detections exceeded at least one guideline. Chemical-matrix interference was cited by two laboratories to explain why they did not detect VOCs and organochlorine pesticides in any samples; failure to detect these compounds, however, does not imply their absence.

Regional variability was not taken into consideration in interpreting incidence of toxicity data; nevertheless, there is no reason to expect that the incidence of toxicity data calculated from contaminant concentrations in New England sediments would be different from data calculated from contaminant concentrations in any other region. Approximately one third of the sediment samples could be expected to exhibit toxic effects (lethality, growth inhibition, or reproductive diminution) on test organisms with a likelihood of 50 percent or more. Although USEPA guidelines that focus on the health of aquatic organisms were commonly exceeded in the impoundments, the MDEP guidelines for landfill disposal of dredged materials were exceeded in only a small percentage of samples. If sediment dredging were undertaken, it may be possible to dilute sediments that exceed MDEP disposal standards with less contaminated sediments to produce an acceptable mixture. Selective dam removal or modification (partial removal or lowering of dam crests) might improve aesthetics and, to some extent, restore natural conditions, but could still leave toxic sediments intact or allow them to be transported downstream to the next impoundment.

If adequate disposal areas can be found, these results could be interpreted to suggest that extensive dredging might improve the aquatic habitat of the Assabet River. Dredging could also remove much of the sediment phosphorus, which is most highly concentrated in surficial sediments, but whether this removal would reverse the eutrophic conditions in the impoundments is unknown because the relation between bulksediment phosphorus concentrations and phosphorus availability as an algal nutrient is not well understood. Dredging could create deeper pools with increased thermal stratification and additional potential for sediment-phosphorus release. In addition, the high nutrient concentrations in wastewater effluent from treatment plants may still be sufficient to support nuisance growths of rooted and floating macrophytes and epiphytic algae in the impounded and free-flowing reaches of the river, in which case the dredging would only provide shortterm benefits. 
Table 10. Selected characteristics of six impoundments in the Assabet River Basin, Massachusetts. Exceedances listed reflect one or more samples in an impoundment.

[PEC, probable effect concentration; PEL, probable effect level; $\mathrm{m}^{3}$, cubic meter; $\mathrm{m}$, meter; $\mathrm{m}^{2}$, square meter]

\begin{tabular}{|c|c|c|c|c|c|c|c|}
\hline Impoundment & $\begin{array}{c}\text { Maximum } \\
\text { water depth } \\
\text { (m) }\end{array}$ & $\begin{array}{l}\text { Maximum } \\
\text { sediment } \\
\text { thickness } \\
(\mathrm{m})\end{array}$ & $\begin{array}{l}\text { Sediment } \\
\text { volume } \\
\left(\mathrm{m}^{3}\right)\end{array}$ & $\begin{array}{l}\text { Approximate } \\
\text { impoundment } \\
\text { length } \\
\text { (m) }\end{array}$ & $\begin{array}{l}\text { Impound- } \\
\text { ment area } \\
\left(\mathrm{m}^{2}\right)\end{array}$ & $\begin{array}{l}\text { Chemical groups that } \\
\text { exceeded aquatic- } \\
\text { life guidelines } \\
\text { (PEL or PEC) }\end{array}$ & $\begin{array}{l}\text { Chemical groups } \\
\text { that exceeded } \\
\text { landfill-reuse } \\
\text { guidelines }\end{array}$ \\
\hline Aluminum City & 1.2 & 1.0 & 380 & 110 & 1,600 & $\mathrm{Cr}, \mathrm{Cu}, \mathrm{Pb}, \mathrm{PCB}, \mathrm{PAH}$ & $\mathrm{Cr}$ \\
\hline Allen Street & 2.5 & 3.6 & 42,000 & 890 & 28,000 & $\begin{array}{l}\mathrm{Cd}, \mathrm{Cr}, \mathrm{Cu}, \mathrm{Pb}, \mathrm{Zn}, \\
\text { PCB, PAH }\end{array}$ & \\
\hline Gleasondale & 3.3 & 5.6 & 67,000 & 990 & 55,000 & $\begin{array}{l}\mathrm{As}, \mathrm{Cd}, \mathrm{Cr}, \mathrm{Cu}, \mathrm{Pb}, \mathrm{Ni}, \\
\text { Zn, PCB, PAH }\end{array}$ & As, PCB \\
\hline Ben Smith & 3.3 & 7.5 & 580,000 & 11,000 & 590,000 & $\begin{array}{l}\mathrm{As}, \mathrm{Cd}, \mathrm{Cr}, \mathrm{Cu}, \mathrm{Pb}, \mathrm{Ni} \text {, } \\
\text { Zn, PCB, PAH }\end{array}$ & $\mathrm{As}, \mathrm{Pb}$ \\
\hline Powdermill & 2.5 & 2.7 & 120,000 & 4,800 & 110,000 & $\begin{array}{l}\mathrm{As}, \mathrm{Cd}, \mathrm{Cr}, \mathrm{Cu}, \mathrm{Pb}, \mathrm{Ni}, \\
\mathrm{Zn}, \mathrm{PCB}, \mathrm{PAH}\end{array}$ & As, $\mathrm{Cr}, \mathrm{Pb}, \mathrm{PAH}$ \\
\hline
\end{tabular}




\section{Part 2. Phosphorus Dynamics in a Wastewater-Dominated Impoundment, Hudson, Massachusetts}

\section{Introduction}

Nutrient total maximum daily loads (TMDLs) are being developed for streams in Massachusetts, many of which have water-quality-impairment issues similar to those of the Assabet River. Recent TMDL assessment and modeling studies of the Assabet River have documented the extent of eutrophication of the river's impoundments and free-flowing reaches, and suggested that phosphorus releases from bed sediments may continue to promote excessive plant growth in the river even if loads from wastewater-treatment plants and other point sources were eliminated (ENSR International, 2001, 2004). Data from environmental-assessment and laboratory studies of phosphorus release from sediments were used by ENSR International to develop and test the model that developed several management scenarios to provide acceptable alternatives for improving water quality enough to meet standards. All alternatives included reductions in phosphorus loadings from treatment plants and from sediments. According to the ENSR International study recommendations, attainment of water-quality standards may entail a combination of removal of the bed sediments, chemical treatment to immobilize sediment phosphorus, or dam removal or breaching to increase flows and disperse some of the sediments. More detailed information on the distribution, transport, and internal cycling of phosphorus between sediments and surface water as well as on external phosphorus loading would help managers select the most cost-effective course of action. A judgment could then be made whether annual fluxes of sediment phosphorus in the river are of sufficient magnitude to require dredging, or if dam removal or breaching can be used to achieve water-quality and other environmental goals.

The relation between bulk-sediment phosphorus concentrations, discussed elsewhere in this report, and the release of phosphorus from sediments remains uncertain. Sediment pore water may contain phosphorus in high enough concentrations to become available to aquatic plants as a nutrient in the water column if conditions permit. Mortimer (1971), Boström and others (1982), and Nürnberg (1988) describe many factors that combine to control the release of sediment phosphorus to the water column. Foremost among these are the oxidationreduction (redox) conditions at the sediment-water interface that control the availability of loosely bound, or adsorbed, phosphorus, and phosphorus that is bound to iron hydroxides.
As reducing conditions intensify, phosphorus unbinds and may move into the water column in the form of a dissolved phosphate ion that is available for absorption by aquatic plants. Anoxic conditions are most likely to develop in the deep parts of impoundments during summer and early autumn low-flow periods and perhaps in areas where floating macrophytes (for example, Lemna sp.) completely cover the surface; the combination of biochemical oxygen demand in the water column and macrophytes blocking light needed to support oxygen-yielding photosynthesis by algae could create this situation. However, the presence of nitrate is known to suppress the release of phosphorus by maintaining a high redox potential (Golterman, 2004; Tiren and Petterson, 1985; Andersen, 1982); high ambient nitrate concentrations sustained by releases from treatment plants along the Assabet River might produce this effect.

Recent laboratory studies by ENSR International (2001) to determine the potential for Assabet River sediments to release phosphorus sufficient to constitute a substantial fraction of the measured water-column phosphorus mass yielded mixed results. The water column actually lost phosphorus to sediment cores collected in March 2000 and incubated at ambient temperatures. Phosphorus release was observed from cores that were incubated at temperatures elevated above ambient; however, phosphorus released from the sediments amounted to less than 3 percent of the water-column phosphorus. When the water overlying cores collected in September 2000 was allowed to become anaerobic, however, the study reported that the sediments released as much as 170 percent of the pre-existing water-column phosphorus concentrations into the water column. On the other hand, the report noted that the waters in the impoundments rarely became anaerobic. Sediments never previously exposed to anaerobic conditions may have substantial amounts of iron-bound phosphorus that would not have been released under normal (aerobic) conditions.

To resolve uncertainty inherent in extrapolating laboratory results to field conditions, a field study examining changes in concentrations of total phosphorus and orthophosphorus took place from July to September 2003. The purpose of the field study was to determine whether phosphorus was likely to be released from the sediments in concentrations sufficient to negate improved wastewater treatment. Because the project was innovative and funding was limited, only one impoundment was studied. 


\section{Site Selection and Sample Collection}

The Hudson impoundment was selected for this study because available data indicated that its summer ambient phosphorus concentrations were among the lowest of the six impoundments (ENSR International, 2001); substantial releases of phosphorus would be more easily detected there than in an impoundment with higher ambient concentrations. Furthermore, point sources and tributaries do not contribute significantly to streamflow in this impoundment during lowflow periods.

In this study, field measurements of water-column temperature, dissolved oxygen (DO), and specific conductance were made to determine the extent of hypoxia. In addition, samples were collected from multiple depths in the water column for analyses of chloride, ortho-, and total phosphorus; ortho- and total phosphorus samples were also collected from sediment pore water at selected sites. Different forms of phosphorus were analyzed to determine the proportion of labile (available for plant uptake) phosphate. Estimates of sediment phosphorus fluxes obtained in this way are inherently more realistic than measurements made under laboratory conditions. Thus, this approach was considered better than repeating the TMDL experiments on cores in the laboratory or measuring benthic phosphorus flux rates directly in the impoundments; the latter method would likely give a large range of flux rates and would also be prohibitively expensive.

\section{Reconnaissance and Site Selection}

One week before the start of the study, a reconnaissance consisting of preliminary measurements in the water column of $\mathrm{DO}$, specific conductance, $\mathrm{pH}$, and temperature was made at 37 locations to determine sites where sampling would most clearly reveal variations in the water quality. At all sites along the preimpoundment river channel, or thalweg, water-quality measurements showed no stratification. Some areas that did not lie along the thalweg, however, showed signs of potential stratification that could lead to anaerobic conditions and possibly phosphorus release.

Five sites were selected for use in this part of the study (fig. 17): one near the upstream end (17), one at the outlet (37); one off the main channel in a shallow embayment covered with Lemna (20); one in a deeper offchannel embayment with rooted macrophytes and some Lemna (27); and one in the middle of the impoundment off the main channel in dense, rooted macrophyte beds (29). All rooted macrophytes had heavy coatings of epiphytic algae.

\section{Field Measurements and Collection of Phosphorus and Chloride Samples}

From July 16 to September 8, 2003, the Hudson impoundment was monitored once each week in a study to determine whether phosphorus release from sediments could be evaluated in spite of the high background concentrations. Each day, after the water-column-profile measurements were made, water samples for total phosphorus and orthophosphorus and chloride analyses were collected with a stainless-steel pushpoint sampler.

Water samples were collected from the water column at approximately $0.5-\mathrm{m}$ or smaller intervals at five locations with a peristaltic pump attached to pushpoint samplers, stainless-steel rods about 1- or 2-m long that are screened at the tip. The pushpoint samplers are normally used for shallow ground-water sampling. For pore-water sampling, a platform was attached to the bottom of the sampler (fig. 18). When the platform was resting on the sediment surface, the screened tip of the sampler was stabilized at a depth of $5 \mathrm{~cm}$ below the surface.

Samples were analyzed for total phosphorus, dissolved phosphorus, and chloride by standard methods (Patten and Truitt, 1992; Fishman, 1993; Strickland and Parsons, 1968; Stauffer, 1983). Total phosphorus and chloride samples were analyzed by the USGS National Water Quality Laboratory, and orthophosphorus samples were analyzed in the USGS Massachusetts-Rhode Island Water Science Center office's laboratory. Differences in phosphorus concentrations in samples from the main river channel and the backwater areas were examined to determine if there was a measurable net release of phosphorus from the sediments. The chloride served as a conservative tracer and check on the calculations of the phosphorus generation from the sediments; a larger upstream than downstream ratio of chloride to total phosphorus would suggest net phosphorus release in the impoundment. It was assumed that there were no unaccounted-for sources of chloride or water in the impoundment.

\section{Quality Control}

To ensure quality control of the samples, replicate and blank samples were collected during the study (table 17, at back of report). Replicate samples demonstrated that the method yielded consistent results and supported their reliability. Field-blank analyses showed that neither the equipment nor the procedures employed caused any contamination of the samples that would lead to misinterpretation of data. 


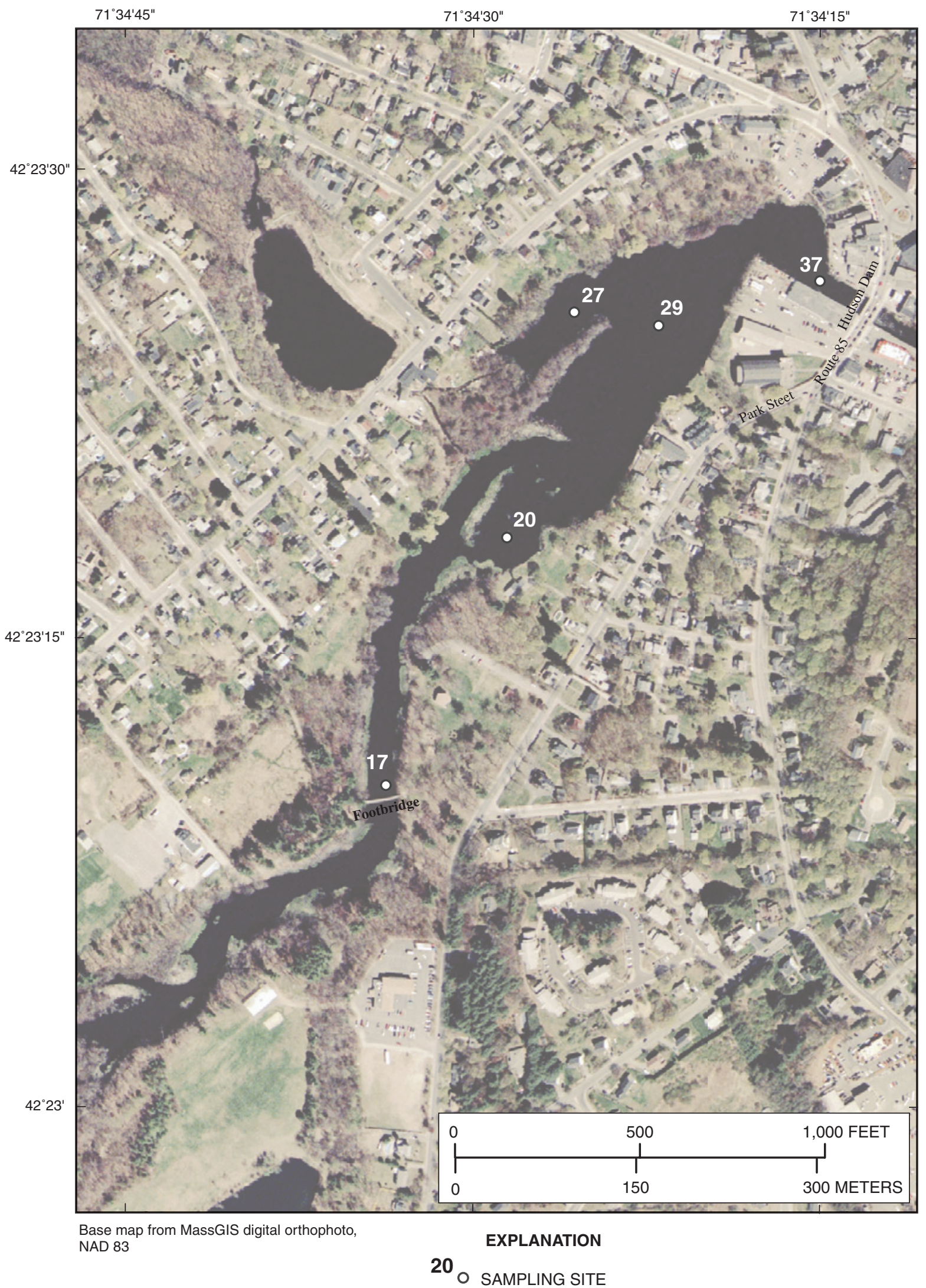

Figure 17. Hudson, Massachusetts, impoundment with sampling sites for phosphorus-release dynamics study, July to September 2003. 


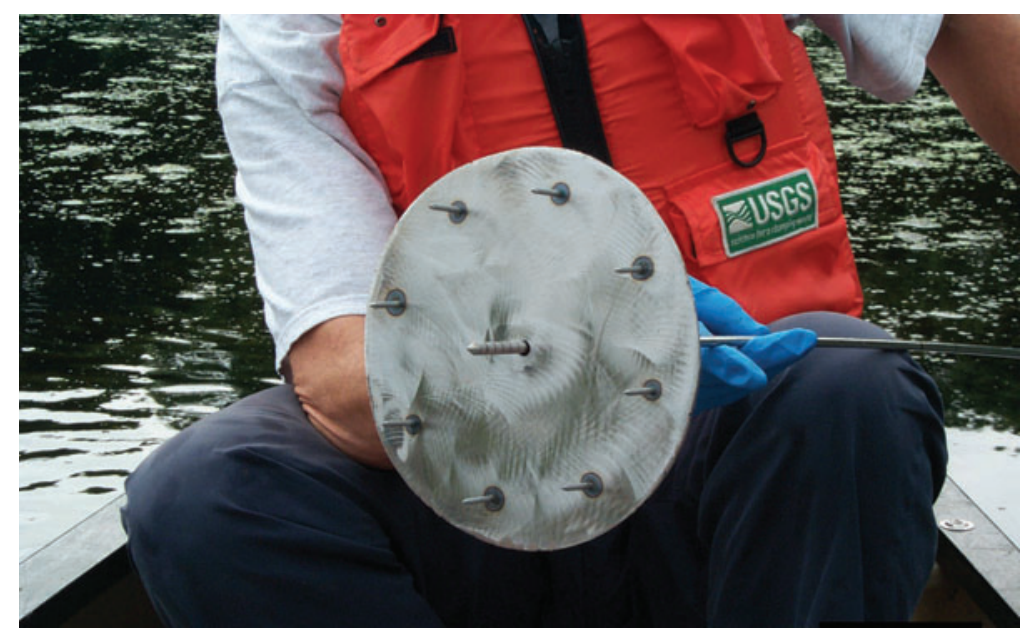

Figure 18. Platform attached to pushpoint sampler in preparation for porewater sampling. The sampler's screened tip protrudes through a hole in the bottom of the platform.

\section{Field Study of Phosphorus Dynamics}

Vertical-profile data collected in 2003 at the five study sites in the Hudson impoundment for total phosphorus, orthophosphorus, and DO concentrations were plotted in relation to time and compared with rainfall data to reveal the relations among phosphorus concentrations in the water column and sediment, DO concentrations in the water column, and the effects of rainfall on total phosphorus storage in the impoundment (fig. 19).

On the first sampling date, July 16, all field measurements indicated minimal, if any, stratification in the water column at any of the sampling stations (table 17; fig. 19). DO profiles were similar, too, with all concentrations approximately 6 to $7 \mathrm{mg} / \mathrm{L}$. As the study period progressed, DO profiles at stations 17 and 37 demonstrated little stratification, while at stations 20,27, and 29, DO concentrations frequently showed marked stratification.

The mean total phosphorus concentrations of all watercolumn samples were approximately twice the orthophosphorus concentrations at each station (table 11). Mean total phosphorus and orthophosphorus concentrations were generally higher at the midimpoundment stations, 20, 27, and 29, than at 17 and 37. Station 20 had the highest mean total phosphorus and orthophosphorus concentrations, $0.3890 \mathrm{mg} / \mathrm{L}$ and $0.155 \mathrm{mg} / \mathrm{L}$, respectively. Medians of total phosphorus concentrations were also approximately twice the orthophosphorus median concentrations. The median total phosphorus concentrations, however, did not differ as much as the mean total phosphorus concentrations, and the median orthophosphorus concentrations ranged only from 0.0550 to $0.0690 \mathrm{mg} / \mathrm{L}$.
Table 11. Mean and median total phosphorus and orthophosphorus concentrations, in milligrams per liter, of all samples in the water column or pore water at each sampling station in the Hudson, Massachusetts, impoundment, July to September 2003.

\begin{tabular}{|c|c|c|c|c|}
\hline \multirow[b]{2}{*}{$\begin{array}{l}\text { Station } \\
\text { number }\end{array}$} & \multicolumn{2}{|c|}{ Mean } & \multicolumn{2}{|c|}{ Median } \\
\hline & $\begin{array}{l}\text { Total } \\
\text { phos- } \\
\text { phorus }\end{array}$ & $\begin{array}{l}\text { Ortho } \\
\text { phos- } \\
\text { phorus }\end{array}$ & $\begin{array}{c}\text { Total } \\
\text { phos- } \\
\text { phorus }\end{array}$ & $\begin{array}{c}\text { Ortho } \\
\text { phos- } \\
\text { phorus }\end{array}$ \\
\hline \multicolumn{5}{|c|}{ Water Column } \\
\hline 17 & 0.1365 & 0.0687 & 0.1283 & 0.0550 \\
\hline 20 & .3890 & .1548 & .1524 & .0605 \\
\hline 27 & .1483 & .0839 & .1209 & .0660 \\
\hline 29 & .1860 & .0629 & .1434 & .0690 \\
\hline 37 & .1246 & .0676 & .1122 & .0590 \\
\hline \multicolumn{5}{|c|}{ Pore Water } \\
\hline 20 & 2.192 & 1.148 & 1.676 & 0.660 \\
\hline 27 & .8381 & .3244 & .6540 & .323 \\
\hline 29 & 1.245 & .4309 & 1.2090 & .271 \\
\hline
\end{tabular}

Total phosphorus and orthophosphorus concentrations in the sediment pore water were substantially higher than in the water column, with mean orthophosphorus concentrations several times greater than concentrations in the overlying water. The highest mean and median concentrations of orthophosphorus in sediment pore water were found at station 20, the shallowest station and the one where the surface was always covered with Lemna. 


\section{Site-Specific Profiles}

At stations 17 and 37, the impoundment inflow and outflow stations, respectively, total phosphorus and orthophosphorus concentrations were approximately the same on any given date; total phosphorus generally ranged from 0.10 to $0.15 \mathrm{mg} / \mathrm{L}$ and orthophosphorus concentrations were generally about two-thirds the concentration of the total. At station 17, on September 8, the sample collected nearest the bottom had the highest concentration of total phosphorus at the site, $0.4200 \mathrm{mg} / \mathrm{L}$, and the DO concentration was $6.56 \mathrm{mg} / \mathrm{L}$ (table 17). The total phosphorus concentrations at station 37 were particularly consistent, and indicated a well-mixed condition throughout the water column; on July 16, the bottom sample had a total phosphorus concentration of approximately $0.3 \mathrm{mg} / \mathrm{L}$; otherwise, concentrations were not greater than $0.15 \mathrm{mg} / \mathrm{L}$ (fig. 19).

At stations 20, 27, and 29, the bottom and pore-water phosphorus concentrations were higher and varied more with time than concentrations at other depths in the water column (fig. 19). The highest pore-water total phosphorus and orthophosphorus concentrations, approximately 5 and $7 \mathrm{mg} / \mathrm{L}$, respectively, were detected on July 24 at station 20, where total phosphorus concentrations in the pore water had been measured as above $2 \mathrm{mg} / \mathrm{L}$ twice. At station 27, measured pore-water total phosphorus concentrations were higher than $1 \mathrm{mg} / \mathrm{L}$ twice and were generally about $0.5 \mathrm{mg} / \mathrm{L}$. At station 29 , total phosphorus concentrations in the pore water commonly approached or exceeded $1.0 \mathrm{mg} / \mathrm{L}$. Phosphorus concentrations at the lowest levels of the water column and in the pore water did not appear to correlate well among the stations. Low DO concentrations in the water column did not correlate strongly with high phosphorus concentrations in the surface or pore waters. In addition, higher phosphorus concentrations in the samples taken from the greatest depth did not seem to be mirrored by increased concentrations elsewhere in the water column at any given station (fig. 19). This last finding indicated that phosphorus released from the sediments was taken up quickly, adsorbed onto particles, or precipitated when it entered the oxidized zone.

In general, the phosphorus concentrations detected in this study were not as great as previously detected in the ENSR International (2001) study. Hydrologic conditions differed substantially between summers, with 2000 (the ENSR study) being extremely dry and 2003 (this USGS study) moderately wet. ENSR International cited discharges less than $0.57 \mathrm{~m}^{3} / \mathrm{s}$, whereas discharges during the present study were about
$2.8 \mathrm{~m}^{3} / \mathrm{s}$. The higher discharges in 2003 probably contributed to greater dilution of phosphorus, and probably affected flushing rates and stratification dynamics as well.

\section{Changes in Phosphorus Storage}

By combining the knowledge gained during the initial bathymetric mapping with the data obtained on phosphorus distribution in the water column, it was also possible to estimate the amount of phosphorus generated internally from the impounded sediment; that is, it was possible to calculate the mass of phosphorus at different depths within the water column to determine if increases were caused by sediment release.

To examine the magnitude of phosphorus release throughout the impoundment during the study period, a geographic information system (GIS) was used to divide the bathymetric map into five sections, each represented by one of the stations in the study, and to estimate the volume of water in a series of 0.5 -m-thick vertical layers in each section. The concentration of phosphorus in each layer was multiplied by the layer's volume to give an estimate of the mass of phosphorus in that layer. The masses of phosphorus in the layers were added for each section, as were the sums for all sections, to give the total mass of phosphorus in the impoundment on a given sampling date. This series of estimates was intended to enable a visualization of the hydrologic effect of rainfall on the mass of phosphorus during the summer study period (table 12; fig. 19). Although rains fell frequently during the summer, there were no large storms with torrential rains, which could have destratified and flushed the impoundment. In addition, there were no extended drought-like periods. Storms in late July and early August seemed to precede increases in the mass of total phosphorus; possibly the increases were the result of nonpoint runoff. In August, the one period with frequent rainfall exhibited an increase in phosphorus mass and, after the rainy period ended, the mass of total phosphorus decreased. The rise could be a result of runoff and the drop may be attributable to dilution and flushing of phosphorus from the impoundment. Overall, the data acquired for this study and the estimated areas selected and delineated as representative of the conditions at the five sampling stations indicated no strong relations between rainfall and phosphorus mass. More frequent collection of samples, however, would be needed to establish a definite cause-and-effect relation between the two variables. 
A.
SEDIMENT-WATER INTERFACE

\section{EXPLANATION}

TOTAL PHOSPHORUS

ORTHOPHOSPHORUS

$\longrightarrow$ DISSOLVED OXYGEN

INTERFACE
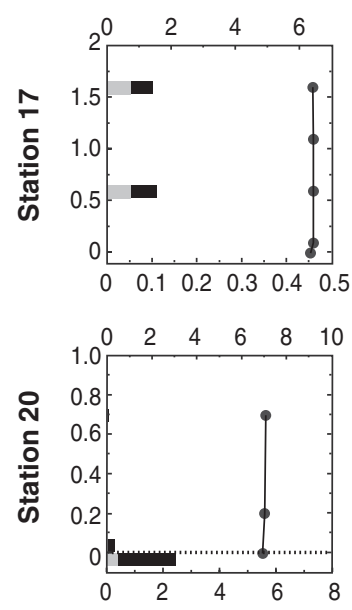

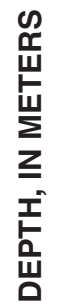

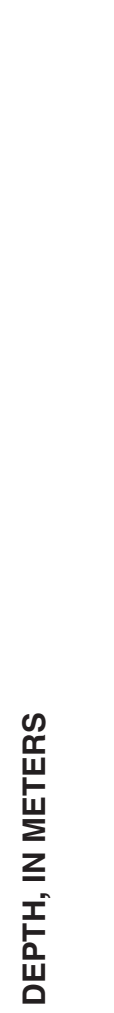
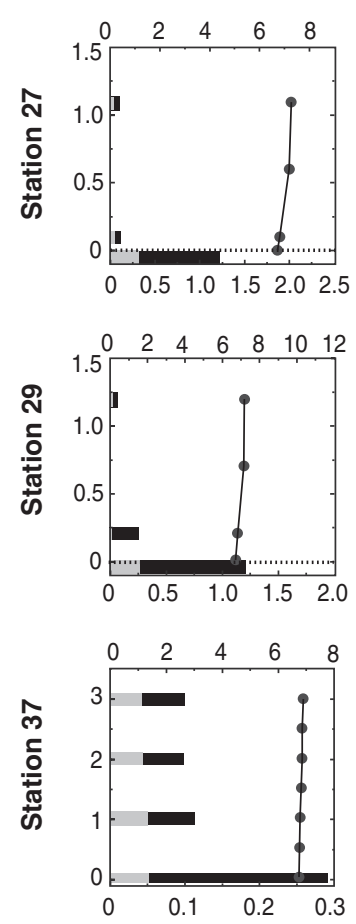

07/24/2003

07/29/2003
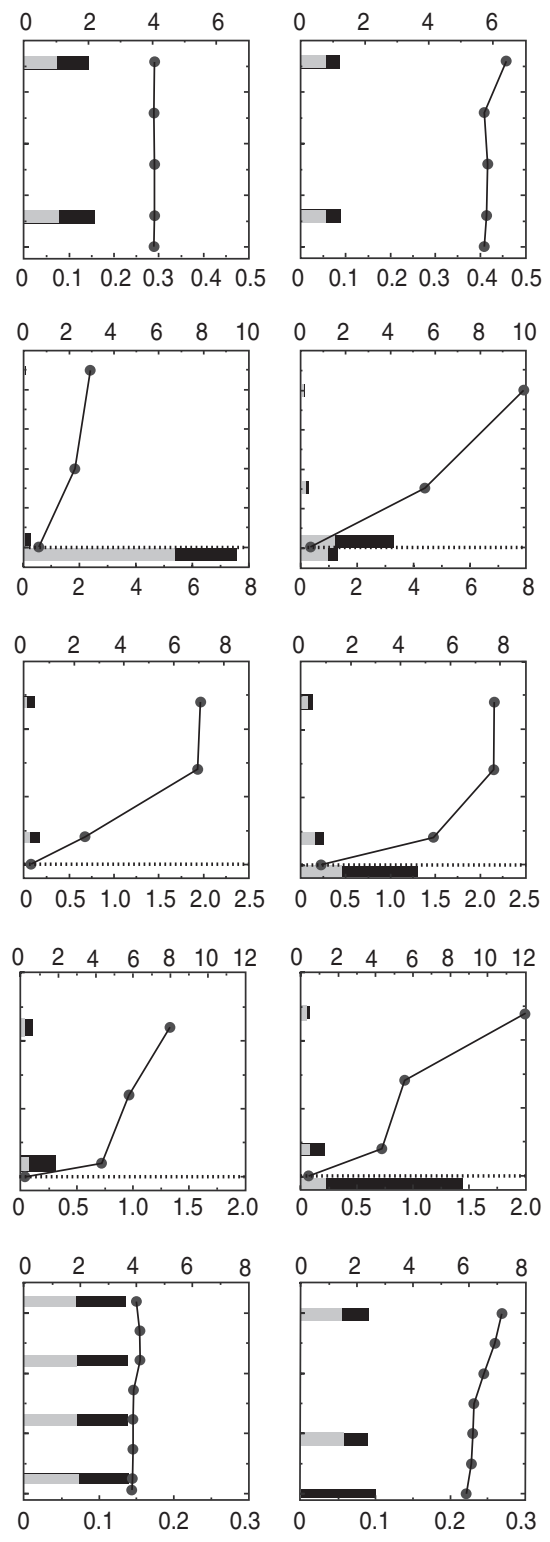

Figure 19. $A$, Total and orthophosphorus and dissolved oxygen water-column profiles at five stations in the Hudson impoundment, July to September 2003. Depth is given as vertical distance from sediment surface to water surface. $B$, Rainfall and changes in estimated total phosphorus storage in the Hudson impoundment, July to September 2003.
B.

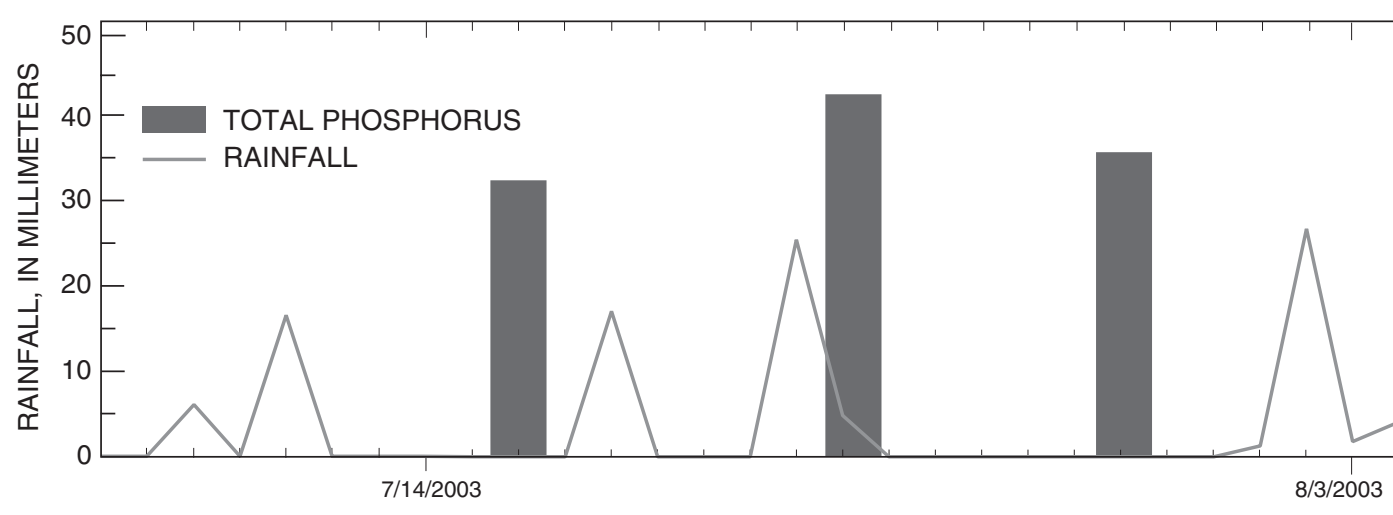


08/07/2003

08/13/2003

DISSOLVED OXYGEN, IN MILLIGRAMS PER LITER
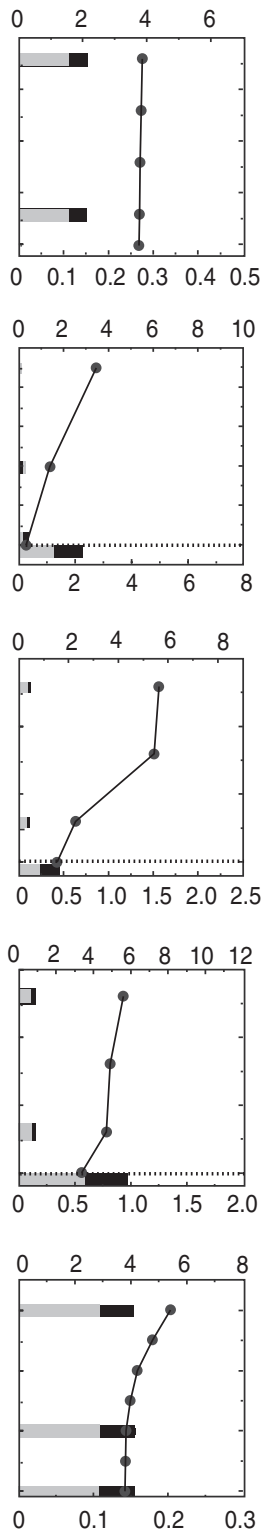
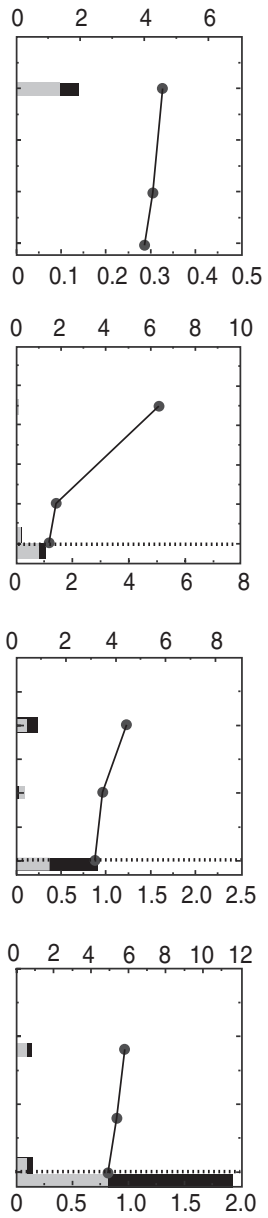

$08 / 21 / 2003$
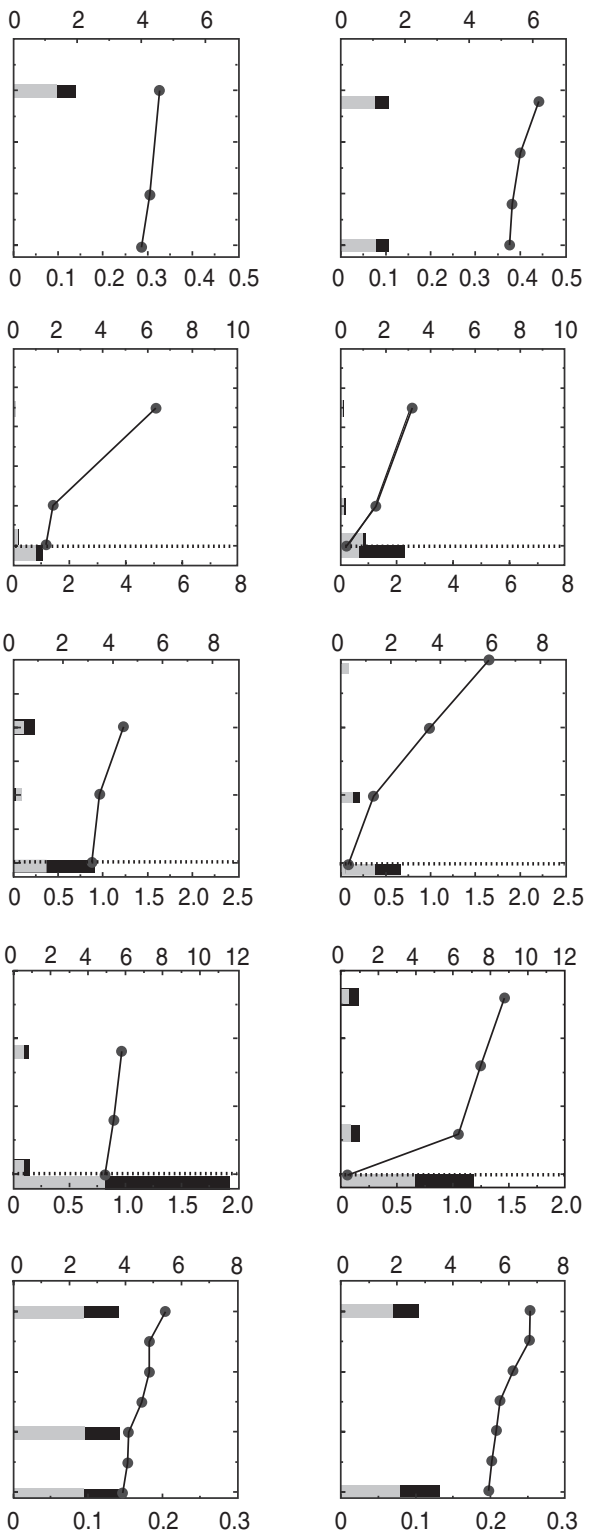

$08 / 28 / 2003$

09/08/2003
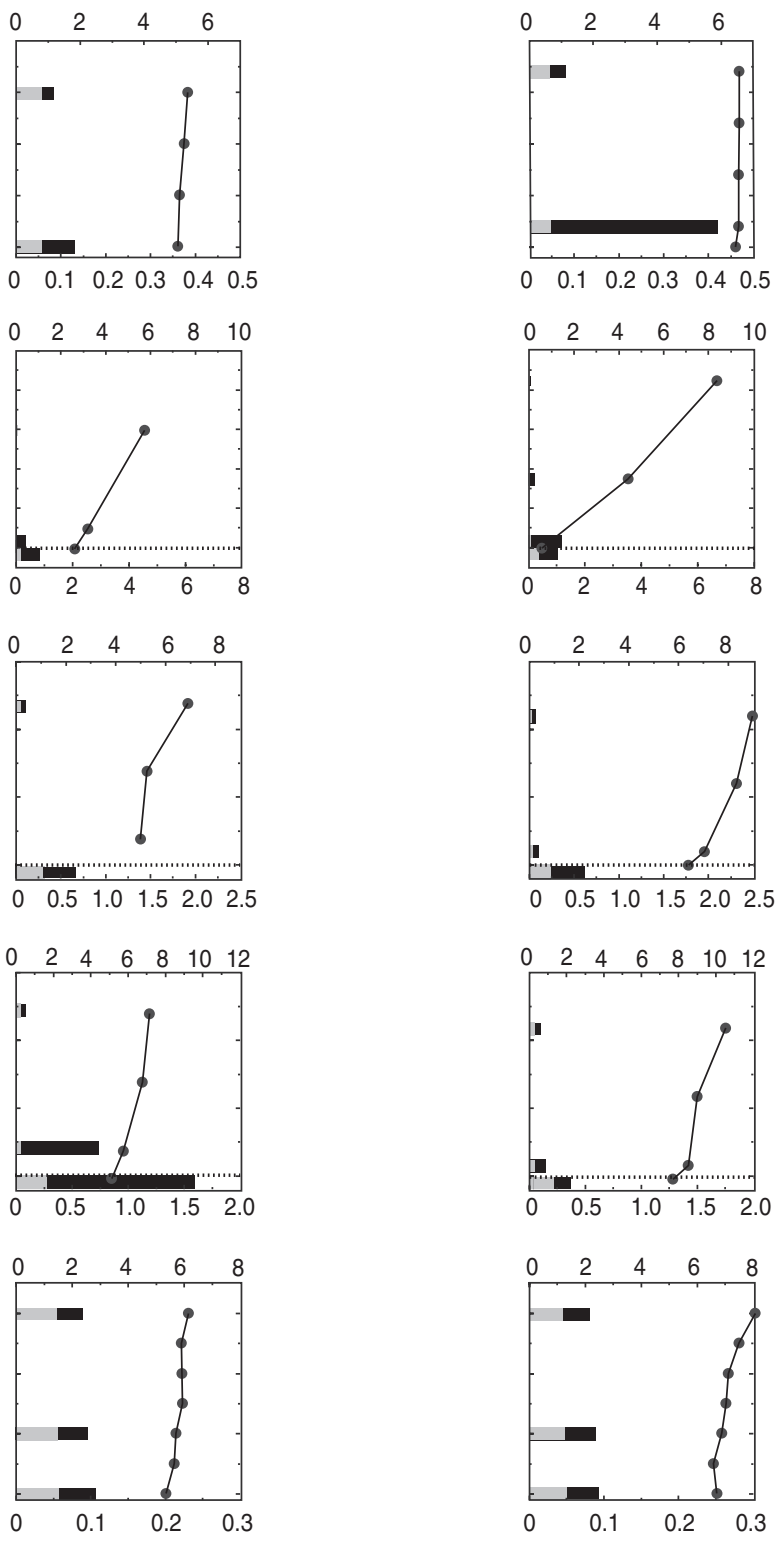

PHOSPHORUS AS P, IN MILLIGRAMS PER LITER
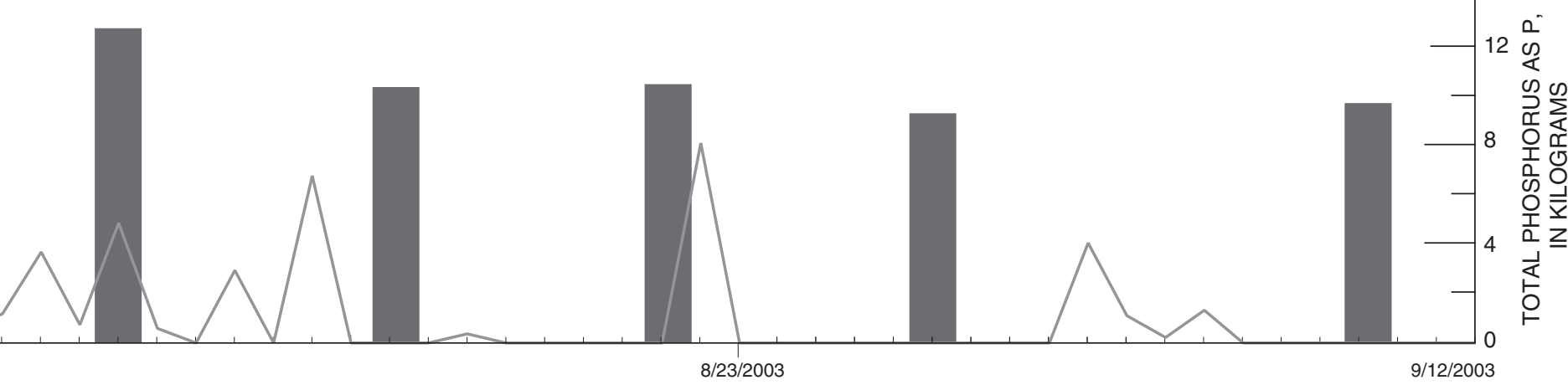
Table 12. Estimated phosphorus storage in the Hudson, Massachusetts, impoundment sections, July to September 2003. $\left[\mathrm{m}^{3}\right.$, cubic meter $]$

\begin{tabular}{|c|c|c|c|c|c|c|c|c|c|}
\hline $\begin{array}{c}\text { Station number/ } \\
\text { range } \\
\text { of layer } \\
\text { thickness }\end{array}$ & $\begin{array}{c}\text { Layer } \\
\text { volume } \\
\left(\mathrm{m}^{3}\right)\end{array}$ & \multicolumn{8}{|c|}{ Total phosphorus mass, in kilograms, on sampling date } \\
\hline \multicolumn{10}{|c|}{ Station 17} \\
\hline $0-0.5$ & 15,000 & 1.52 & 2.18 & 1.27 & 2.28 & 2.05 & 1.58 & 1.23 & 1.23 \\
\hline $0.5-1.0$ & 9,400 & .95 & 1.36 & .80 & 1.43 & 1.28 & .99 & .77 & .77 \\
\hline $1.5-2.0$ & 2,200 & .24 & .35 & .19 & .33 & .30 & .23 & .28 & .92 \\
\hline $2.0-2.3$ & 220 & .02 & .03 & .02 & .03 & .03 & .02 & .03 & .09 \\
\hline Total & & 3.33 & 4.76 & 2.75 & 4.92 & 4.43 & 3.43 & 2.90 & 4.42 \\
\hline \multicolumn{10}{|c|}{ Station 20} \\
\hline Total & & 1.11 & 0.90 & 2.05 & 0.98 & 0.73 & 1.13 & 0.93 & 1.27 \\
\hline \multicolumn{10}{|c|}{ Station 27} \\
\hline $0-0.5$ & 5,100 & 0.49 & 0.61 & 0.65 & 0.70 & 0.07 & 0.59 & 0.53 & 0.38 \\
\hline $0.5-1.0$ & 7,400 & .81 & 1.08 & 1.42 & .93 & .37 & 1.17 & .76 & .67 \\
\hline $1.0-1.5$ & 920 & .11 & .16 & .24 & .10 & .08 & .18 & .23 & .10 \\
\hline $1.5-2.0$ & 440 & .05 & .08 & .11 & .05 & .04 & .09 & .17 & .05 \\
\hline Total & & 1.47 & 1.92 & 2.43 & 1.79 & 0.56 & 2.04 & 1.69 & 1.20 \\
\hline \multicolumn{10}{|c|}{ Station 29} \\
\hline $0-0.5$ & 9,200 & 0.91 & 1.26 & 0.84 & 1.40 & 1.29 & 0.95 & 0.80 & 0.74 \\
\hline $0.5-1.0$ & 7,900 & .78 & 1.09 & .72 & 1.21 & 1.12 & .86 & .64 & .65 \\
\hline $1.0-1.5$ & 6,600 & .66 & .91 & .60 & 1.01 & .93 & .76 & .54 & .56 \\
\hline $1.5-2.0$ & 3,200 & .36 & .44 & .29 & .50 & .46 & .38 & .31 & .28 \\
\hline $2.0-2.5$ & 900 & .12 & .13 & .09 & .14 & .13 & .02 & .09 & .08 \\
\hline $2.5-2.8$ & 90 & .01 & .01 & .01 & .01 & .01 & .01 & .01 & .01 \\
\hline Total & & 2.84 & 3.84 & 2.54 & 4.28 & 3.94 & 2.99 & 2.38 & 2.31 \\
\hline $\begin{array}{c}\text { Total in all } \\
\text { sections }\end{array}$ & & 9.49 & 12.44 & 10.46 & 12.90 & 10.50 & 10.62 & 9.42 & 9.88 \\
\hline
\end{tabular}




\section{Mass Balance (Chloride:Total Phosphorus)}

To determine whether there was a net export of phosphorus from the Hudson impoundment as a result of sediment release, the ratio of chloride to total phosphorus in the water column was traced during the study (table 13). With no known inputs of phosphorus or chloride besides inflowing water or sediment, sediment release would be expected to cause increases in total $\mathrm{P}$ concentrations and a lowering of the ratio. Comparison of the ratio for the upstream, influent site (station 17) with the downstream outflow site (station 37) demonstrated no decreasing trend from upstream to downstream, as would be expected if sediments released phosphorus that was transported to the outflow; the values were not statistically different $(\mathrm{p}=0.3551)$. This information suggests that there was no net gain of total phosphorus in the water column from the upstream to the downstream end of the impoundment. However, the data leave open the possibility that any phosphorus releases were rapidly cycled internally, either taken up by rooted or floating plant life or settled to the bottom as particulate matter.

\section{Phosphorus Dynamics in the Hudson Impoundment}

Phosphorus release from sediments is largely limited to those parts of the impoundment in which DO becomes depleted near the sediment-water interface; this depletion mainly occurs in offchannel areas where advection does not cause mixing. Because the temperature profiles do not indicate strong stratification, these low DO conditions probably do not persist for long periods of time; they may easily be disrupted by wind-induced mixing or light rain storms that increase local flows. The results of the phosphorus-dynamics study in the Hudson impoundment suggest that sediment release of phosphorus does not substantially affect the mass of phosphorus in the impoundment's water column; from the hypoxic zone nearest the impoundment bottom, the DO concentrations increase toward the water surface. Two phenomena may prevent sediment phosphorus from mixing throughout the water column. First, high concentrations of nitrate may maintain high redox potentials and keep the iron in an oxidized state. Second, any phosphorus that is not taken up by plants after being released from the sediments may form colloids with iron hydroxides in the vicinity of the sediment-water interface; the precipitation of the colloids would inhibit phosphorus movement from sediments to the water column. However, the elevated mean and median concentrations of total phosphorus and orthophosphorus in the embayment areas of the impoundment in comparison to the main channel suggest that morphology and hydrodynamics play a large role in phosphorus dynamics in these impoundments. A more detailed phosphorusbudget study, including phosphorus transport and deposition and detailed analysis of the forms of phosphorus, might help define the effect of sediment phosphorus on the overall water quality in this and the other Assabet River impoundments.

Table 13. Ratios of chloride to total phosphorus at the inflow and outflow of the Hudson, Massachusetts, impoundment, July to September 2003.

\begin{tabular}{ccc}
\hline Date & $\begin{array}{c}\text { Inflow } \\
\text { (station 17) }\end{array}$ & $\begin{array}{c}\text { Outflow } \\
\text { (station 37) }\end{array}$ \\
\hline $7-24-03$ & 810 & 890 \\
$7-29-03$ & 1,700 & 1,600 \\
$8-07-03$ & 720 & 720 \\
$8-13-03$ & 820 & 820 \\
$8-21-03$ & 1,200 & 1,200 \\
$8-28-03$ & 2,000 & 1,700 \\
$9-08-03$ & 1,800 & 1,800 \\
\hline
\end{tabular}




\section{Summary}

This study of the quantity, distribution, and chemistry of sediments in six impoundments on the Assabet River was undertaken during the summer and early fall of 2003 in cooperation with the Massachusetts Department of Environmental Protection and the U.S. Environmental Protection Agency. The results of the study provide information to enable managers, regulators, and other stakeholders to make informed decisions regarding the management of sediment to improve the river's sediment and water quality.

This two-part report provides the results of an assessment of the sediment extent and chemistry in six impoundments in the Assabet River and describes the study of the potential for the release of phosphorus from sediment to affect water quality in the Hudson impoundment. Obtaining data about the distribution of phosphorus in the sediments and the concentrations of phosphorus in the water column links the two parts of this study. Sediment volumes in the impoundments ranged from 380 cubic meters to 580,000 cubic meters. The interpretations of bulk-sediment chemistry data in this report include results of analyses for polycyclic (or polynuclear) aromatic hydrocarbons (PAHs), polychlorinated biphenyls (PCBs), extractable petroleum hydrocarbons (EPH), reactive sulfide, and a selected group of metals and other elements, including phosphorus. Contract laboratories were unable to obtain data for organochlorine pesticides and volatile organic compounds (VOCs) because of matrix interference and sample dilution. The concentrations of these chemical constituents in the sediments are compared to standards for the disposal of dredged hazardous materials, for human contact, and for potential effects, including toxicity, on aquatic organisms.

The incidence of toxicity calculations show that approximately one third of the surficial sediment samples may be expected to have some toxic effect on test organisms. These effects may include mortality, diminished growth, and reduced reproductive capacity. Although the database used to estimate the incidence of toxicity did not contain results of toxicity testing for New England sediments, the calculated values are based on contaminant concentrations and should not be affected by regional differences. If no action is taken to mitigate the effects of sediment toxicity, efforts to restore the Assabet River may not be fully successful.

Bulk-sediment phosphorus concentrations generally decreased with depth below the sediment surface and generally increased in the downstream direction. Concentrations of phosphorus in the bulk-sediment samples ranged from less than 0.1 percent to 0.86 percent. If the amount of sediment removal required to deplete the mass of phosphorus to levels that will not adversely affect water-column concentrations of phosphorus can be calculated, then the bulk-sedimentphosphorus data should prove useful in mapping the areas to be dredged. However, the relations between bulk-sediment- phosphorus concentrations and phosphorus availability as an aquatic-plant nutrient have not been determined in the six impoundments that are the subjects of this study.

The analytical results of the first part of the study show that the distribution of potentially hazardous or toxic materials in the sediments is extremely complex. Concentrations of toxic metals, PAHs, and PCBs exceeded U.S. Environmental Protection Agency guidelines for the protection of aquatic life in most of the impoundments. PCBs were not detected only in the Hudson impoundment. The Powdermill impoundment had the largest number of contaminants exceeding Massachusetts Department of Environmental Protection guidelines for landfill disposal of sediments.

During the two-month period of the study of the Hudson impoundment, the water column in the areas of the impoundment studied did not stratify long enough to allow substantial amounts of phosphorus to be released from underlying sediments. High concentrations of nitrate in the water column may also have prevented favorable conditions for phosphorus release. A comparison of changes in phosphorus storage did not indicate that the total mass of phosphorus increased with time, only to be dispersed by storm-generated increases in streamflow; rather, there was a suggestion that increases in the calculated mass of phosphorus were associated with storm runoff into the impoundment. On the basis of the ratio of chloride to total phosphorus, changes in phosphorus concentrations in the stratified areas of the impoundment did not lead to increases in the mass of phosphorus in the water column and to increases in the net phosphorus transport out of the impoundment. This result indicates that phosphorus was either released from the sediments in less than measurable amounts or that it was absorbed quickly before it could be transported out of the impoundment.

\section{Acknowledgments}

Successful completion of the mapping, sediment sampling field work, and sample processing could not have been accomplished without the assistance of the USGS Massachusetts-Rhode Island Water Science Center staff members David Armstrong, Lora Barlow, Kimberly Campo, Leslie DeSimone, Jonathan King, Paul Nardone, Lance Ostiguy, Vicki-Rose Siegel, Britt Stock, Bruce Taggart, and Marcus Waldron. USGS colleague reviewers Jonathan Morrison and John Colman made valuable technical recommendations that substantially improved this report. The entire staff of the Water Science Center's Publications Unit - Mary Ashman, Mark Bonito, Matthew Cooke, Christine Mendelsohn, and Anne Weaver - is thanked for their patience and support. The Organization for the Assabet River not only enthusiastically encouraged this project, but also provided maps and insights that made our work easier. 


\section{References}

Andersen, J.M., 1982, Effect of nitrate concentration in lake water on phosphate release from the sediment: Water Research, v. 16, p. 1119-1126.

Boström, B., Jansson, M., and Forsberg, C., 1982, Phosphorus release from lake sediments: Archiv für Hydrobiologie Beiheft Ergebnisse der Limnologie, v. 18, p. 5-59.

Chalmers, A.T., 2002, Trace elements and organic compounds in streambed sediment and fish tissue of coastal New England streams, 1998-99, U.S. Geological Survey WaterResources Investigations Report 02-4179, 30 p.

ENSR International, 2001, SuAsCo Watershed Assabet River TMDL Study, Phase One: Assessment, Final Report, variously paged.

ENSR International, 2004, SuAsCo Watershed Assabet River TMDL Study, Phase Two: Analysis, Final Report, variously paged.

ESRI, Inc., 2002, Arc/Info, version 8.3, Redlands, CA.

Fishman, M.J., ed., 1993, Methods of analysis by the U.S. Geological Survey National Water Quality LaboratoryDetermination of inorganic and organic constituents in water and fluvial sediments: U.S. Geological Survey OpenFile Report 93-125, 217 p.

Golterman, H.L., 2004, The chemistry of phosphate and nitrogen compounds in sediments: Dordrecht, The Netherlands, Kluwer Academic Publications, 251 p.

Harris, S.L., 1997, Inorganic and organic constituents and grain-size distribution in streambed sediment and ancillary data for the Connecticut, Housatonic, and Thames River Basins Study Unit, 1992-94: U.S. Geological Survey OpenFile Report 96-397, 39 p.

Ingersoll, C.G., McDonald, D.D., Ning, W., Crane, J.L., Field, L.J., Haverland, P.S., Kemble, N.E., Lindskoog, R.A., Severn, C., and Smorong, D.E., 2001, Predictions of sediment toxicity using consensus-based freshwater sediment quality guidelines: Archives of Environmental Contamination and Toxicology, v. 41, p. 81-21.

Massachusetts Department of Environmental Protection, 1995, Interim policy for sampling, analysis, handling and tracking requirements for dredged sediment reused or disposed at Massachusetts permitted landfills, accessed on June 24, 2005, at http://www.mass.gov/dep/bwp/dswm/files/dredge. htm 1
Massachusetts Department of Environmental Protection, 2002, Characterizing risks posed by petroleum contaminated sites: Implementation of the MADEP VPH/EPH Approach, last viewed on April 22, 2004 at http://www.mass.gov/dep/ bwsc/files/02-411.pdf.

Massachusetts Department of Environmental Protection, 2004, Method for the determination of extractable petroleum hydrocarbons (EPH), last viewed on December 15, 2004, at http://www.mass.gov/dep/bwsc/files/data/eph0504.pdf.

McDonald, D.D., Ingersoll, C.G., and Berger, T.S., 2000, Development and evaluation of consensus-based sediment quality guidelines for freshwater ecosystems: Archives of Environmental Contamination and Toxicology v. 39, p. $20-31$.

Mortimer, C.H., 1971, Chemical exchanges between sediments and water in the Great Lakes - Speculations on probable regulatory mechanisms: Limnology and Oceanography, v. 16 , p. $387-404$.

Nürnberg, G.K.,1988, Prediction of phosphorus release rates from total and reductant-soluble phosphorus in anoxic lake sediments: Canadian Journal of Fisheries and Aquatic Science, v. 45, p. 453-461.

Patton, C.J., and Truitt, E.P., 1992, Methods of analysis by the U.S. Geological Survey National Water Quality Laboratory-Determination of total phosphorus by a Kjeldahl digestion method and an automated colorimetric finish that includes dialysis: U.S. Geological Survey OpenFile Report 92-146, 39 p.

Robinson, G.R., Jr., Kapo, K.E., and Grossman, J.N., 2004, Chemistry of stream sediments and surface waters in New England, U.S. Geological Survey Open-File Report 20041026, accessed on April 26, 2004, at http://pubs.usgs.gov/ of/2004/1026/

Scott, J. C., 1990, Computerized stratified random site-selection approaches for design of a ground-water-quality sampling network: U.S. Geological Survey Water-Resources Investigations Report 90-4101, 109 p.

Somers, C.M., McCarry, B.E., Malek, F., and Quinn, J.S., 2004, Reduction of particulate air pollution lowers the risk of heritable mutations in mice: Science, v. 304, p. 10081010 .

Stauffer, R.E., 1983, Determination of arsenic and phosphorus compounds in groundwater with reduced molybdenum blue: Analytical Chemistry, v. 555, p. 1205-1210. 
Strickland, J.D.H., and Parsons, T.R., 1968, A practical handbook of seawater analysis: Ottawa, Canada, Fisheries Research Board of Canada, Special Publication No. 167, $311 \mathrm{p}$.

Tiren, T., and Petterson, K., The influence of nitrate on the phosphorus flux to and from oxygen depleted lake sediments: Hydrobiologia v. 120, p. 207-223.

U.S. Environmental Protection Agency, 1996a, Volatile organic compounds by gas chromatography/mass spectrometry (GC/MS), accessed on March 3, 2004, at http://www. epa.gov/epaoswer/hazwaste/test/pdfs/8260b.pdf.

U.S. Environmental Protection Agency, 1996b, Titrimetric procedure for acid-soluble and acid insoluble sulfides, accessed on March 5, 2004 at http://www.epa.gov/ epaoswer/hazwaste/test/pdfs/9034.pdf.
U.S. Environmental Protection Agency, 1996c, Polychlorinated biphenyls (PCB) by gas chromatography, accessed on March 5, 2004, at http://www.epa.gov/epaoswer/hazwaste/ test/pdfs/8082.pdf

U.S. Environmental Protection Agency, 1996d, Organochlorine pesticides by gas chromatography, accessed on March 5, 2004, at http://www.epa.gov/epaoswer/hazwaste/ test/pdfs/8081a.pdf.

U.S. Environmental Protection Agency, 2000, Standard operating procedure for the extraction and analysis of polynuclear aromatic hydrocarbons (PAH) in solid samples using SIMBC/MS analysis, USEPA Region I SOP: EIA-PAH in soil (PAH) PAHSOLL.SOP, 33 p.

Zimmerman, M.J., and Breault, R.F., 2003, Sediment quantity and quality in three impoundments in Massachusetts, U.S. Geological Survey Water-Resources Investigations Report 03-4013, $36 \mathrm{p}$. 
Tables 14-17 

Table 14. Concentrations of selected metals in sediment samples from six impoundments in the Assabet River Basin, Massachusetts, 2003.

[Quantity in brackets is detection limit. All values are in milligrams per kilogram. Map ID: The identifier associated with a sampling site on a map (figs. 9-14). Sample ID: Identifier for a sample collected from a particular core, arranged alphabetically from the top of the core, with Q designating a replicate sample. NA, not applicable because of nondetects; <, actual value is less than value shown]

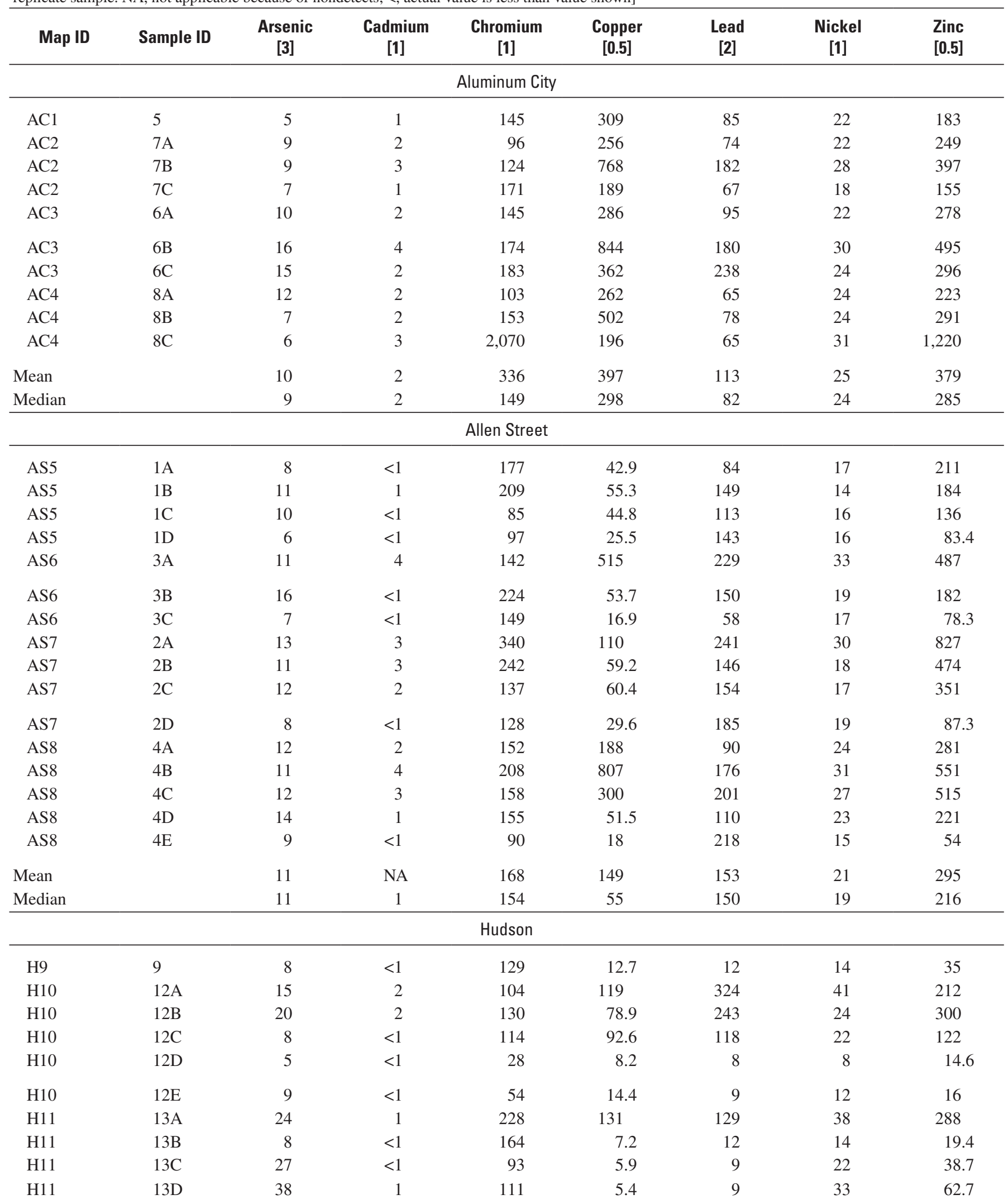


Table 14. Concentrations of selected metals in sediment samples from six impoundments in the Assabet River Basin, Massachusetts, 2003.-Continued

[Quantity in brackets is detection limit. All values are in milligrams per kilogram. Map ID: The identifier associated with a sampling site on a map (figs. 9-14). Sample ID: Identifier for a sample collected from a particular core, arranged alphabetically from the top of the core, with Q designating a replicate sample. NA, not applicable because of nondetects; <, actual value is less than value shown]

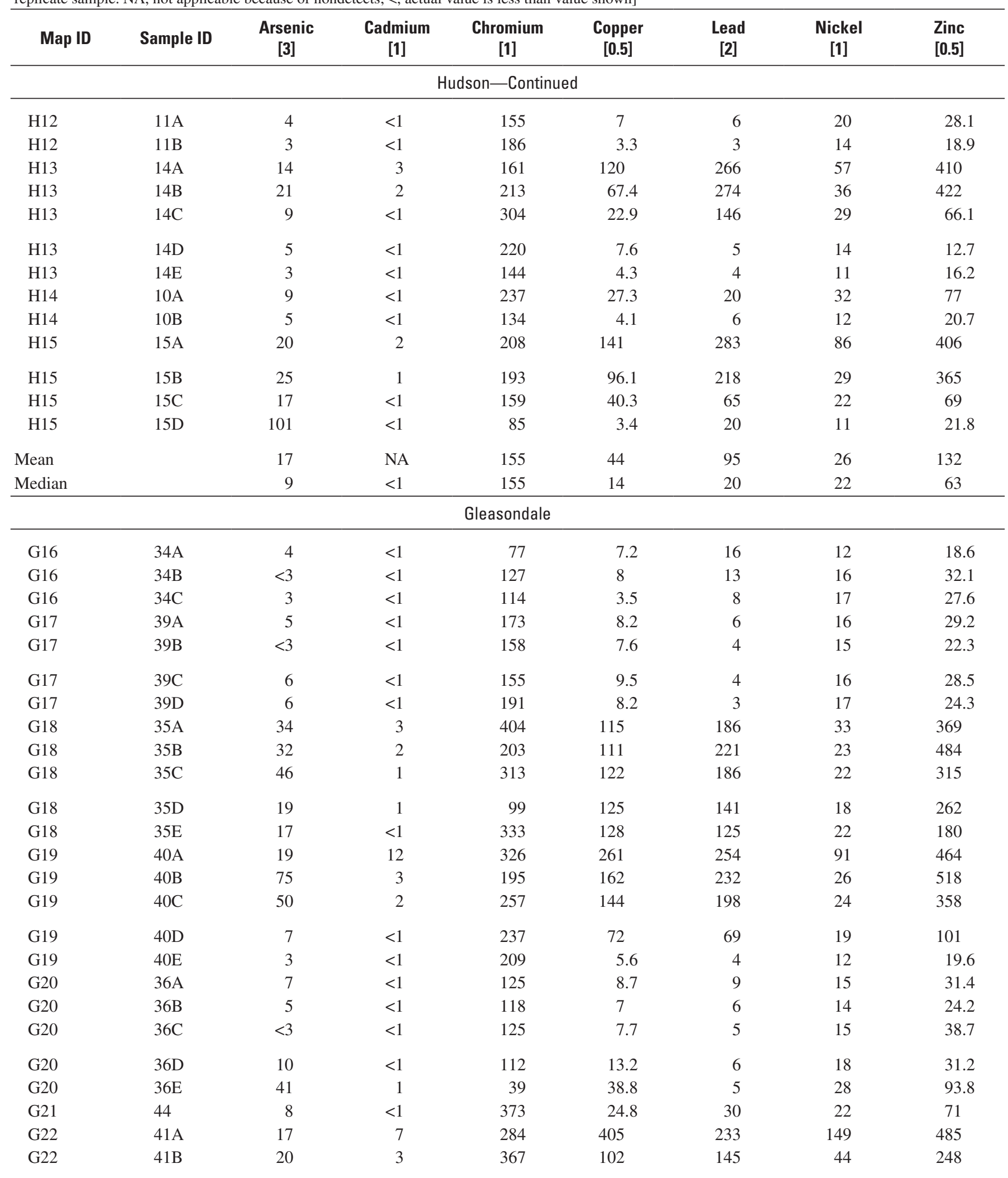


Table 14. Concentrations of selected metals in sediment samples from six impoundments in the Assabet River Basin, Massachusetts, 2003.-Continued

[Quantity in brackets is detection limit. All values are in milligrams per kilogram. Map ID: The identifier associated with a sampling site on a map (figs. 9-14). Sample ID: Identifier for a sample collected from a particular core, arranged alphabetically from the top of the core, with Q designating a replicate sample. NA, not applicable because of nondetects; <, actual value is less than value shown]

\begin{tabular}{|c|c|c|c|c|c|c|c|c|}
\hline Map ID & Sample ID & $\begin{array}{c}\text { Arsenic } \\
\text { [3] }\end{array}$ & $\begin{array}{c}\text { Cadmium } \\
\text { [1] }\end{array}$ & $\begin{array}{c}\text { Chromium } \\
\text { [1] }\end{array}$ & $\begin{array}{c}\text { Copper } \\
{[0.5]}\end{array}$ & $\begin{array}{c}\text { Lead } \\
\text { [2] }\end{array}$ & $\begin{array}{c}\text { Nickel } \\
\text { [1] }\end{array}$ & $\begin{array}{l}\text { Zinc } \\
{[0.5]}\end{array}$ \\
\hline \multicolumn{9}{|c|}{ Gleasondale-Continued } \\
\hline G22 & $41 \mathrm{C}$ & 14 & $<1$ & 409 & 81.6 & 87 & 22 & 142 \\
\hline G23 & $37 \mathrm{~A}$ & $<3$ & $<1$ & 219 & 10.2 & 17 & 15 & 31.7 \\
\hline G23 & $37 \mathrm{~B}$ & 7 & $<1$ & 246 & 9.2 & 12 & 13 & 36.8 \\
\hline G24 & $42 \mathrm{~A}$ & 14 & $<1$ & 101 & 7.1 & 20 & 17 & 33.7 \\
\hline G24 & $42 \mathrm{~B}$ & 9 & $<1$ & 149 & 4.6 & 9 & 17 & 25.3 \\
\hline G25 & 45 & 5 & $<1$ & 223 & 7 & 9 & 11 & 23.7 \\
\hline G26 & $38 \mathrm{~A}$ & 11 & $<1$ & 64 & 7.9 & 11 & 9 & 15 \\
\hline Mean & & 17 & NA & 205 & 61 & 68 & 24 & 134 \\
\hline Median & & 11 & $<1$ & 194 & 11 & 16 & 17 & 37 \\
\hline \multicolumn{9}{|c|}{ Ben Smith } \\
\hline BS28 & $16 \mathrm{~A}$ & 9 & $<1$ & 157 & 23.2 & 30 & 20 & 82.8 \\
\hline BS28 & $16 \mathrm{~B}$ & 8 & $<1$ & 195 & 11.4 & 15 & 15 & 50.1 \\
\hline BS29 & $18 \mathrm{~A}$ & 7 & $<1$ & 157 & 19.2 & 26 & 14 & 43.9 \\
\hline BS29 & $18 \mathrm{~B}$ & 6 & $<1$ & 100 & 5.4 & 13 & 9 & 5.7 \\
\hline BS29 & $18 \mathrm{C}$ & 5 & $<1$ & 174 & 3.5 & 12 & 16 & 9.8 \\
\hline BS31 & $19 \mathrm{C}$ & 17 & $<1$ & 210 & 72.6 & 74 & 23 & 112 \\
\hline BS31 & $19 \mathrm{D}$ & 5 & $<1$ & 197 & 7.5 & 9 & 20 & 21.6 \\
\hline BS31 & $19 \mathrm{E}$ & 6 & $<1$ & 236 & 8.3 & 6 & 22 & 16.8 \\
\hline BS32 & $20 \mathrm{~A}$ & 17 & 7 & 170 & 318 & 192 & 132 & 492 \\
\hline BS32 & $20 \mathrm{~B}$ & 35 & 5 & 173 & 124 & 263 & 36 & 481 \\
\hline BS32 & $20 \mathrm{C}$ & 6 & $<1$ & 116 & 14.8 & 12 & 16 & 34.4 \\
\hline BS32 & $20 \mathrm{D}$ & 6 & $<1$ & 48 & 9.4 & 6 & 12 & 23 \\
\hline BS32 & $20 \mathrm{E}$ & 9 & $<1$ & 165 & 10.6 & 6 & 19 & 29.8 \\
\hline BS33 & $21 \mathrm{~A}$ & 35 & 2 & 179 & 123 & 144 & 26 & 334 \\
\hline BS33 & $21 \mathrm{~B}$ & 8 & $<1$ & 85 & 14.4 & 20 & 16 & 30.9 \\
\hline BS33 & $21 \mathrm{C}$ & 4 & $<1$ & 85 & 7.5 & 8 & 14 & 21.6 \\
\hline BS33 & $21 \mathrm{D}$ & 4 & $<1$ & 132 & 8.9 & 7 & 17 & 25.1 \\
\hline BS33 & $21 \mathrm{E}$ & 3 & $<1$ & 151 & 8.3 & 6 & 16 & 26.6 \\
\hline
\end{tabular}


Table 14. Concentrations of selected metals in sediment samples from six impoundments in the Assabet River Basin, Massachusetts, 2003.-Continued

[Quantity in brackets is detection limit. All values are in milligrams per kilogram. Map ID: The identifier associated with a sampling site on a map (figs. 9-14). Sample ID: Identifier for a sample collected from a particular core, arranged alphabetically from the top of the core, with Q designating a replicate sample. NA, not applicable because of nondetects; <, actual value is less than value shown]

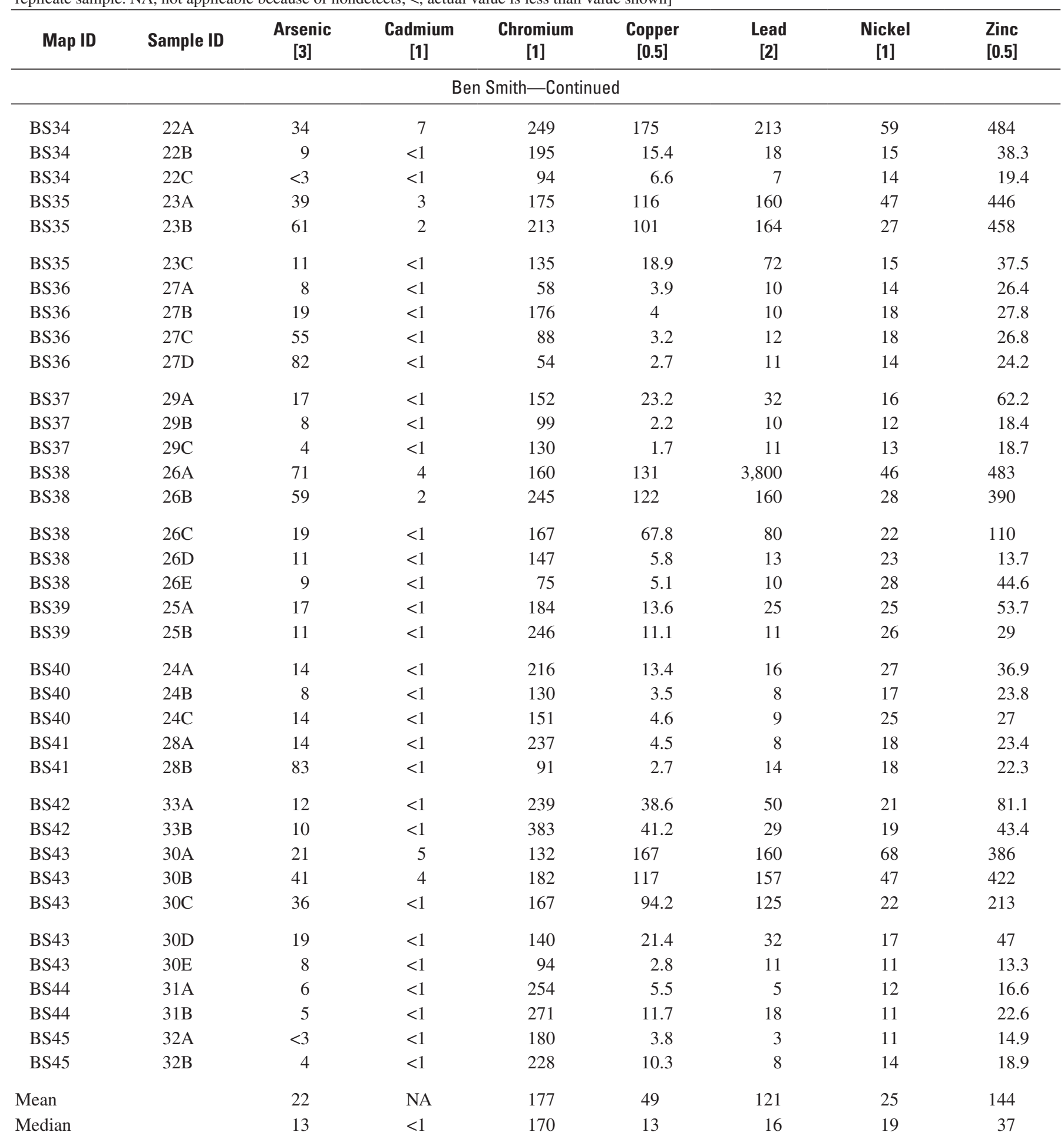


Table 14. Concentrations of selected metals in sediment samples from six impoundments in the Assabet River Basin, Massachusetts, 2003.-Continued

[Quantity in brackets is detection limit. All values are in milligrams per kilogram. Map ID: The identifier associated with a sampling site on a map (figs. 9-14). Sample ID: Identifier for a sample collected from a particular core, arranged alphabetically from the top of the core, with Q designating a replicate sample. NA, not applicable because of nondetects; <, actual value is less than value shown]

\begin{tabular}{|c|c|c|c|c|c|c|c|c|}
\hline Map ID & Sample ID & $\begin{array}{c}\text { Arsenic } \\
\text { [3] }\end{array}$ & $\begin{array}{c}\text { Cadmium } \\
\text { [1] }\end{array}$ & $\begin{array}{c}\text { Chromium } \\
\text { [1] }\end{array}$ & $\begin{array}{c}\text { Copper } \\
{[0.5]}\end{array}$ & $\begin{array}{c}\text { Lead } \\
\text { [2] }\end{array}$ & $\begin{array}{c}\text { Nickel } \\
{[1]}\end{array}$ & $\begin{array}{l}\text { Zinc } \\
{[0.5]}\end{array}$ \\
\hline \multicolumn{9}{|c|}{ Powdermill } \\
\hline P46 & 48 & 21 & 2 & 899 & 280 & 233 & 40 & 289 \\
\hline P47 & 49 & 8 & $<1$ & 394 & 50.9 & 110 & 30 & 152 \\
\hline P48 & $46 \mathrm{~A}$ & 34 & 1 & 1,290 & 257 & 259 & 26 & 162 \\
\hline P49 & 47 & 5 & $<1$ & 268 & 19.4 & 58 & 27 & 59.3 \\
\hline P50 & $52 \mathrm{~A}$ & 15 & 2 & 272 & 109 & 231 & 54 & 331 \\
\hline P50 & $52 \mathrm{~B}$ & 13 & 2 & 339 & 123 & 261 & 77 & 298 \\
\hline P50 & $52 \mathrm{C}$ & 11 & 1 & 311 & 78.3 & 244 & 41 & 183 \\
\hline P51 & $55 \mathrm{~B}$ & 58 & 3 & 1,830 & 386 & 343 & 24 & 1,010 \\
\hline P51 & $55 \mathrm{C}$ & $<3$ & $<1$ & 97 & 22.4 & 12 & 51 & 10.8 \\
\hline P51 & $55 \mathrm{D}$ & 6 & $<1$ & 128 & 40 & 7 & 52 & 17.5 \\
\hline P52 & $53 \mathrm{~A}$ & 16 & 2 & 399 & 100 & 167 & 56 & 354 \\
\hline P52 & $53 \mathrm{~B}$ & 13 & 4 & 404 & 184 & 371 & 53 & 339 \\
\hline P52 & $53 \mathrm{C}$ & 101 & 7 & 2,270 & 330 & 621 & 29 & 726 \\
\hline P52 & $53 \mathrm{D}$ & 20 & $<1$ & 421 & 194 & 115 & 21 & 163 \\
\hline P52 & $53 \mathrm{E}$ & 10 & $<1$ & 302 & 26.8 & 71 & 25 & 44.8 \\
\hline P53 & $56 \mathrm{~A}$ & 18 & 6 & 416 & 669 & 580 & 272 & 379 \\
\hline P55 & $51 \mathrm{C}$ & 9 & $<1$ & 173 & 6.2 & 7 & 22 & 31.4 \\
\hline P55 & $51 \mathrm{D}$ & 6 & $<1$ & 274 & 5.5 & 7 & 29 & 28.7 \\
\hline P55 & $51 \mathrm{E}$ & 4 & $<1$ & 240 & 5.9 & 7 & 30 & 29.3 \\
\hline P56 & $50 \mathrm{~A}$ & 17 & 6 & 332 & 720 & 411 & 179 & 572 \\
\hline P56 & $50 \mathrm{~B}$ & 28 & 10 & 786 & 910 & 1,250 & 84 & 1,200 \\
\hline P56 & $50 \mathrm{C}$ & 48 & 9 & 1,320 & 459 & 305 & 28 & 703 \\
\hline P56 & $50 \mathrm{D}$ & 9 & $<1$ & 187 & 23.7 & 40 & 26 & 48.2 \\
\hline P56 & $50 \mathrm{E}$ & $<3$ & $<1$ & 221 & 9.1 & 7 & 13 & 10.3 \\
\hline P57 & 57 & $<3$ & $<1$ & 272 & 18 & 45 & 30 & 66.9 \\
\hline Mean & & 25 & NA & 588 & 284 & 242 & 47 & 319 \\
\hline Median & & 17 & $<1$ & 311 & 78 & 167 & 30 & 163 \\
\hline
\end{tabular}




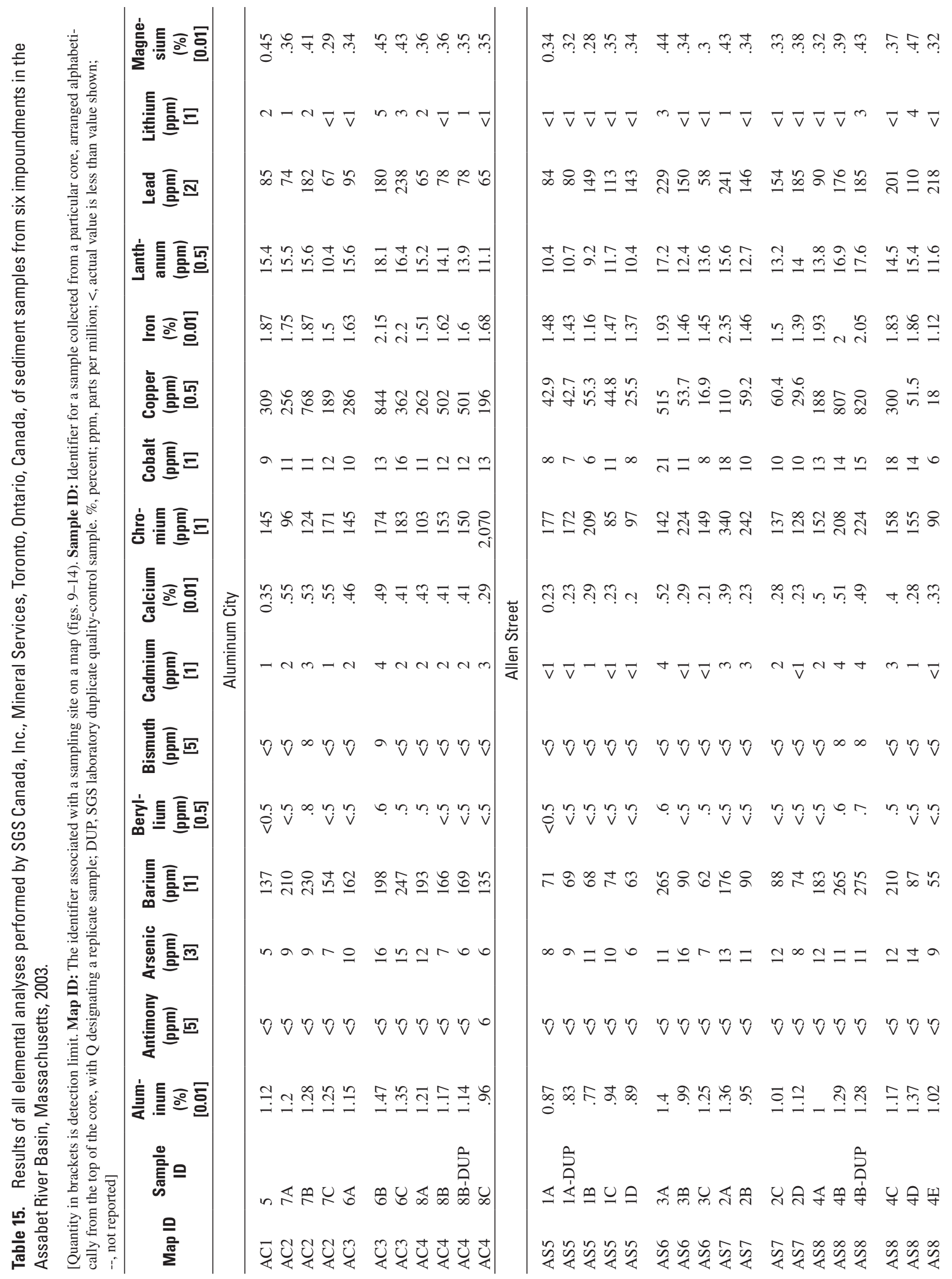




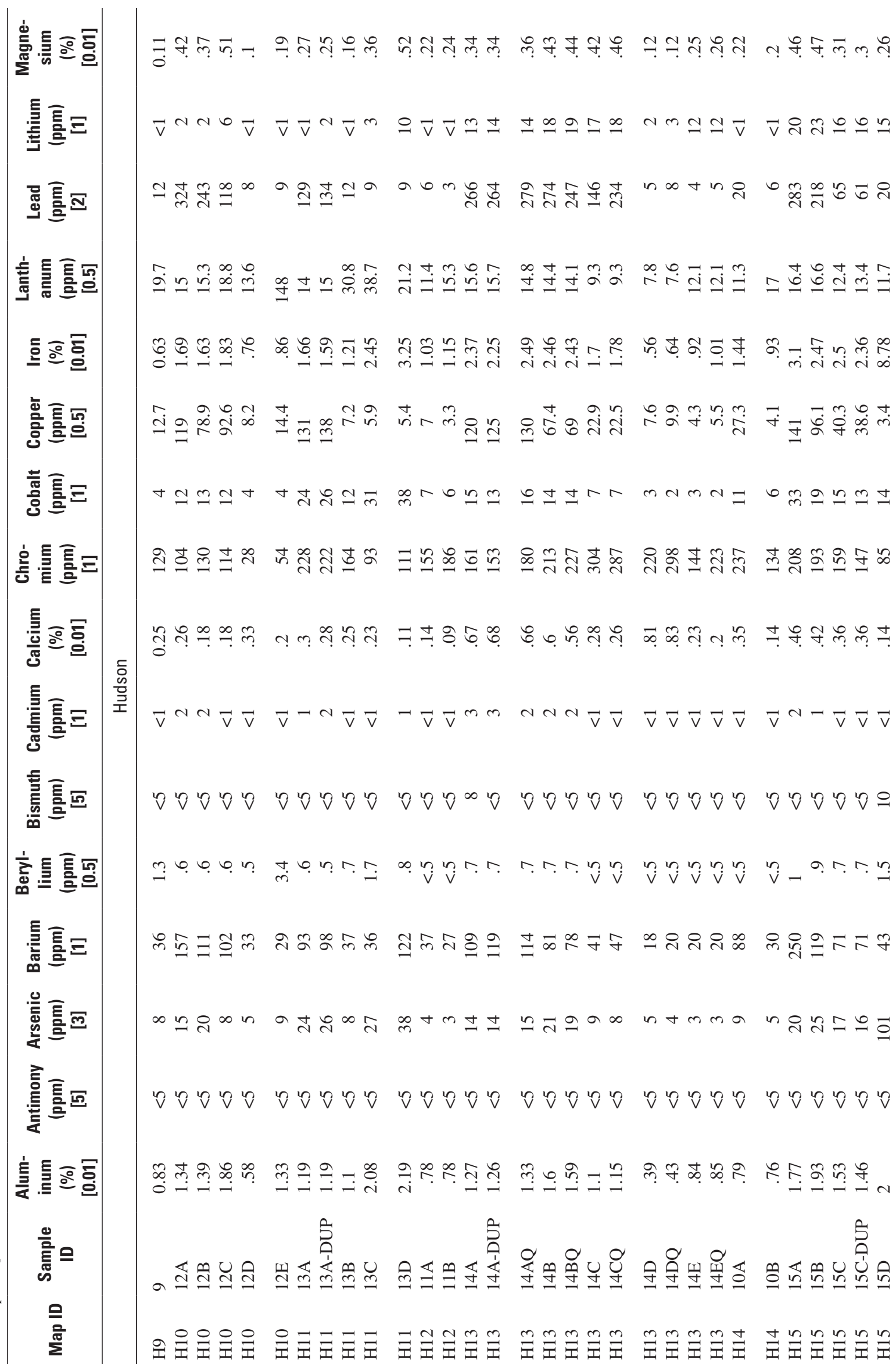




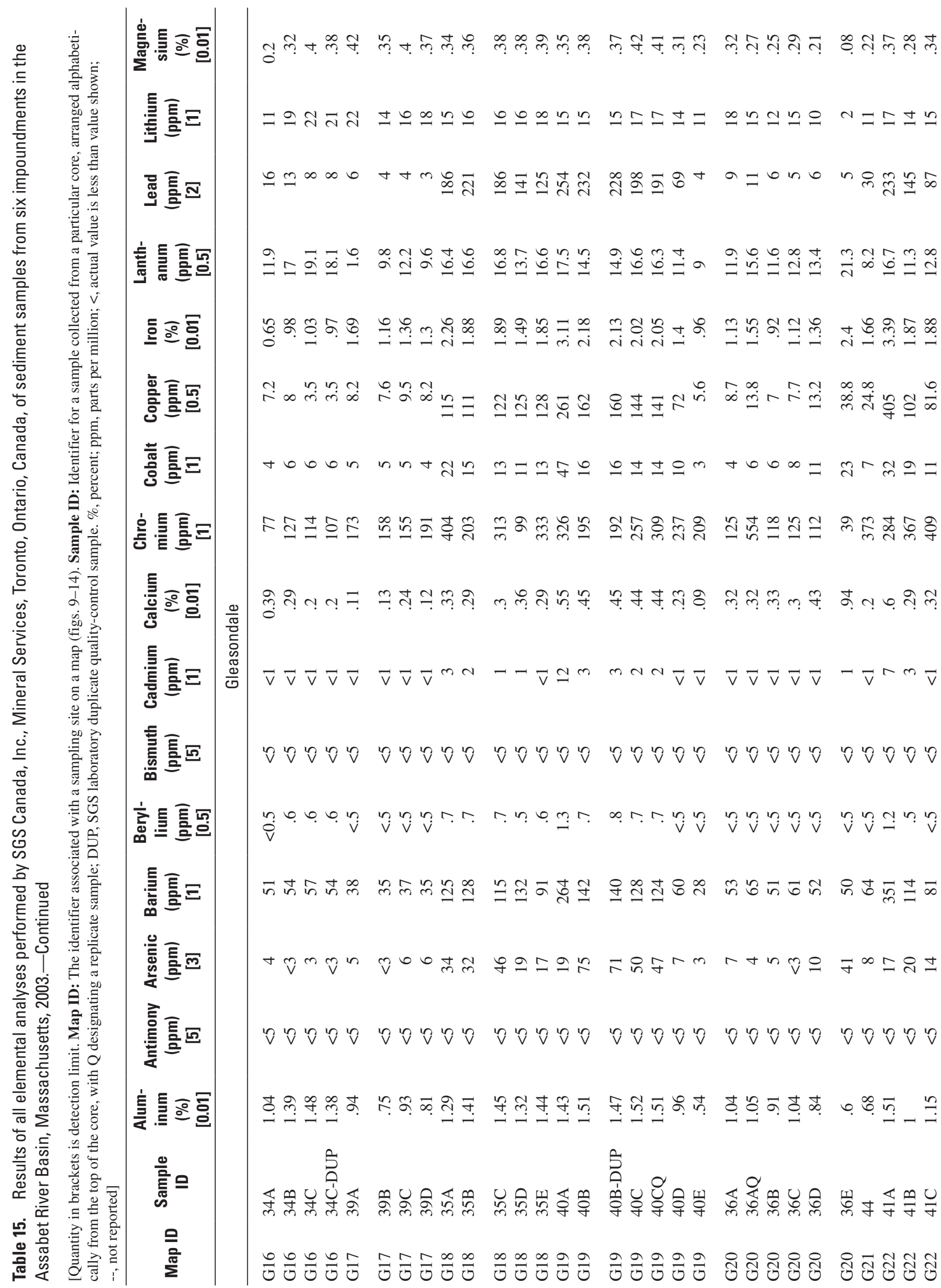




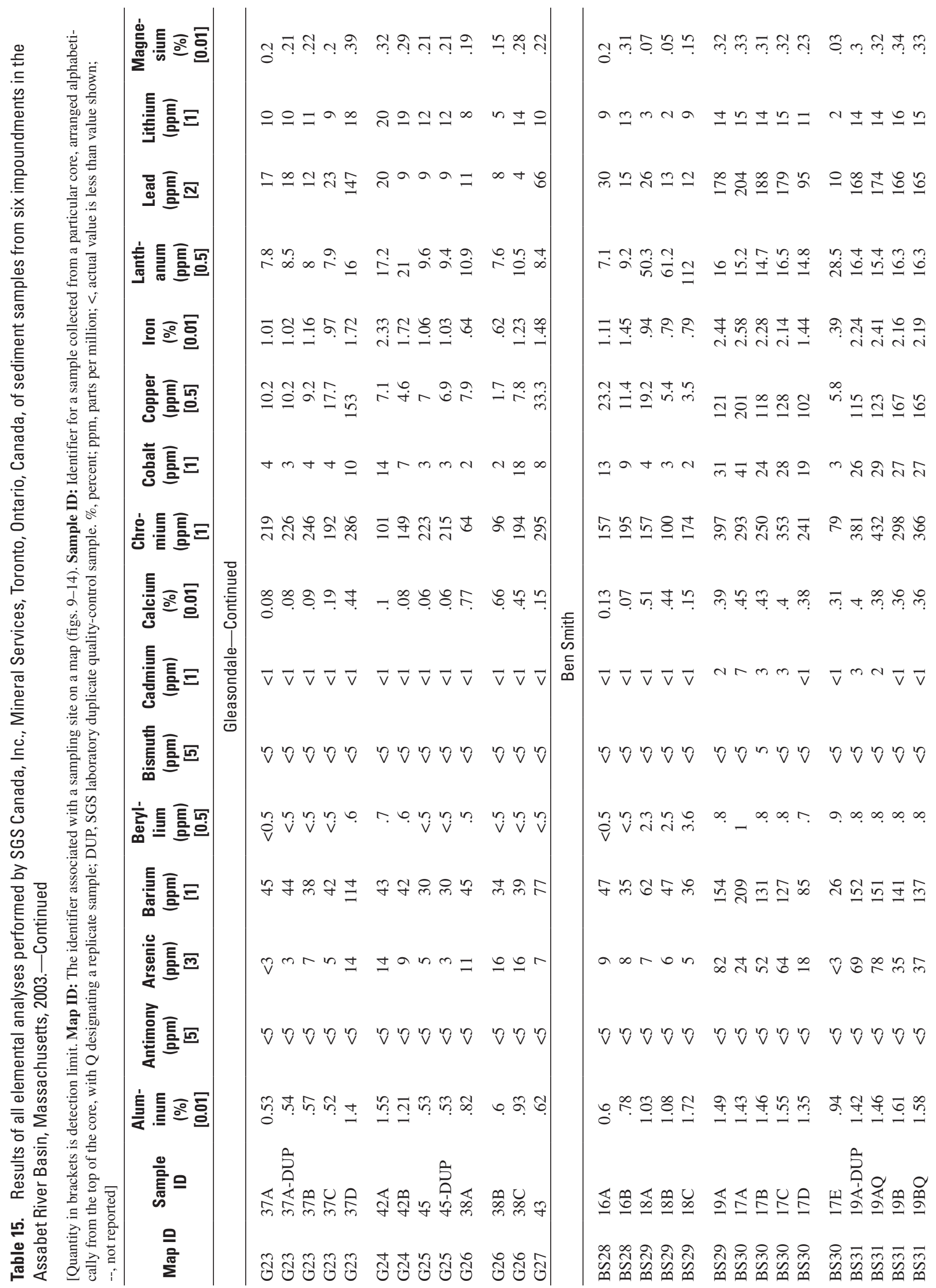




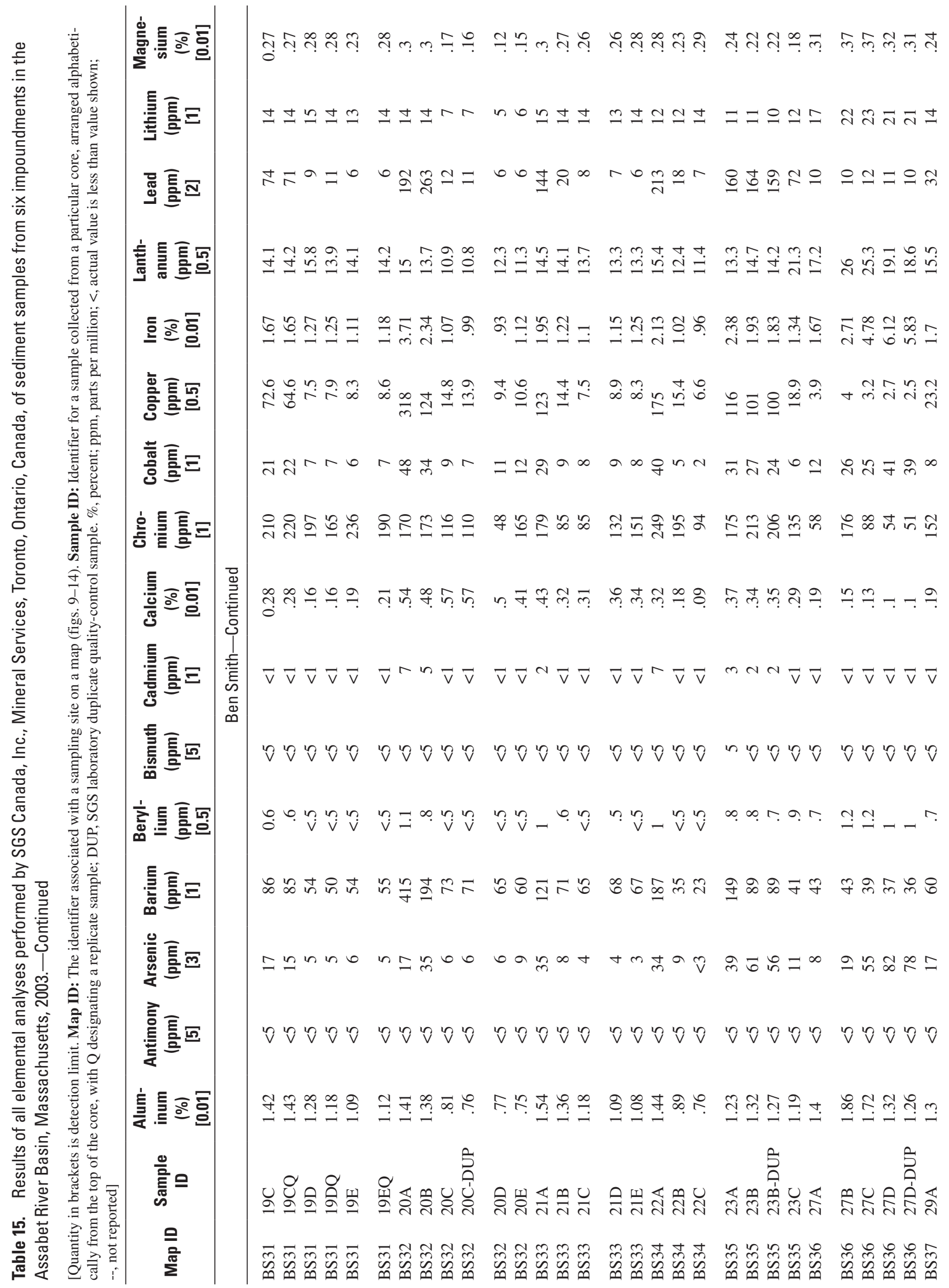




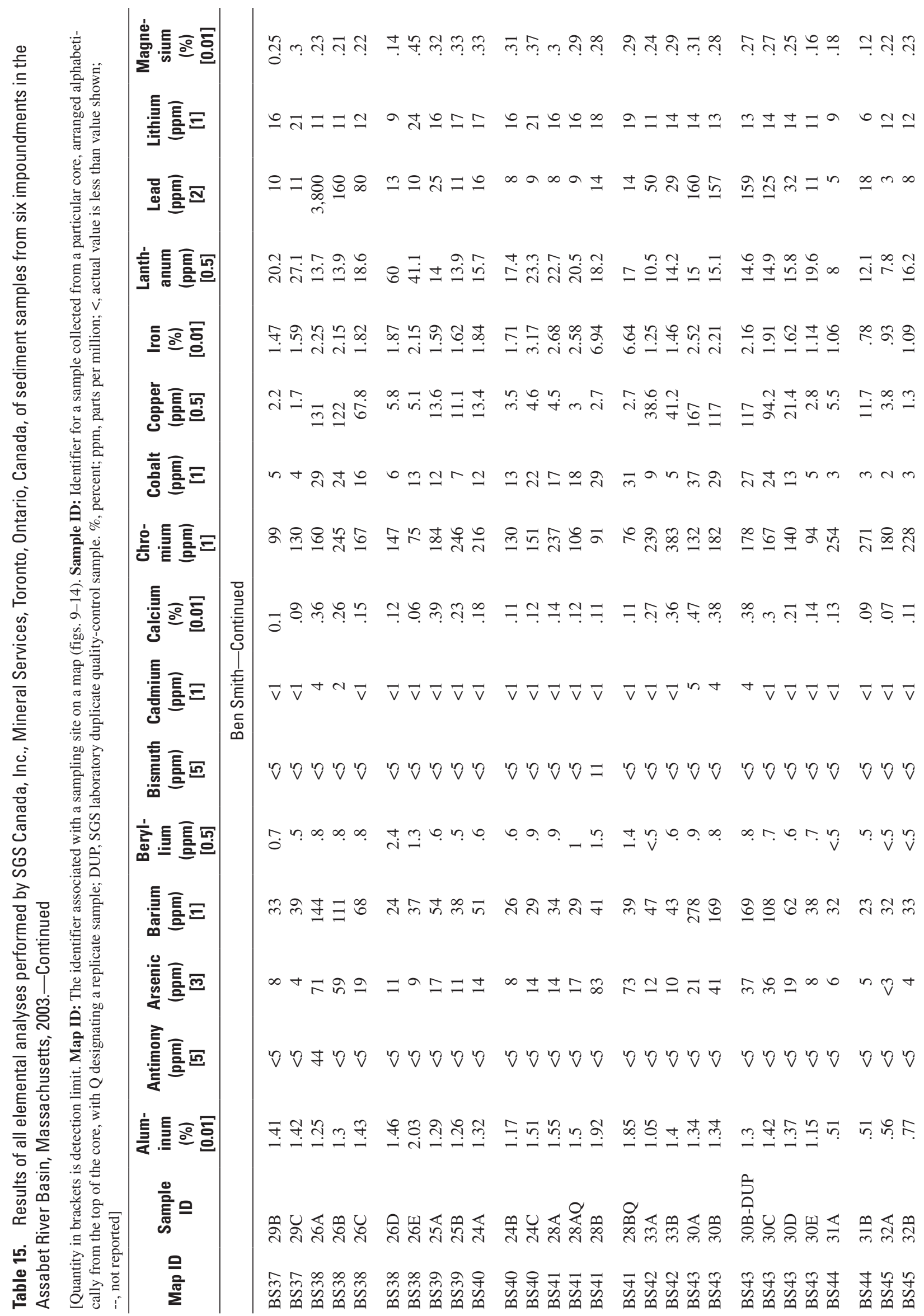




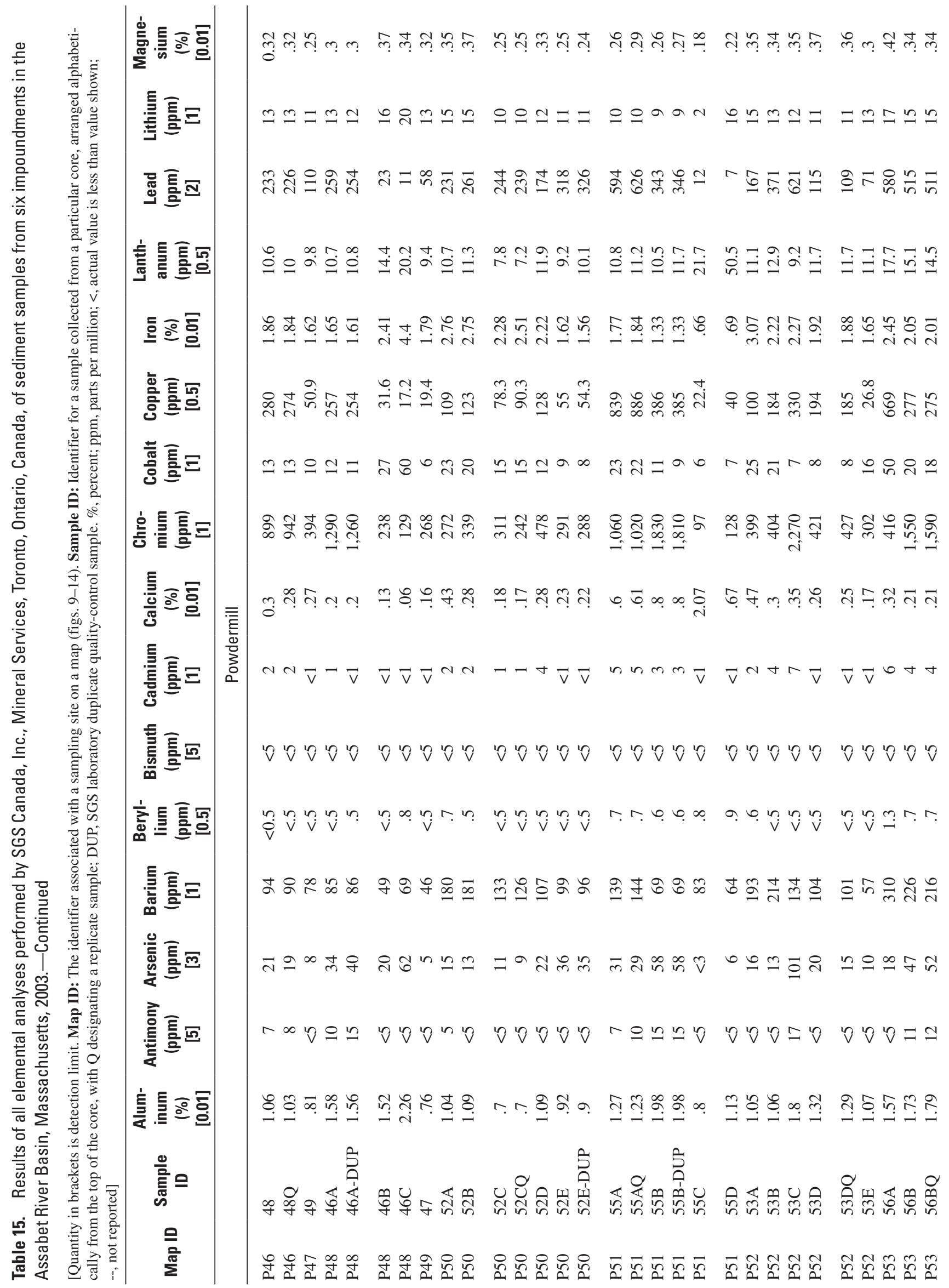




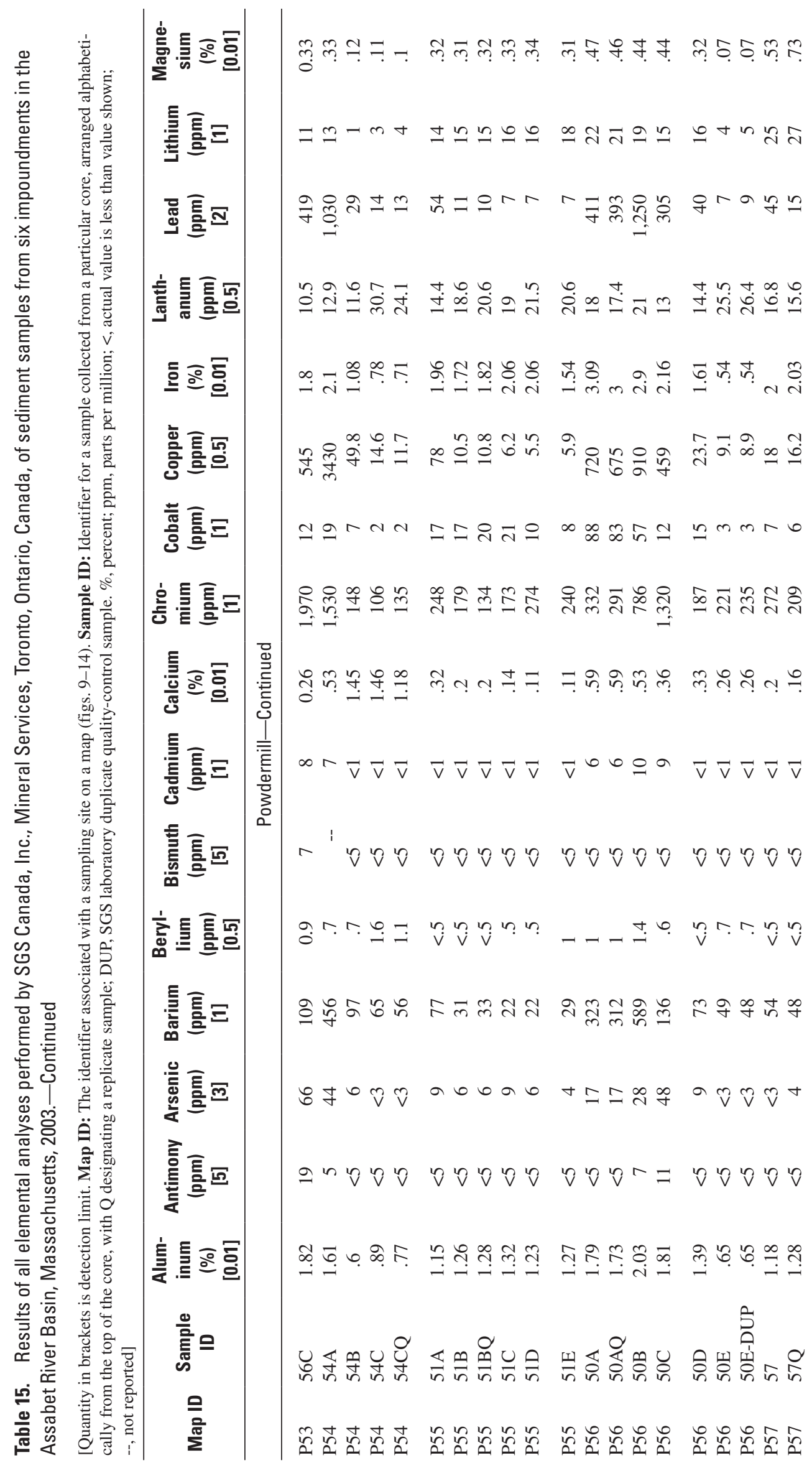




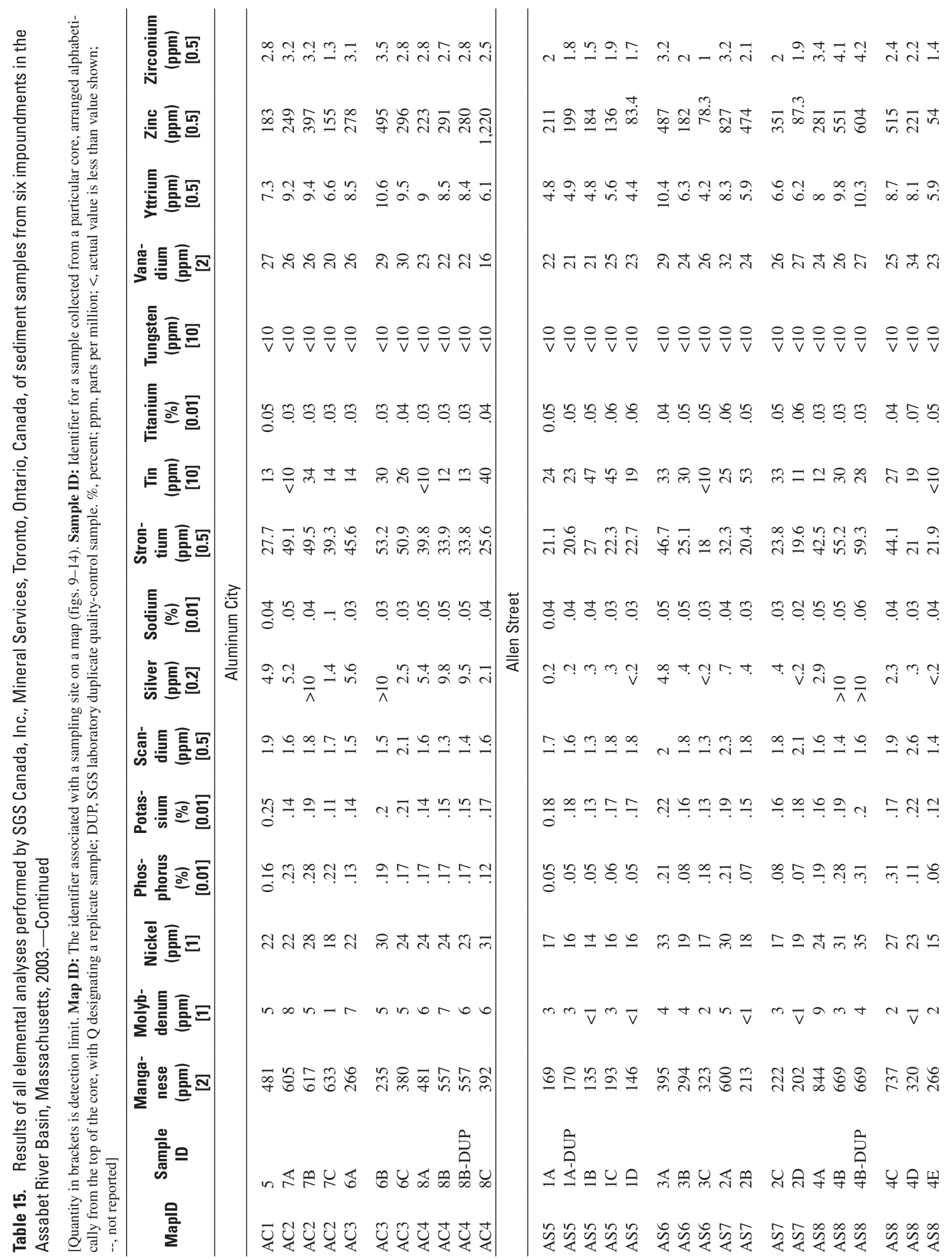




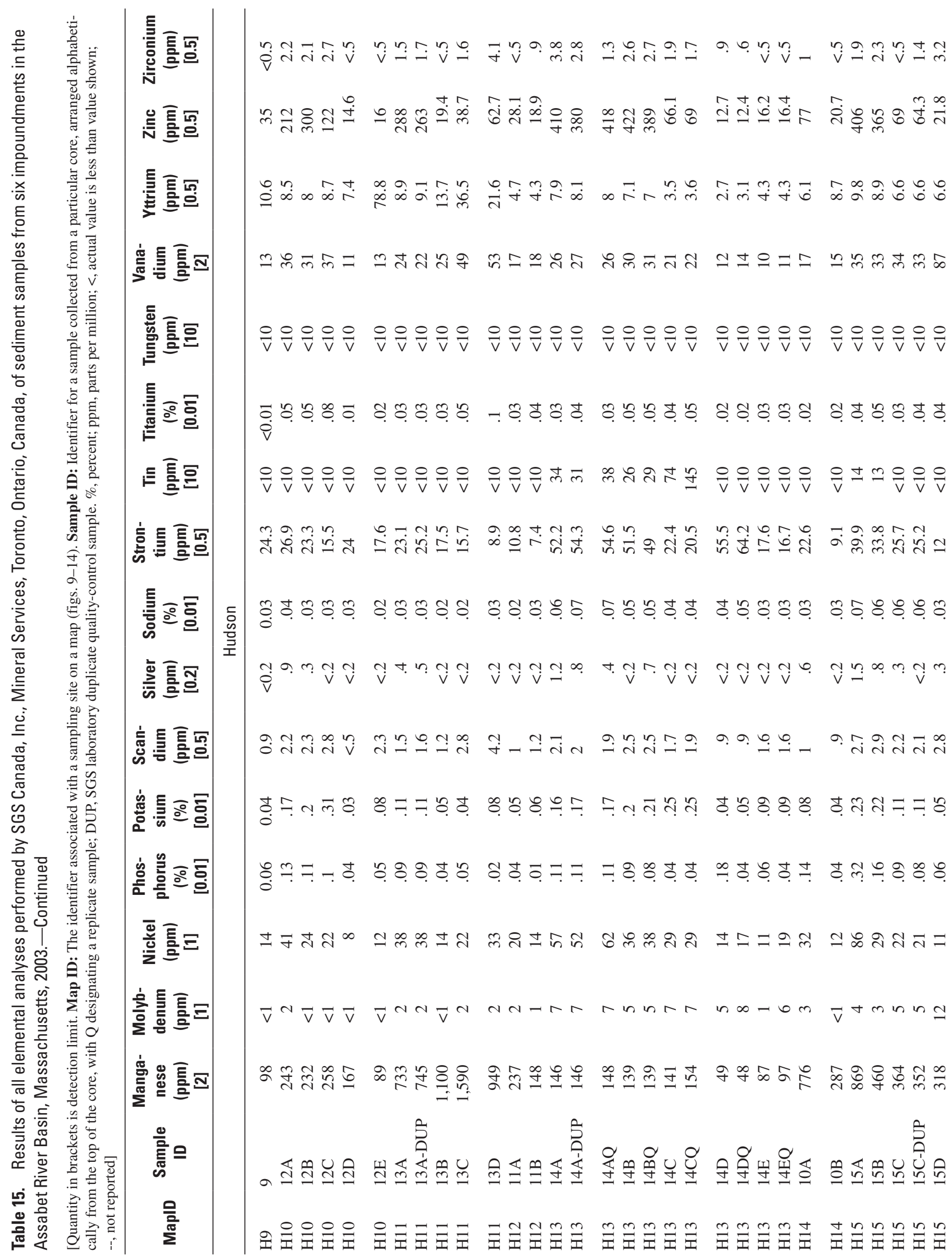




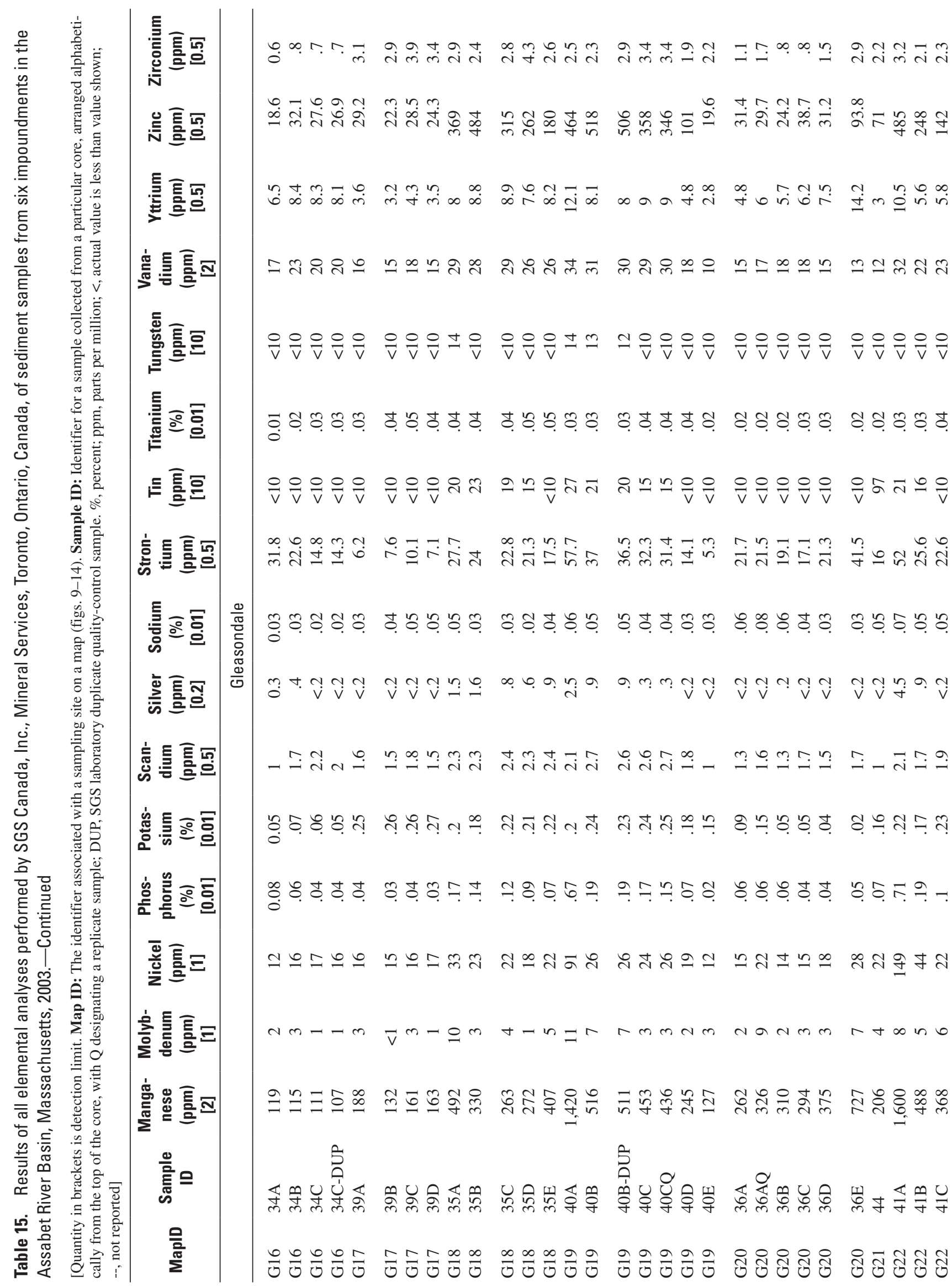




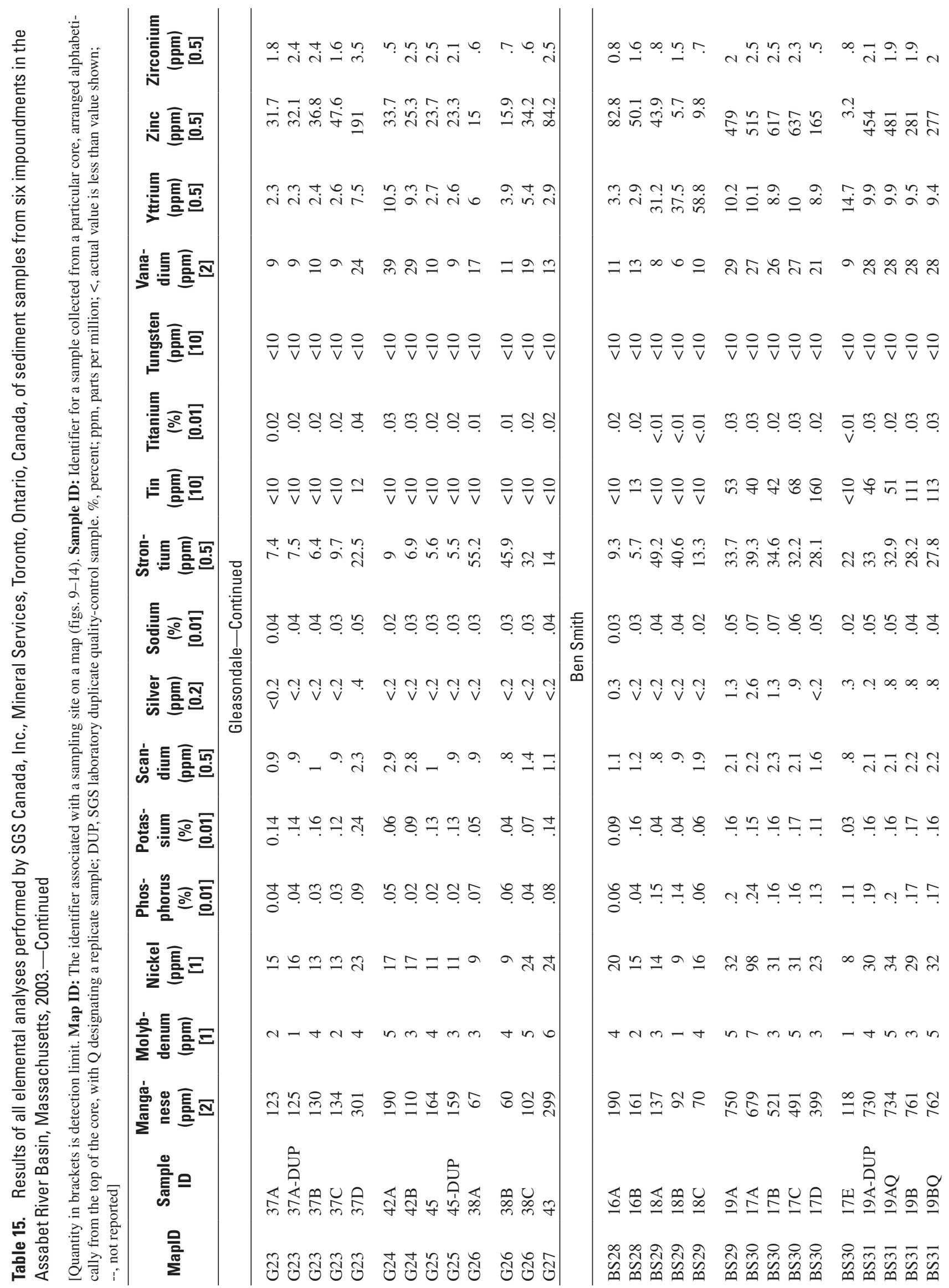




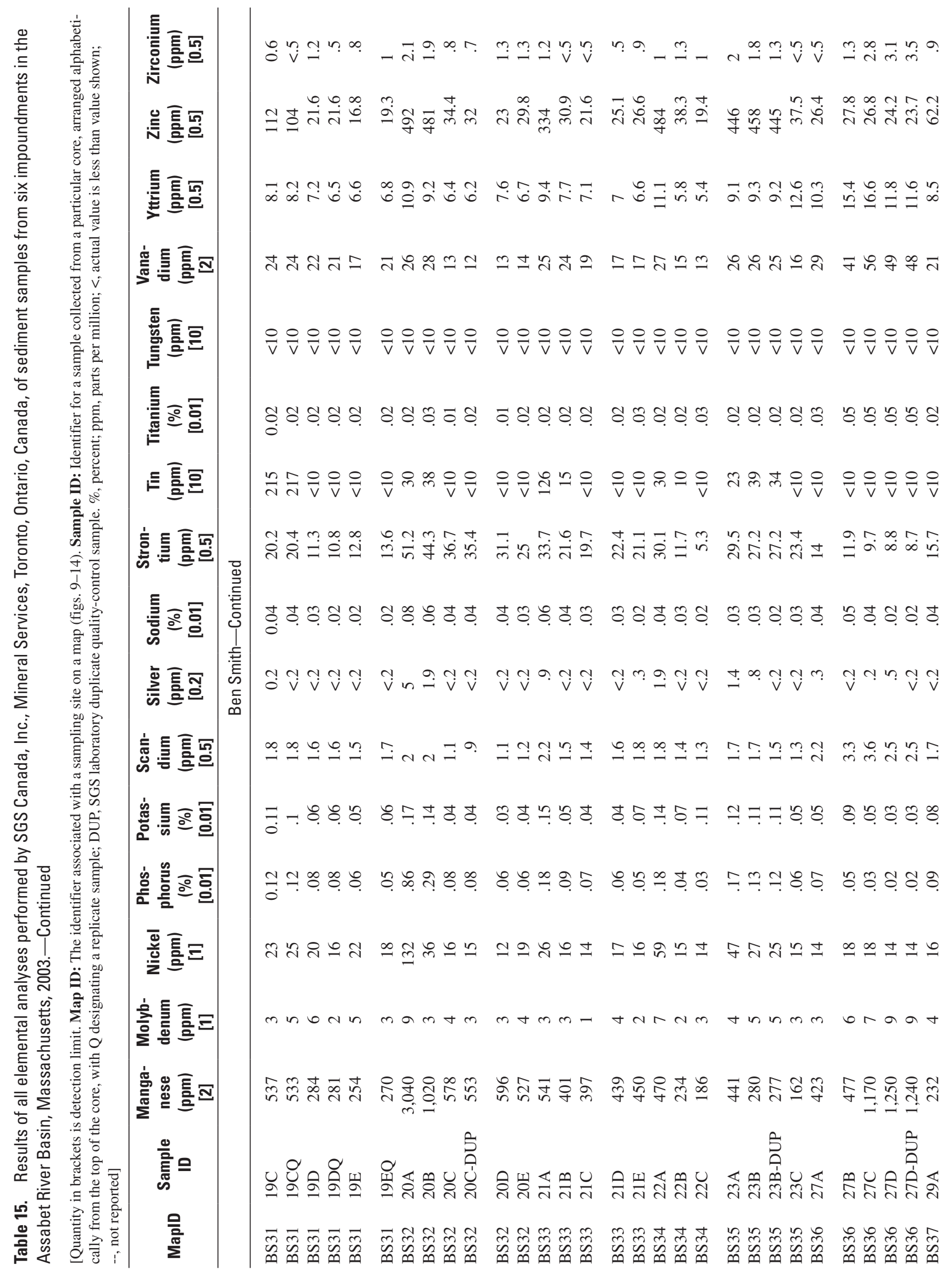




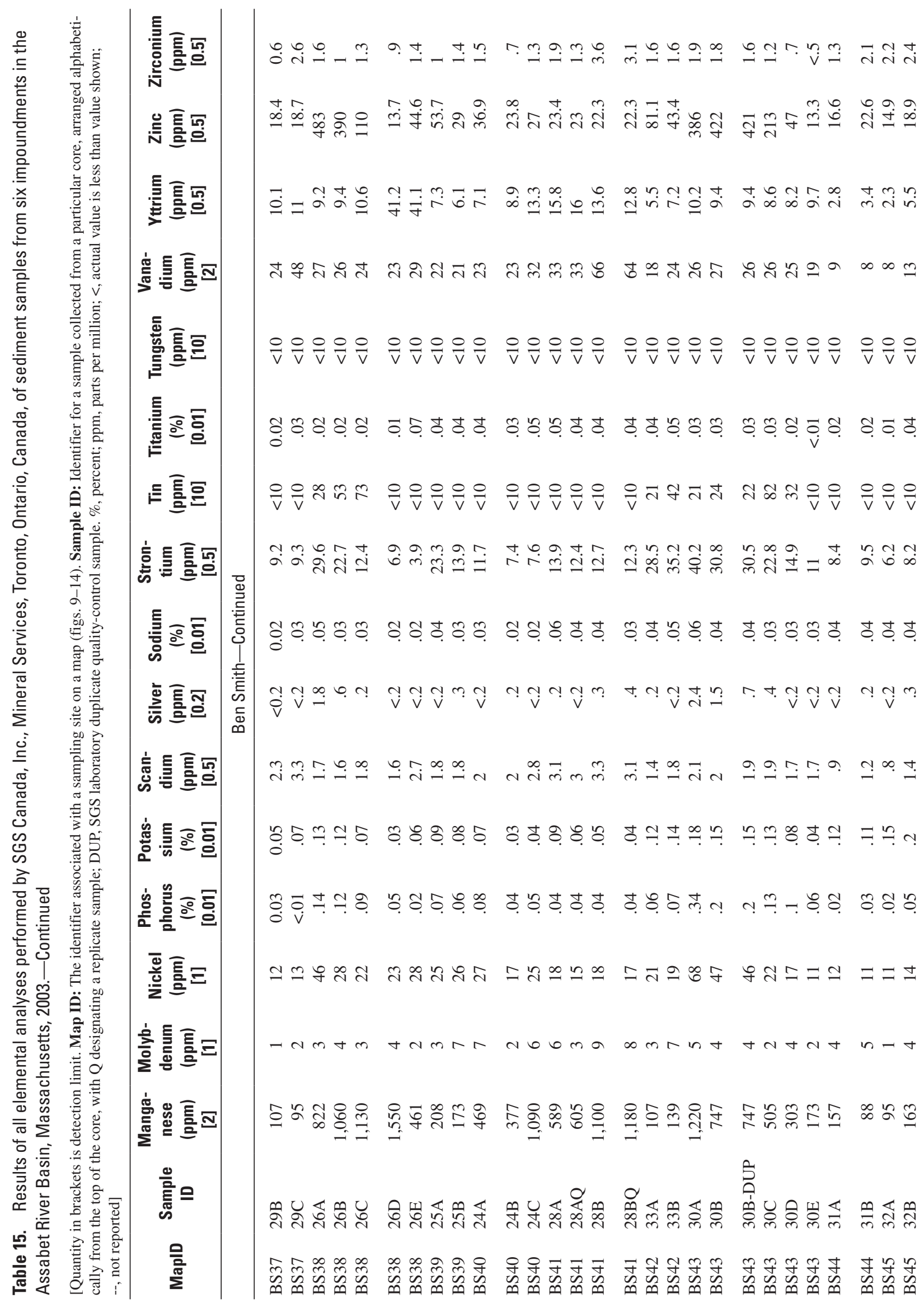




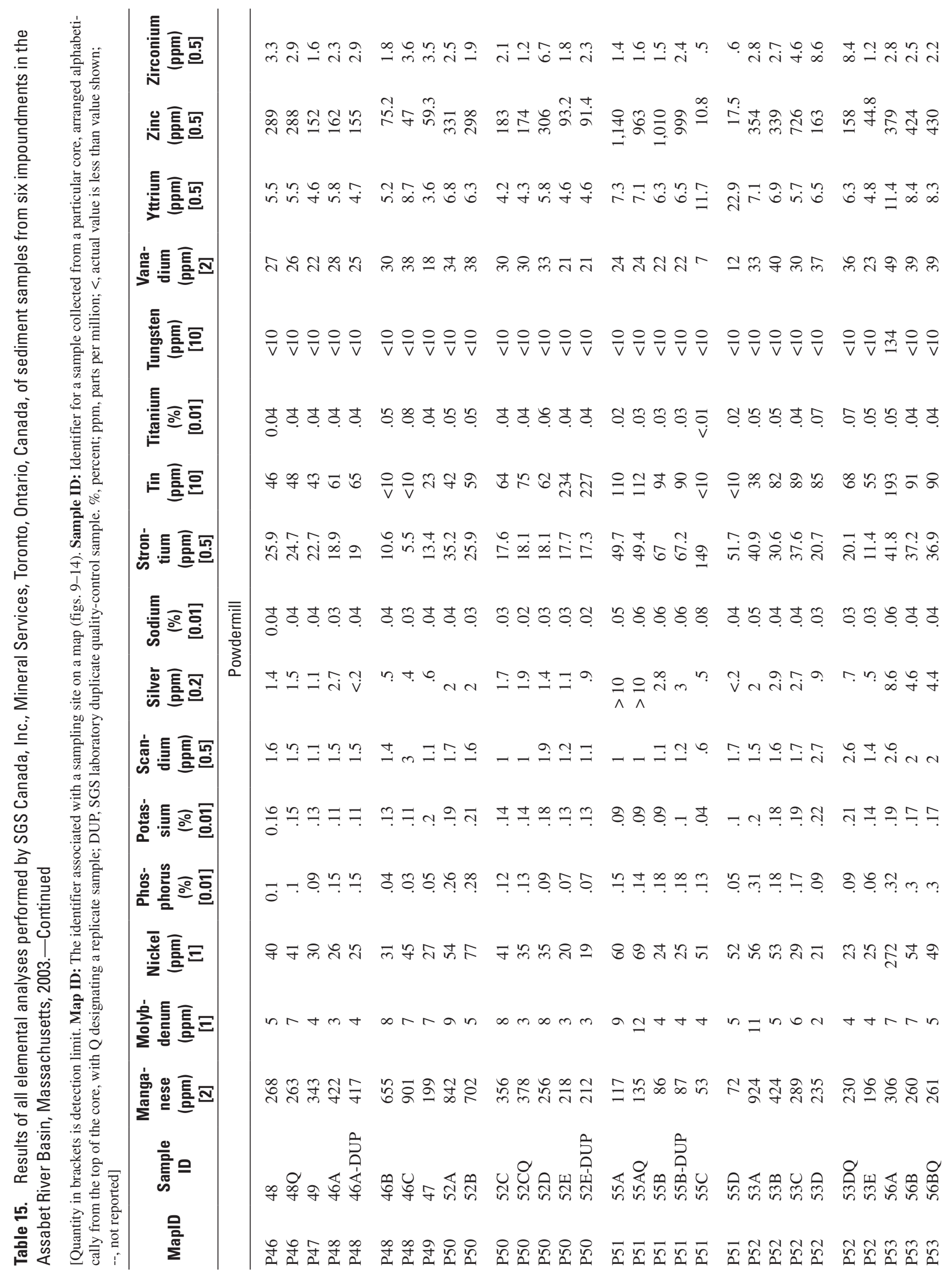




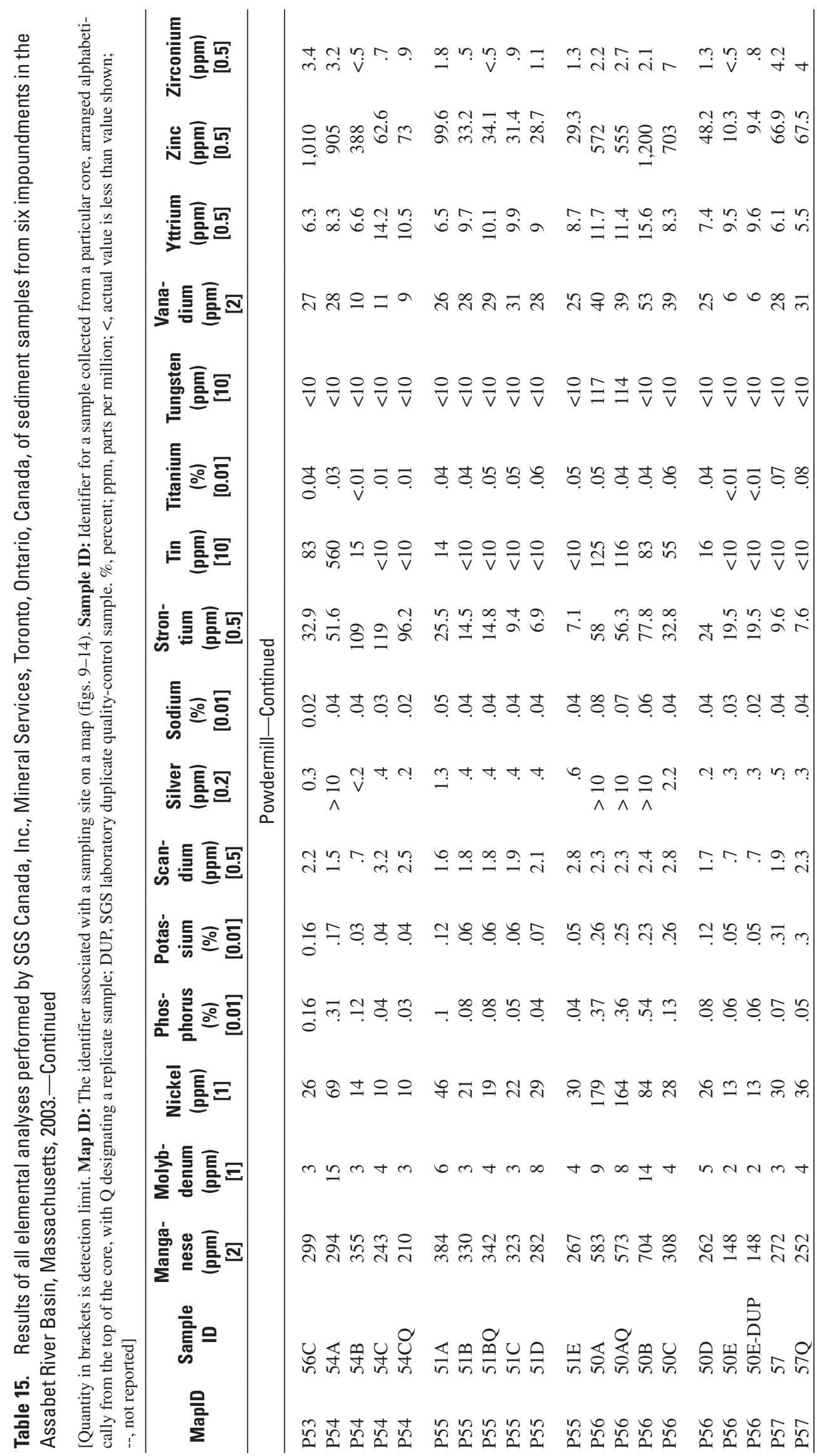


Table 16. Concentrations of polycyclic aromatic hydrocarbons detected in sediment samples from six impoundments in the Assabet River Basin, Massachusetts, 2003.

[All values are in micrograms per kilogram. Minimum reporting level is 0.017 micrograms per kilogram. Data are rounded to two significant figures. Map ID: The identifier associated with a sampling site on a map (figs. 9-14). Sample ID: Identifier for a sample collected from a particular core, arranged alphabetically from the top of the core, with Q designating a replicate sample. Shaded numbers exceed sediment-quality guidelines (table 2). There are no guidelines for benzo[b]fluoranthene. PAH, polycyclic aromatic hydrocarbon; --, not detected]

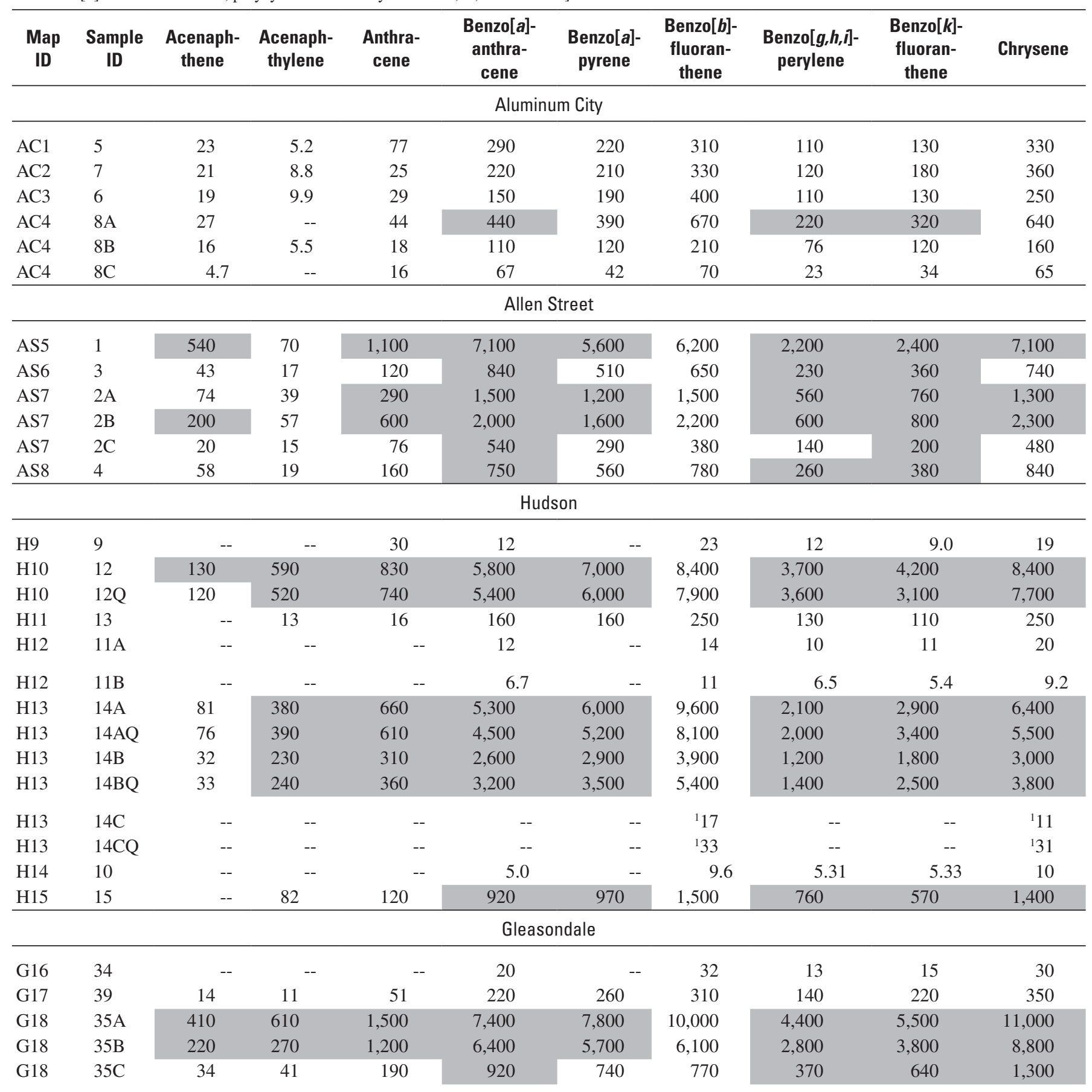


Table 16. Concentrations of polycyclic aromatic hydrocarbons detected in sediment samples from six impoundments in the Assabet River Basin, Massachusetts, 2003.-Continued

[All values are in micrograms per kilogram. Minimum reporting level is 0.017 micrograms per kilogram. Data are rounded to two significant figures. Map ID: The identifier associated with a sampling site on a map (figs. 9-14). Sample ID: Identifier for a sample collected from a particular core, arranged alphabetically from the top of the core, with Q designating a replicate sample. Shaded numbers exceed sediment-quality guidelines (table 2). There are no guidelines for benzo[b]fluoranthene. PAH, polycyclic aromatic hydrocarbon; --, not detected]

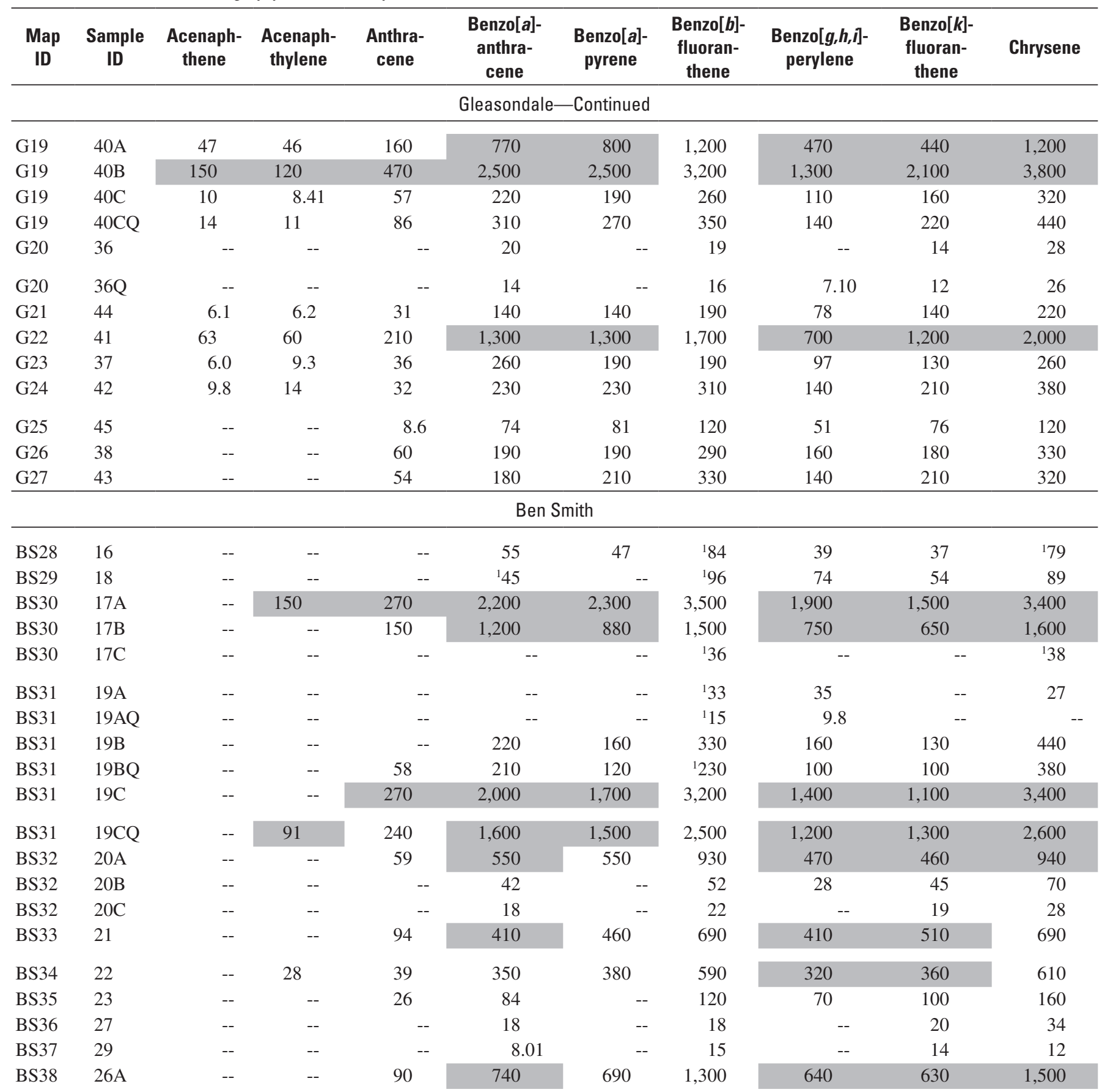


Table 16. Concentrations of polycyclic aromatic hydrocarbons detected in sediment samples from six impoundments in the Assabet River Basin, Massachusetts, 2003.-Continued

[All values are in micrograms per kilogram. Minimum reporting level is 0.017 micrograms per kilogram. Data are rounded to two significant figures. Map ID: The identifier associated with a sampling site on a map (figs. 9-14). Sample ID: Identifier for a sample collected from a particular core, arranged alphabetically from the top of the core, with Q designating a replicate sample. Shaded numbers exceed sediment-quality guidelines (table 2). There are no guidelines for benzo[ $b]$ fluoranthene. PAH, polycyclic aromatic hydrocarbon; --, not detected]

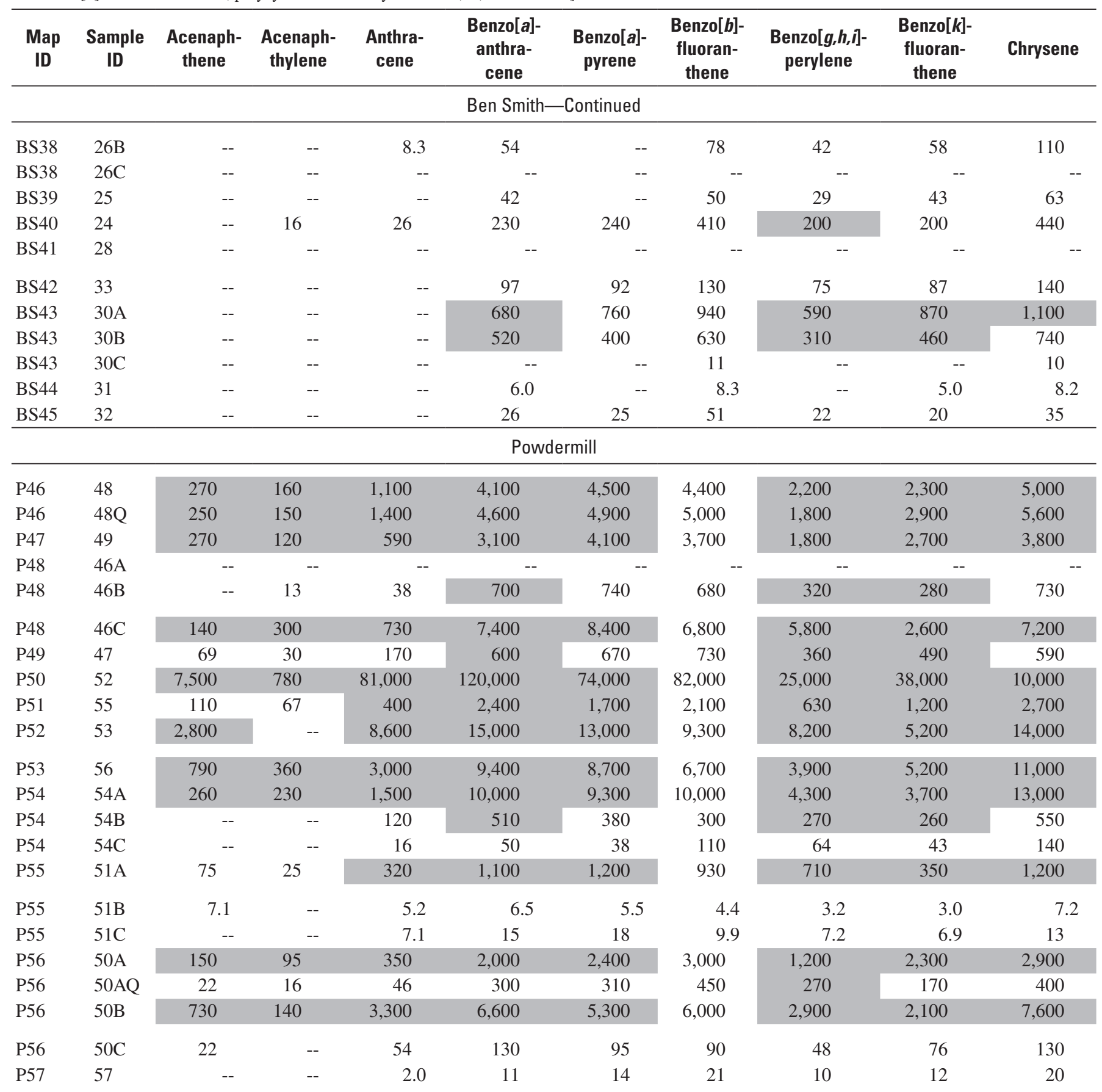


Table 16. Concentrations of polycyclic aromatic hydrocarbons detected in sediment samples from six impoundments in the Assabet River Basin, Massachusetts, 2003.-Continued

[All values are in micrograms per kilogram. Minimum reporting level is 0.017 micrograms per kilogram. Data are rounded to two significant figures. Map ID: The identifier associated with a sampling site on a map (figs. 9-14). Sample ID: Identifier for a sample collected from a particular core, arranged alphabetically from the top of the core, with Q designating a replicate sample. Shaded numbers exceed sediment-quality guidelines (table 2). There are no guidelines for benzo[ $b]$ fluoranthene. PAH, polycyclic aromatic hydrocarbon; --, not detected]

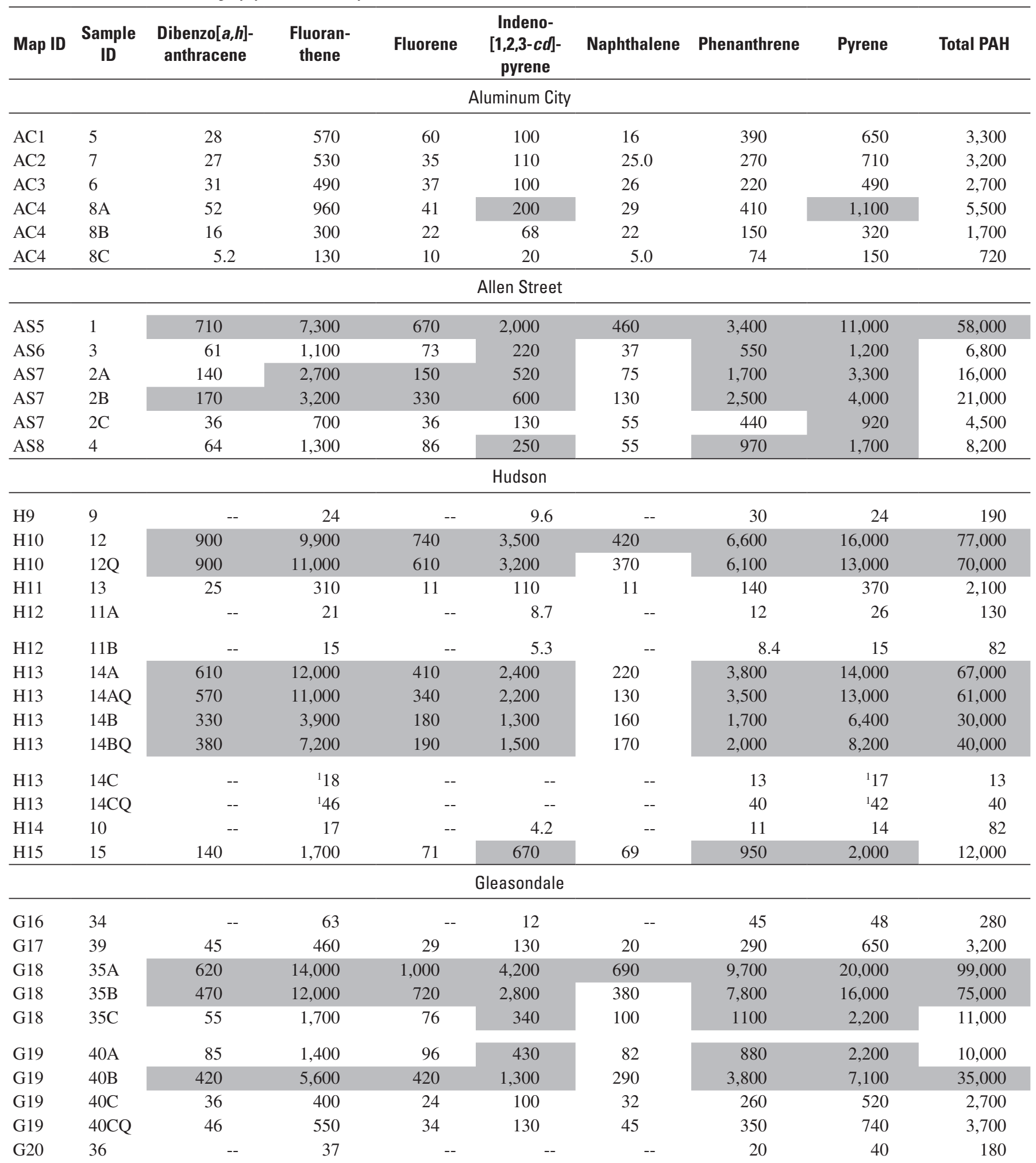


Table 16. Concentrations of polycyclic aromatic hydrocarbons detected in sediment samples from six impoundments in the Assabet River Basin, Massachusetts, 2003.-Continued

[All values are in micrograms per kilogram. Minimum reporting level is 0.017 micrograms per kilogram. Data are rounded to two significant figures. Map ID: The identifier associated with a sampling site on a map (figs. 9-14). Sample ID: Identifier for a sample collected from a particular core, arranged alphabetically from the top of the core, with Q designating a replicate sample. Shaded numbers exceed sediment-quality guidelines (table 2). There are no guidelines for benzo[b]fluoranthene. PAH, polycyclic aromatic hydrocarbon; --, not detected]

\begin{tabular}{|c|c|c|c|c|c|c|c|c|c|}
\hline Map ID & $\begin{array}{c}\text { Sample } \\
\text { ID }\end{array}$ & $\begin{array}{c}\text { Dibenzo[a,h]- } \\
\text { anthracene }\end{array}$ & $\begin{array}{l}\text { Fluoran- } \\
\text { thene }\end{array}$ & Fluorene & $\begin{array}{c}\text { Indeno- } \\
{[1,2,3-c d]-} \\
\text { pyrene }\end{array}$ & Naphthalene & Phenanthrene & Pyrene & Total PAH \\
\hline \multicolumn{10}{|c|}{ Gleasondale-Continued } \\
\hline G20 & $36 \mathrm{Q}$ & -- & 35 & -- & 7.8 & -- & 19 & 39 & 180 \\
\hline G21 & 44 & 23 & 260 & 10 & 74 & 7.10 & 120 & 320 & 1,800 \\
\hline $\mathrm{G} 24$ & 42 & 45 & 430 & 22 & 120 & 20 & 290 & 700 & 3,200 \\
\hline $\mathrm{G} 25$ & 45 & 15 & 140 & 5.7 & 46 & 5.98 & 54 & 220 & 1,000 \\
\hline G26 & 38 & 38 & 450 & -- & 130 & -- & 250 & 550 & 2,800 \\
\hline $\mathrm{G} 27$ & 43 & 47 & 420 & 21 & 120 & 17 & 190 & 500 & 2,800 \\
\hline $\mathrm{BS} 30$ & $17 \mathrm{~A}$ & 360 & 4,100 & 230 & 1,600 & 150 & 2,600 & 6,300 & 31,000 \\
\hline BS30 & 17B & 140 & 1,800 & 110 & 650 & 97 & 1,100 & 2,600 & 13,000 \\
\hline BS30 & $17 \mathrm{C}$ & -- & ${ }^{1} 70$ & -- & -- & -- & 39 & ${ }^{1} 44$ & 39 \\
\hline BS31 & $19 \mathrm{~A}$ & -- & ${ }^{1} 25$ & -- & 28 & -- & -- & -- & 90 \\
\hline BS31 & 19AQ & -- & ${ }^{1} 16$ & -- & -- & -- & 14 & ${ }^{1} 12$ & 24 \\
\hline BS31 & 19B & -- & 390 & -- & 140 & -- & 280 & 650 & 2,900 \\
\hline BS31 & 19BQ & -- & 410 & -- & 81 & -- & 300 & 660 & 2,400 \\
\hline BS31 & $19 \mathrm{C}$ & 280 & 3,500 & 220 & 1,300 & 200 & 2,100 & 5,400 & 26,000 \\
\hline BS31 & 19CQ & 250 & 2,900 & 180 & 1,100 & 130 & 1,700 & 4,000 & 21,000 \\
\hline BS37 & 29 & -- & 13 & -- & -- & -- & 12 & 15 & 89 \\
\hline BS38 & $26 \mathrm{~A}$ & 150 & 1,400 & 79 & 560 & 89 & 670 & 2,200 & 11,000 \\
\hline BS38 & $26 B$ & 13 & 69 & 11 & 35 & 9.59 & 64 & 150 & 700 \\
\hline BS38 & $26 \mathrm{C}$ & -- & -- & -- & -- & -- & -- & -- & -- \\
\hline BS39 & 25 & -- & 82 & -- & 25 & -- & 69 & 130 & 530 \\
\hline BS40 & 24 & 50 & 460 & 21 & 170 & 21 & 270 & 740 & 3,500 \\
\hline BS41 & 28 & -- & -- & -- & -- & -- & -- & -- & -- \\
\hline BS42 & 33 & -- & 150 & -- & 67 & -- & 79 & 260 & 1,200 \\
\hline BS43 & $30 \mathrm{~A}$ & -- & 1,300 & -- & 560 & -- & 770 & 2,000 & 9,600 \\
\hline BS43 & $30 \mathrm{~B}$ & -- & 770 & -- & 280 & -- & 450 & 1,100 & 5,700 \\
\hline BS43 & $30 \mathrm{C}$ & -- & 19 & -- & -- & -- & 13 & 17 & 70 \\
\hline BS44 & 31 & -- & -- & -- & -- & -- & 5.88 & 12 & 45 \\
\hline BS45 & 32 & -- & 47 & -- & 20 & -- & 21 & 67 & 330 \\
\hline
\end{tabular}


Table 16. Concentrations of polycyclic aromatic hydrocarbons detected in sediment samples from six impoundments in the Assabet River Basin, Massachusetts, 2003.-Continued

[All values are in micrograms per kilogram. Minimum reporting level is 0.017 micrograms per kilogram. Data are rounded to two significant figures. Map ID: The identifier associated with a sampling site on a map (figs. 9-14). Sample ID: Identifier for a sample collected from a particular core, arranged alphabetically from the top of the core, with Q designating a replicate sample. Shaded numbers exceed sediment-quality guidelines (table 2). There are no guidelines for benzo[ $b]$ fluoranthene. PAH, polycyclic aromatic hydrocarbon; --, not detected]

\begin{tabular}{|c|c|c|c|c|c|c|c|c|c|}
\hline Map ID & $\begin{array}{c}\text { Sample } \\
\text { ID }\end{array}$ & $\begin{array}{c}\text { Dibenzo[a,h]- } \\
\text { anthracene }\end{array}$ & $\begin{array}{c}\text { Fluoran- } \\
\text { thene }\end{array}$ & Fluorene & $\begin{array}{c}\text { Indeno- } \\
{[1,2,3-c d]-} \\
\text { pyrene }\end{array}$ & Naphthalene & Phenanthrene & Pyrene & Total PAH \\
\hline \multicolumn{10}{|c|}{ Powdermill } \\
\hline P46 & 48 & 580 & 6,100 & 350 & 1,800 & 710 & 3,000 & 11,000 & 48,000 \\
\hline P46 & 48Q & 470 & 6,500 & 360 & 1,600 & 700 & 3,300 & 10,000 & 50,000 \\
\hline P48 & $46 \mathrm{~B}$ & 71 & 300 & 10 & 240 & 16 & 110 & 940 & 5,200 \\
\hline P48 & $46 \mathrm{C}$ & 1,200 & 5,900 & 260 & 4,200 & 550 & 3,000 & 11,000 & 65,000 \\
\hline P49 & 47 & 92 & 1,100 & 84 & 310 & 78 & 770 & 1,600 & 7,700 \\
\hline P50 & 52 & 10,000 & 200,000 & 18,000 & 29,000 & 1,300 & 150,000 & 210,000 & $1,100,000$ \\
\hline P51 & 55 & 140 & 2,900 & 140 & 540 & 200 & 700 & 4,700 & 21,000 \\
\hline P54 & $54 \mathrm{~B}$ & -- & 700 & -- & 180 & -- & 560 & 1,500 & 5,300 \\
\hline P54 & $54 \mathrm{C}$ & -- & 210 & -- & 22 & -- & 74 & 460 & 1,200 \\
\hline P55 & $51 \mathrm{~A}$ & 130 & 1,500 & 67 & 460 & 70 & 550 & 3,600 & 12,000 \\
\hline P55 & $51 \mathrm{~B}$ & -- & 11 & -- & -- & 3.5 & 12 & 25 & 94 \\
\hline P55 & $51 \mathrm{C}$ & -- & 17 & -- & 5.3 & -- & 15 & 29 & 140 \\
\hline P56 & $50 \mathrm{~A}$ & 310 & 4,100 & 210 & 1,100 & 260 & 2,200 & 6,900 & 29,000 \\
\hline P56 & $50 A Q$ & 54 & 550 & 29 & 220 & 29 & 290 & 810 & 4,000 \\
\hline P56 & $50 \mathrm{~B}$ & 580 & 10,000 & 1,000 & 2,100 & 1,200 & 9,700 & 19,000 & 78,000 \\
\hline P56 & $50 \mathrm{C}$ & 9.6 & 150 & 20 & 30 & 11 & 180 & 480 & 1,500 \\
\hline
\end{tabular}

${ }^{1}$ Indicates suspected laboratory contamination 
Table 17. Water-quality data collected during study of phosphorus dynamics in the Hudson, Massachusetts, impoundment, 2003.

$\left[\mathrm{cm}\right.$, centimeter; m, meter; mg/L, milligram per liter; $\mu \mathrm{S} / \mathrm{cm}$, microsiemens per centimeter; ${ }^{\circ} \mathrm{C}$, degrees Celsius; --, no data

\begin{tabular}{|c|c|c|c|c|c|c|c|c|c|c|}
\hline Date & Time & $\begin{array}{c}\text { Depth } \\
\text { (m) }\end{array}$ & $\begin{array}{c}\text { Specific } \\
\text { conduc- } \\
\text { tance } \\
(\mu \mathrm{S} / \mathrm{cm})\end{array}$ & $\mathrm{pH}$ & $\begin{array}{c}\text { Temp- } \\
\text { erature } \\
\left({ }^{\circ} \mathrm{C}\right)\end{array}$ & $\begin{array}{c}\text { Dissolved } \\
\text { oxygen } \\
\text { (mg/L) }\end{array}$ & $\begin{array}{l}\text { Chloride } \\
\text { (mg/L) }\end{array}$ & $\begin{array}{c}\text { Total } \\
\text { phosphorus } \\
\text { (mg/L) }\end{array}$ & $\begin{array}{c}\text { Ortho- } \\
\text { phosphorus } \\
\text { (mg/L) }\end{array}$ & Remarks \\
\hline \multicolumn{11}{|c|}{ Station 17} \\
\hline 7-16-03 & 9:00 & 0.00 & 594 & 6.86 & 21.8 & 6.4 & -- & 0.1010 & 0.051 & \\
\hline 7-16-03 & & 1.50 & 594 & 6.82 & 21.8 & 6.4 & -- & -- & -- & \\
\hline 7-16-03 & & 1.60 & 594 & 6.81 & 21.8 & 6.3 & -- & -- & -- & \\
\hline $7-24-03$ & $8: 40$ & .00 & 514 & -- & 22.0 & 4.1 & 118.02 & .1451 & .075 & \\
\hline $7-24-03$ & & .50 & 515 & -- & 22.0 & 4.1 & -- & -- & -- & \\
\hline $7-29-03$ & $8: 50$ & .00 & 601 & -- & 23.3 & 6.4 & 142.44 & .0846 & .054 & \\
\hline $7-29-03$ & & .50 & 601 & -- & 23.3 & 5.7 & -- & -- & -- & \\
\hline $7-29-03$ & & 1.00 & 600 & -- & 23.3 & 5.8 & -- & -- & -- & \\
\hline $7-29-03$ & 9:00 & 1.50 & 600 & -- & 23.3 & 5.8 & -- & .0861 & .055 & \\
\hline $7-29-03$ & & 1.80 & 601 & -- & 23.3 & 5.7 & -- & -- & -- & \\
\hline $8-07-03$ & $9: 10$ & .00 & 485 & 6.42 & 23.2 & 3.8 & 109.64 & .1523 & .109 & \\
\hline $8-07-03$ & 9:11 & & -- & -- & -- & -- & 109.37 & .1526 & .108 & Replicate \\
\hline $8-07-03$ & & .50 & 486 & 6.44 & 23.2 & 3.8 & -- & -- & -- & \\
\hline $8-07-03$ & & 1.00 & 486 & 6.45 & 23.2 & 3.8 & -- & -- & -- & \\
\hline 8-07-03 & $9: 20$ & 1.50 & 486 & 6.47 & 23.2 & 3.7 & -- & .1498 & .109 & \\
\hline $8-21-03$ & & .50 & 525 & 6.6 & 22.8 & 5.6 & -- & -- & -- & \\
\hline $8-21-03$ & & 1.00 & 522 & 6.63 & 22.8 & 5.4 & -- & -- & -- & \\
\hline $8-21-03$ & $9: 35$ & 1.40 & 523 & 6.64 & 22.8 & 5.3 & & .1068 & .076 & \\
\hline $8-28-03$ & $9: 40$ & .00 & 687 & 6.4 & 21.5 & 5.4 & 162.2 & .0821 & .055 & \\
\hline $8-28-03$ & & .50 & 687 & 6.43 & 21.6 & 5.2 & -- & -- & -- & \\
\hline $8-28-03$ & & 1.00 & 687 & 6.51 & 21.5 & 5.1 & -- & -- & -- & \\
\hline $8-28-03$ & 9:50 & 1.50 & 687 & 6.56 & 21.5 & 5.1 & & .1283 & .055 & \\
\hline 9-08-03 & 9:00 & .00 & 631 & 6.48 & 19.4 & 6.6 & 146.58 & .0823 & .046 & \\
\hline 9-08-03 & & .50 & 631 & 6.49 & 19.4 & 6.6 & -- & -- & -- & \\
\hline $9-08-03$ & & 1.00 & 631 & 6.5 & 19.4 & 6.6 & -- & -- & -- & \\
\hline $9-08-03$ & 9:20 & 1.50 & 631 & 6.5 & 19.4 & 6.6 & -- & .4200 & .047 & \\
\hline 9-08-03 & $9: 21$ & & -- & -- & -- & -- & $<.2$ & .0029 & .000 & Blank \\
\hline $9-08-03$ & & 1.70 & 631 & 6.5 & 19.4 & 6.5 & -- & -- & -- & \\
\hline
\end{tabular}


Table 17. Water-quality data collected during study of phosphorus dynamics in the Hudson, Massachusetts, impoundment, 2003.-Continued

$\left[\mathrm{cm}\right.$, centimeter; m, meter; $\mathrm{mg} / \mathrm{L}$, milligram per liter; $\mu \mathrm{S} / \mathrm{cm}$, microsiemens per centimeter; ${ }^{\circ} \mathrm{C}$, degrees Celsius; --, no data

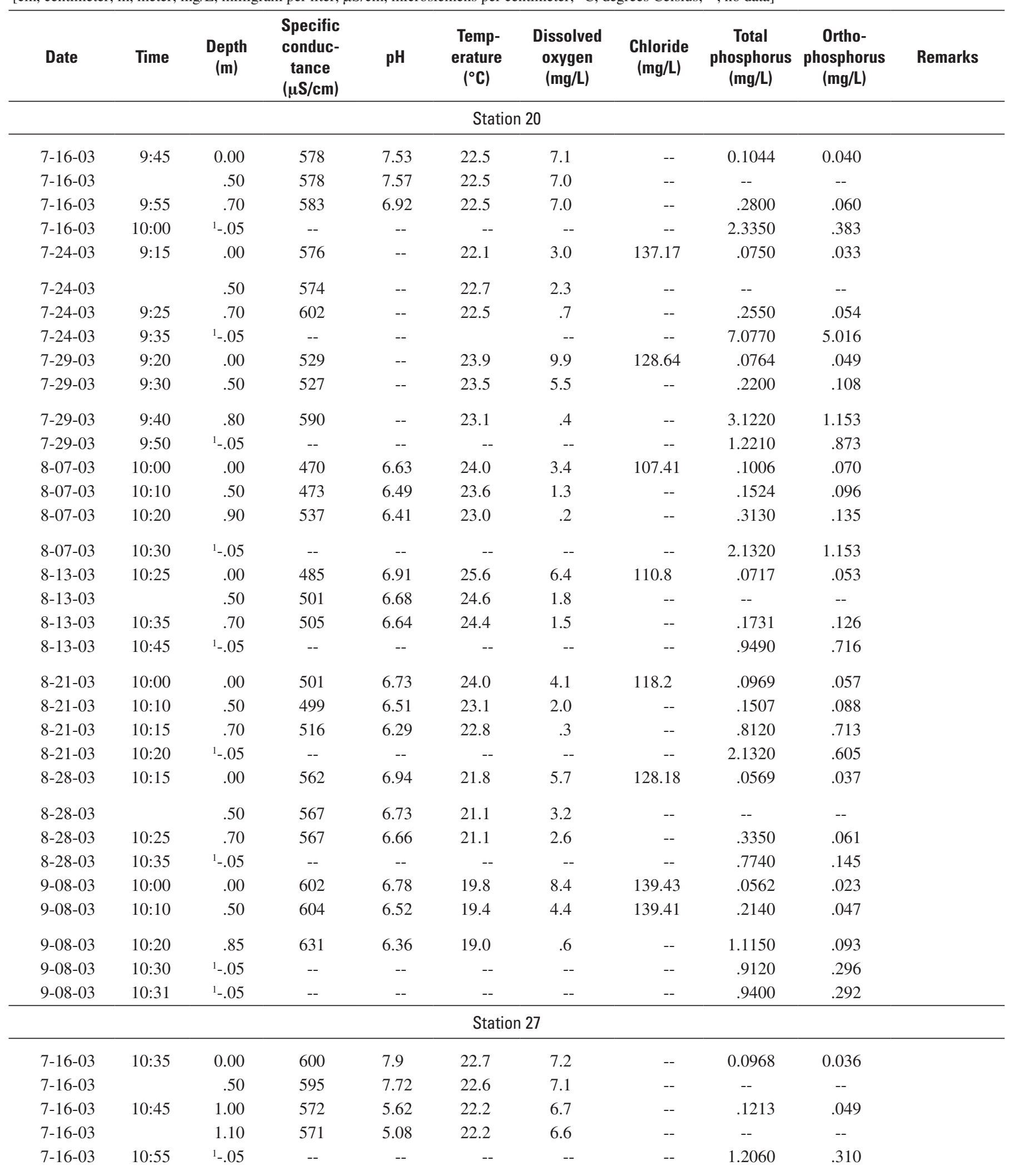


Table 17. Water-quality data collected during study of phosphorus dynamics in the Hudson, Massachusetts, impoundment, 2003.-Continued

[cm, centimeter; m, meter; mg/L, milligram per liter; $\mu \mathrm{S} / \mathrm{cm}$, microsiemens per centimeter; ${ }^{\circ} \mathrm{C}$, degrees Celsius; --, no data

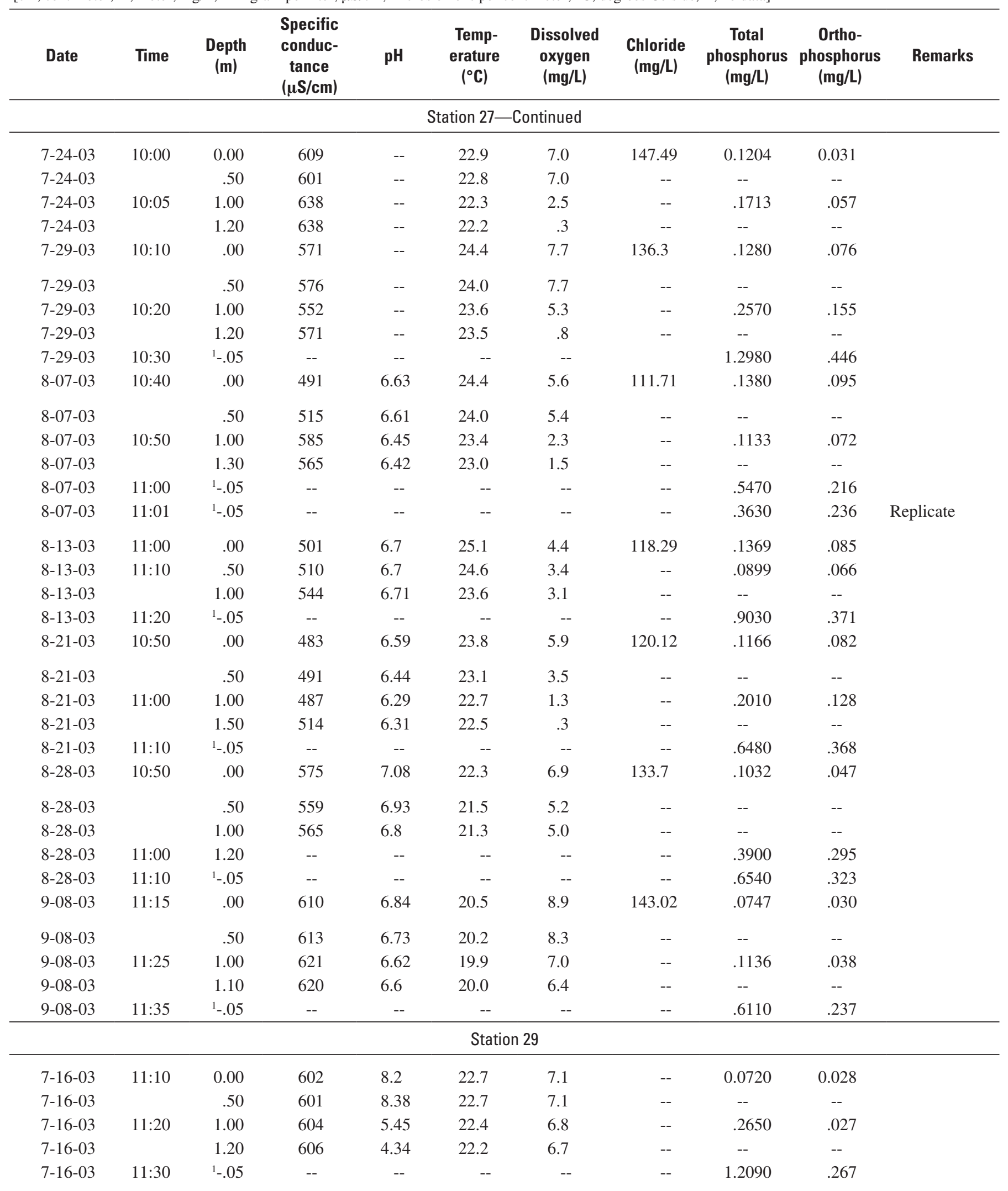


Table 17. Water-quality data collected during study of phosphorus dynamics in the Hudson, Massachusetts, impoundment, 2003.-Continued

$\left[\mathrm{cm}\right.$, centimeter; $\mathrm{m}$, meter; $\mathrm{mg} / \mathrm{L}$, milligram per liter; $\mu \mathrm{S} / \mathrm{cm}$, microsiemens per centimeter; ${ }^{\circ} \mathrm{C}$, degrees Celsius; --, no data

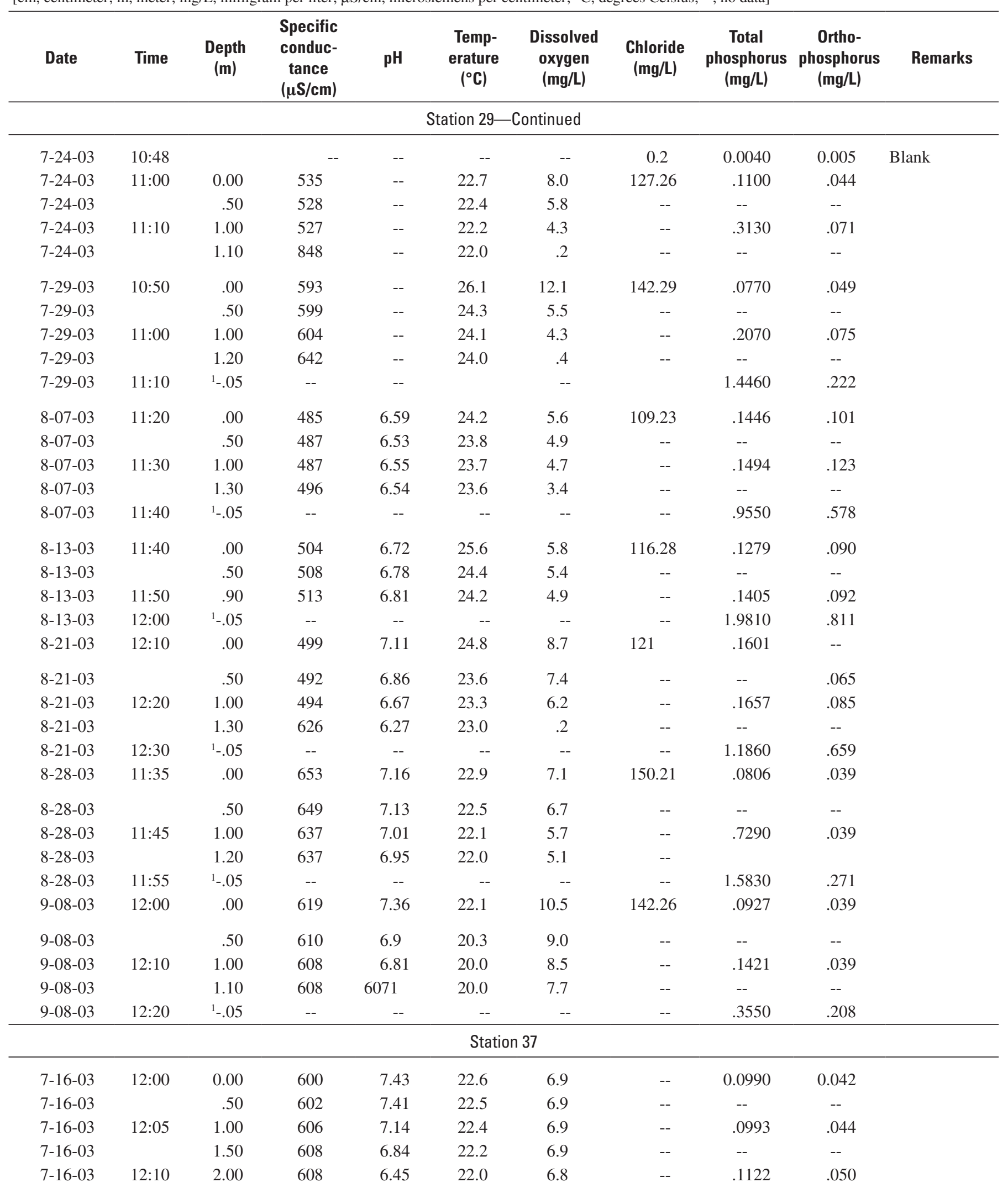


Table 17. Water-quality data collected during study of phosphorus dynamics in the Hudson, Massachusetts, impoundment, 2003.-Continued

$\left[\mathrm{cm}\right.$, centimeter; m, meter; mg/L, milligram per liter; $\mu \mathrm{S} / \mathrm{cm}$, microsiemens per centimeter; ${ }^{\circ} \mathrm{C}$, degrees Celsius; --, no data

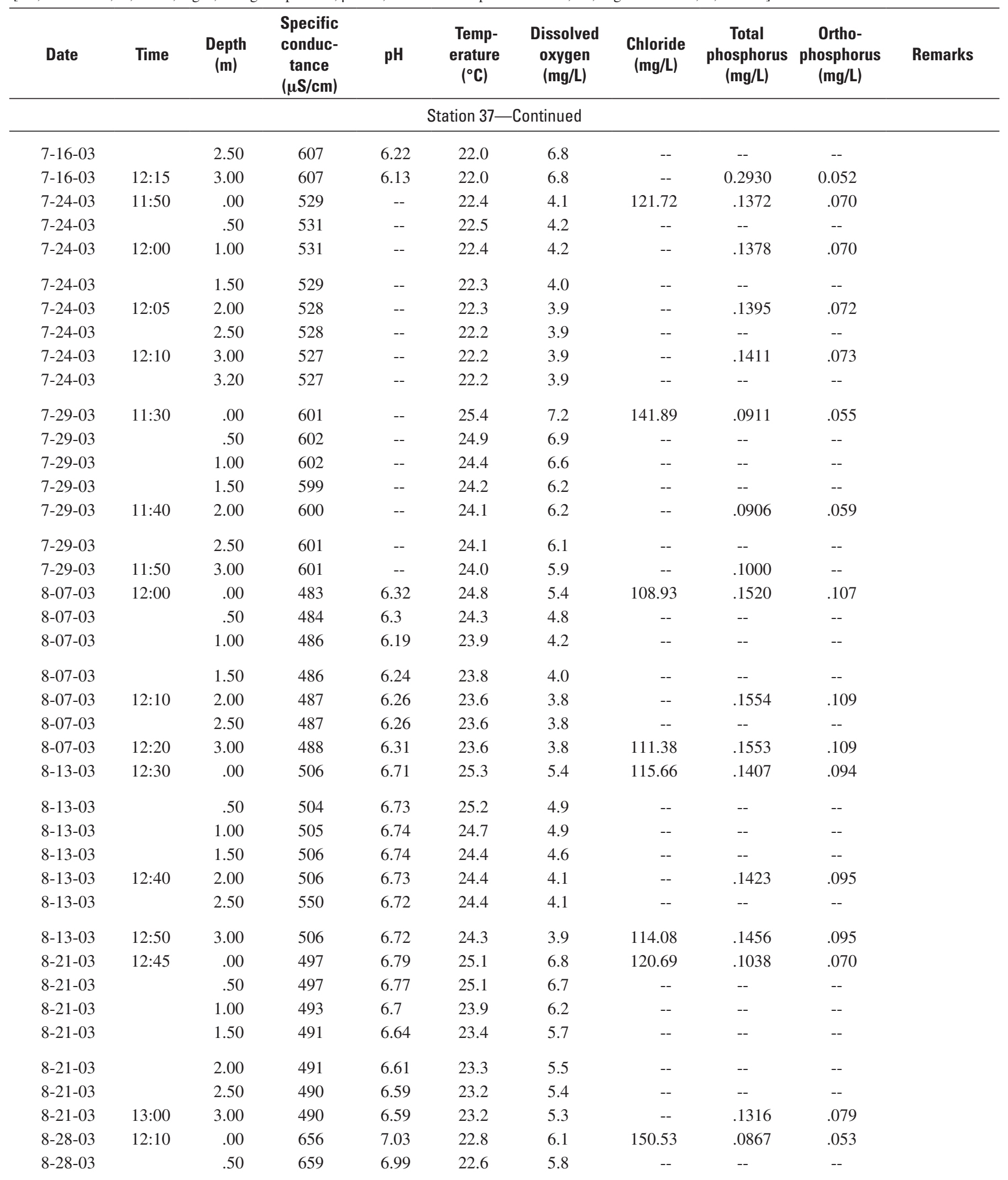


Table 17. Water-quality data collected during study of phosphorus dynamics in the Hudson, Massachusetts, impoundment, 2003.-Continued

$\left[\mathrm{cm}\right.$, centimeter; m, meter; mg/L, milligram per liter; $\mu \mathrm{S} / \mathrm{cm}$, microsiemens per centimeter; ${ }^{\circ} \mathrm{C}$, degrees Celsius; --, no data

\begin{tabular}{|c|c|c|c|c|c|c|c|c|c|c|}
\hline Date & Time & $\begin{array}{l}\text { Depth } \\
\text { (m) }\end{array}$ & $\begin{array}{c}\text { Specific } \\
\text { conduc- } \\
\text { tance } \\
(\mu S / c m)\end{array}$ & $\mathrm{pH}$ & $\begin{array}{c}\text { Temp- } \\
\text { erature } \\
\left({ }^{\circ} \mathrm{C}\right)\end{array}$ & $\begin{array}{c}\text { Dissolved } \\
\text { oxygen } \\
\text { (mg/L) }\end{array}$ & $\begin{array}{c}\text { Chloride } \\
\text { (mg/L) }\end{array}$ & $\begin{array}{c}\text { Total } \\
\text { phosphorus } \\
\text { (mg/L) }\end{array}$ & $\begin{array}{c}\text { Ortho- } \\
\text { phosphorus } \\
\text { (mg/L) }\end{array}$ & Remarks \\
\hline \multicolumn{11}{|c|}{ Station 37-Continued } \\
\hline $8-28-03$ & & 1.00 & 656 & 6.97 & 22.5 & 5.9 & -- & -- & -- & \\
\hline $8-28-03$ & & 2.50 & 644 & 6.91 & 22.0 & 5.6 & -- & -- & -- & \\
\hline $8-28-03$ & $12: 30$ & 3.00 & 644 & 6.89 & 22.0 & 5.3 & -- & .1059 & .056 & \\
\hline $9-08-03$ & $12: 45$ & .00 & -- & -- & -- & -- & $<0.2$ & .0037 & .003 & Blank \\
\hline $9-08-03$ & $12: 50$ & .00 & 623 & 6.76 & 21.2 & 8.0 & 143.79 & .0805 & .044 & \\
\hline $9-08-03$ & $13: 00$ & 2.00 & 628 & 6.64 & 19.8 & 6.8 & -- & .0883 & .047 & \\
\hline $9-08-03$ & & 2.50 & 627 & 6.63 & 19.8 & 6.5 & -- & -- & -- & \\
\hline $9-08-03$ & $13: 10$ & 3.00 & 626 & 6.63 & 19.8 & 6.7 & -- & .0907 & .048 & \\
\hline
\end{tabular}

\footnotetext{
${ }^{1}-0.05$, sample of pore water collected from $5 \mathrm{~cm}$ below sediment surface.
} 



For additional information write to:

Director,

USGS Massachusetts-Rhode Island Water Science Center

10 Bearfoot Road

Northborough, MA 01532

or visit our Web site at

http://ma.water.usgs.gov 